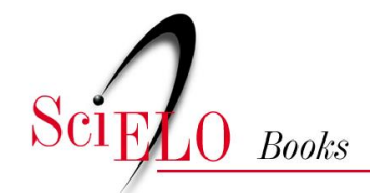

\title{
O que vamos fazer depois do trabalho?

\author{
Reflexões sobre a preparação para aposentadoria
}

José Luiz Riani Costa

Amarilis M. Muscari Riani Costa

Gilson Fuzaro Junior

(orgs.)

COSTA, JLR., COSTA, AMMR., and FUZARO JUNIOR, G., orgs. O que vamos fazer depois do trabalho? Reflexões sobre a preparação para aposentadoria [online]. São Paulo: Cultura Acadêmica, 2016, 153 p. ISBN 978-85-7983-763-0. Available from: doi: 10.7476/9788579837630. Also available in ePUB from: http://books.scielo.org/id/n8k9y/epub/costa-9788579837630.epub.

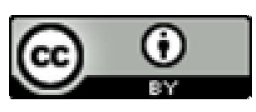

All the contents of this work, except where otherwise noted, is licensed under a Creative Commons Attribution 4.0 International license.

Todo o conteúdo deste trabalho, exceto quando houver ressalva, é publicado sob a licença Creative Commons Atribição 4.0.

Todo el contenido de esta obra, excepto donde se indique lo contrario, está bajo licencia de la licencia Creative Commons Reconocimento 4.0. 


\section{O QUE VAMOS FAZER DEPOIS DO TRABALHO?}




$$
\begin{gathered}
\text { Realização } \\
\text { Pró-reitoria de Extensão Universitária (Proex) } \\
\text { Rua Quirino de Andrade, 215 - 10 andar } \\
\text { 01049-010 - São Paulo - SP }
\end{gathered}
$$

Dirigentes da Universidade Estadual Paulista "Júlio de Mesquita Filho" http://www.unesp.br/portal\#!/reitoria_ses/dirigentes-da-unesp/

Conselho Editorial da Pró-reitoria de Extensão Universitária

Prof. Dr. Cláudio Cesar de Paiva - FCL/Araraquara

Prof. Dr. Eduardo Galhardo - FCL/Assis

Prof. Dr. José Arnaldo Frutuoso Roveda - ICT/Sorocaba

Profa Dra Márcia Pereira da Silva - FCHS/Franca

Profa Dra Maria Cândida Soares Del Masso - FFC/Marília

Profa Dra Rosane Michelli de Castro - FFC/Marília

Prof. Dr. Sebastião Souza Lemes - FCL/Araraquara

Comissão de Avaliação definida pela Pró-reitoria de Extensão Universitária da Unesp

Profa Dra Ana Paula Cordeiro - FFC/Marília

Prof. Dr. Antônio Cézar Leal - FCT/Presidente Prudente

Profa Dra Camila Pires Cremasco Gabriel - FCE/Tupã

Profa Dra Eliana Marques Zanata - FC/Bauru

Prof. Dr. José Carlos Miguel - FFC/Marília

Profa Dra Luciene Cristina Risso - CE/Ourinhos

Profa Dra Maria do Carmo Kobayashi - FC/Bauru

Prof. Dr. Mário Lázaro Camargo - FC/Bauru

Profa Dra Nanci Soares - FCHS/Franca

Profa Dra Rosa Maria Feiteiro Cavalari - IB/Rio Claro

Profa Dra Tânia da Costa Garcia - FCHS/Franca

Profa Dra Tatiana Schneider Vieira de Moraes - FFC/Marília

Prof. Dr. Victor Hugo de Almeida - FCHS/Franca

Membros da Comissão Permanente de Extensão Universitária - CPEU do Instituto de Biociências do Campus de Rio Claro responsáveis pela indicação da obra

Profa Dra Adelita Aparecida Sartori Paoli - Presidente

Prof. Dr. Afonso Antonio Machado

Profa Dra Andreia Osti

Profa Dra Carmen Maria Aguiar

Profa Dra Débora Cristina Fonseca

Profa Dra Laurita Marconi Schiavon

Profa Dra Leila Marrach Basto de Albuquerque

Profa Dra Marcia Reami Pechula

Prof. Dr. Mario Sergio Palma

Prof. Dr. Massanori Takaki

Prof. Dr. Odair Correa Bueno

Profa Dra Patricia Pasquali Parise Maltempi

Profa Dra Regiane Helena Bertagna

Profa Dra Sara Qüenzer Mathiesen

Profa Dra Silvia Deutsch

Profa Dra Silvia Marina Anaruma

Prof. Dr. Wilson do Carmo Junior

Ana Carlota Kronemberger Mantelli

Gilson Fuzaro Junior

Isabel Aparecida Rocha Braz Seneda

Lídia de Azevedo Duarte

Maíra Cabral Martins

Maria Cristina Apolinário Antunes

Paulo Roberto Gimenez

Renan Fernandes Martin 


\section{JOSÉ LUIZ RIANI COSTA \\ AMARILIS M. MUSCARI RIANI COSTA \\ GILSON FUZARO JUNIOR \\ (ORGS.)}

O QUE VAMOS FAZER

DEPOIS DO TRABALHO?

REFLEXÕES SOBRE A PREPARAÇÃO PARA APOSENTADORIA 
(C) 2016 Editora Unesp

Cultura Acadêmica

Praça da Sé, 108

01001-900 - São Paulo - SP

Tel.: (0xx1 1) 3242-7171

Fax: $(0 x x 11)$ 3242-7172

www.editoraunesp.com.br

www.culturaacademica.com.br

www. livrariaunesp.com.br

feu@editora.unesp.br

CIP - Brasil. Catalogação na publicação

Sindicato Nacional dos Editores de Livros, RJ

Q35

O que vamos fazer depois do trabalho? [recurso eletrônico] :

reflexões sobre a preparação para aposentadoria / organização

José Luiz Riani Costa, Amarilis M. Muscari Riani Costa,

Gilson Fuzaro Junior. - 1.ed. - São Paulo : Cultura Acadêmica, 2016.

recurso digital

Formato: ePDF

Requisitos do sistema: Adobe Acrobat Reader

Modo de acesso: World Wide Web

ISBN 978-85-7983-763-0 (recurso eletrônico)

1. Aposentadoria - Aspectos sociais. 2. Benefícios

previdenciários - Aspectos sociais. 3. Lazer. 4. Velhice.

5. Qualidade de vida. 6. Livros eletrônicos. I. Costa, José Luiz Riani.

II. Costa, Amarilis M. Muscari Riani. III. Fuzaro Junior, Gilson.

$16-33486$

CDD: 305.26

CDU: $316.346 .32-053.9$

Este livro é publicado pelo Programa de Publicações da Pró-Reitoria de Extensão Universitária da Universidade Estadual Paulista "Júlio de Mesquita Filho" (UNESP)

Editora afiliada:

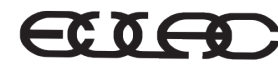

Asociación de Editoriales Universitarias de América Latina y el Caribe

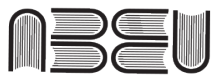

Associaçāo Brasileira de Editoras Universitărias 


\section{SUMÁRIO}

\section{Prefácio 9}

Introdução 13

José Luiz Riani Costa

Amarilis Maria Muscari Riani Costa

O caminho trilhado até o momento 15

O Ciclo de Palestras sobre Preparação para

Aposentadoria e seus desdobramentos 18

Referências bibliográficas 20

1. Envelhecimento e trabalho 23

Amarilis Maria Muscari Riani Costa

Paulo Fernando Moraes

José Luiz Riani Costa

Ruth Gelehrter Costa Lopes

Envelhecimento populacional 23

A questão do trabalho e a população idosa 25

Centralidade do trabalho 28

Referências bibliográficas 31

2. Preparação para a aposentadoria 33

Amarilis Maria Muscari Riani Costa

Pollyanna Natalia Micali

Oscar Gutiérrez Huamaní 
José Luiz Riani Costa

Ruth Gelehrter Costa Lopes

Transição da vida centrada no trabalho para

o tempo do pós-trabalho 34

Programas de preparação para aposentadoria 37

Referências bibliográficas 41

3. Saúde, envelhecimento e aposentadoria 45

Jessica Rodrigues Pereira

Paulo Fernando Moraes

Úrsula Virgínia Pereira

José Luiz Riani Costa

O processo de envelhecimento e seus desdobramentos no âmbito da saúde 50

O envelhecer com saúde 52

A aposentadoria no processo de envelhecimento 53

Referências bibliográficas 57

4. Aspectos psicossociais da aposentadoria 63

Carla Andrezza Andreatto

Amarilis Maria Muscari Riani Costa

Lais Scarpari

Ruth Gelehrter Costa Lopes

Redes de suporte social 66

O protagonismo da população idosa 68

Aposentadoria e a tarefa de cuidar de alguém 71

Referências bibliográficas 73

5. Atividade física e aposentadoria 77

Pollyanna Natalia Micali

Paula Secomandi Donadelli

Paulo Fernando Moraes

Reisa Cristiane de Paula Venancio

Referências bibliográficas 88 
6. Envelhecimento, novas tecnologias e aposentadoria 93

Elisangela Gisele do Carmo

Marisa Silvana Zazzetta

Tecnologias assistivas 97

Referências bibliográficas 99

7. Alimentação e nutrição no envelhecimento e na aposentadoria 103

Gilson Fuzaro Junior

Elisangela Gisele do Carmo

Raiana Lídice Mór Fukushima

Paula Secomandi Donadelli

José Felipe Riani Costa

Nutrição e envelhecimento 104

Influência da saúde bucal do idoso na

alimentação e nutrição 108

Nutrição e aposentadoria 110

Referências bibliográficas 113

8. Outras possibilidades para a aposentadoria 117

Raiana Lídice Mór Fukushima

André Luis Vicente

Gilson Fuzaro Junior

Melissa Riani Costa Machado

José Luiz Riani Costa

A convivência com animais de estimação 117

Animais de estimação no envelhecimento 118

Intervenção assistida por animais 121

Cinema depois do trabalho 123

Envelhecimento, aposentadoria e meio ambiente 125

A participação de idosos na educação ambiental 127

Referências bibliográficas 131 
9. Bases para um programa de preparação para a aposentadoria 135

Amarilis Maria Muscari Riani Costa

José Luiz Riani Costa

Características gerais do PPA 137

Propostas relacionadas à organização de um PPA 137

Propostas que podem ser adotadas como complementação do PPA 138

Considerações finais 141

Apêndice 143

Anexo 147

Lista de filmes que podem ser utilizados em programas de preparação para a aposentadoria (PPA) 147

Sobre os organizadores 149

Sobre os demais autores 151 


\section{Prefácio}

O que vamos fazer depois do trabalho? Reflexões sobre a preparação para aposentadoria, livro cuidadosamente organizado por José Luiz Riani Costa, Amarilis Maria Muscari Riani Costa e Gilson Fuzaro Junior, traz à luz um importante (e atual) debate em torno de questões que associam trabalho, aposentadoria e processo de envelhecimento. As reflexões resultam de experiência acumulada na realização de atividades de extensão na Unesp/Rio Claro relacionadas à preparação para a aposentadoria. Entendo que abordar o tema, tendo em vista o testemunho de uma prática, abre espaço para que as vozes dos sujeitos que dela participaram sejam escutadas: um passo fundamental para que as sociedades capitalistas contemporâneas, em especial a sociedade brasileira, possam atentar para os interesses dos sujeitos, e não só do capital, no enfrentamento das múltiplas questões suscitadas pela aposentadoria como rito de passagem. Nessa perspectiva, problematizá-lo exige cada vez maior explicitação de seus fatores determinantes e de seus desdobramentos, principalmente quando se leva em conta um cenário em que, no Brasil, estão em causa longos anos de trabalho, idades cada vez mais avançadas e ativos financeiros cada vez menores.

Há um consenso, tanto entre estudiosos como entre leigos, de que a conquista de uma vida mais longa não pode estar desvincu- 
lada do bem viver. Fatores de natureza objetiva, mas também subjetiva, jogam aí seu papel, o que, sem dúvida alguma, torna bastante complexa a tarefa de discutir as mudanças implicadas no rito de passagem antes referido. Pode-se afirmar isso não apenas porque há um maior número de pessoas idosas no Brasil e no mundo (leia-se: maior número de pessoas com idade para se aposentar), mas em função da enorme heterogeneidade de demandas para concretizar o viver bem no interior desse grupo.

Não sem razão, reproduzir a ideia de que a aposentadoria é a passagem da categoria dos economicamente ativos para a de inativos soa como uma abordagem reducionista da questão. Mesmo desconfiando que, nos dias atuais, o par ativo/inativo não reflete adequadamente a vida vivida depois dela, para ir além nesta reflexão, parece-me ser necessário responder, entre outras, a indagações como: 1) qual o impacto desse rito de passagem em contextos socioculturais particulares e, consequentemente, como ele é coletivamente significado?; 2) quais os seus efeitos subjetivos e como determinam caminhos singulares no viver a vida na velhice?; 3) como trabalho, aposentadoria e velhice se entrelaçam enquanto acontecimentos marcantes no curso de vida?; 4) de que modo eles podem se integrar mais espontaneamente quando se tornam objeto de uma política? Afinal, trabalho não é só trabalho assalariado; aposentadoria é algo mais que "recolher-se aos aposentos" e velhice não é sinônimo de invalidez e; 5) o que responderia pelo frequente paradoxo de desejar mas, ao mesmo tempo, repelir a ideia de se aposentar?

De muitos modos, os capítulos que compõem este livro tangenciam essas e outras questões pertinentes ao tema, base para encaminhar proposições que orientem a implantação de programas de preparação para a aposentadoria (PPA) em instituições públicas e privadas. Assim, o Capítulo 1 - "Envelhecimento e trabalho" - começa com uma breve discussão sobre o envelhecimento populacional, particularmente no Brasil, para então discorrer sobre a questão do trabalho quando ela está especificamente voltada para a população idosa. Na sequência, o foco do debate do Capítulo 2 - 
"Preparação para a aposentadoria" - recai sobre a centralidade do trabalho na vida das pessoas e as consequências da transição de uma vida assim concebida para o tempo do pós-trabalho. Coloca-se em relevo a importância de ações efetivas no sentido de preparar os trabalhadores para a aposentadoria, ações que promovam uma abertura do olhar para outros modos de viver a vida, o que pode contribuir para tornar menos traumática a sua desvinculação com o mundo do trabalho. Ainda nesse capítulo, encontramos um detalhamento dos programas que buscam disponibilizar informações específicas sobre questões que incluem a disponibilização de recursos socioculturais e serviços da comunidade para esse segmento da sociedade. No Capítulo 3 - "Saúde, envelhecimento e aposentadoria" -, o que está em causa é uma reflexão acerca do processo de envelhecimento e seus desdobramentos no âmbito da saúde. Destaque é dado à articulação entre saúde e trabalho, o que inclui problematizar a relação entre saúde e aposentadoria. O Capítulo 4, por sua vez, coloca em pauta os "Aspectos psicossociais da aposentadoria". A importância das redes de suporte social constitui um dos pontos fundamentais do debate, no qual se abre espaço para considerações sobre a relação entre aposentadoria e a tarefa de cuidar de alguém. O Capítulo 5 volta a atenção para a relação entre "Atividade física e aposentadoria". Partindo da hipótese de que a realização de atividade física seja de fundamental importância para viver a vida com qualidade, o debate ressalta os desafios a serem enfrentados para que isso se cumpra na vida pós-trabalho. O Capítulo 6 traz um tema bastante atual: "Envelhecimento, novas tecnologias e aposentadoria". Advoga-se a favor da ideia de que o uso de tecnologias abre uma gama de novas, interessantes e desafiadoras possibilidades para agregar qualidade ao cotidiano de sujeitos idosos. Atenta-se para o fato de que usufruir de seus benefícios depende de que tais tecnologias sejam mais acessíveis financeiramente a um número cada vez maior de usuários. Destaque é dado, no final do capítulo, para os robôs de assistência, ou robôs sociais, utilizados para estimulação cognitiva e interação, além de desempenho em diversas atividades domésticas. No Capítulo 7, intitulado "Alimentação e nutrição no envelhecimento e na aposenta- 
doria", discutem-se os determinantes de um estilo de vida saudável, em que atividade física e nutrição comparecem como centrais. Atenção especial é dada à questão que envolve a influência da saúde bucal do idoso na alimentação e nutrição. "Outras possibilidades para a aposentadoria" é o tema central do Capítulo 8. Mais especificamente, a reflexão está voltada para: a) os efeitos positivos da convivência com animais de estimação; nessa perspectiva, inclui-se tanto a Terapia Assistida por Animais, ou Pet-Terapia, quanto outras atividades assistidas por animais que oferecem oportunidades recreativas, motivacionais e educacionais que podem integrar um PPA; b) o cinema como uma alternativa de educação não formal no âmbito do PPA; c) a participação de aposentados na educação ambiental como outra abordagem inovadora a ser encaminhada nos PPA's. O Capítulo 9 apresenta as "Bases para um Programa de Preparação para a Aposentadoria", tendo como fundamento a reflexão encaminhada nos capítulos anteriores e a experiência acumulada no PPA da Unesp/Rio Claro. Nas "Considerações finais", os autores reafirmam a expectativa de que o livro possa colaborar para o debate do tema no interior das instituições públicas e nas empresas, buscando garantir condições dignas de aposentadoria aos trabalhadores, bem como de vida pós-trabalho. O livro apresenta, ainda, um "Apêndice" - com links de um conjunto de rádio releases (Podcasts) sobre diversos assuntos abordados ao longo do livro - e um "Anexo" - com uma lista de filmes que podem ser utilizados em Programas de Preparação para a Aposentadoria.

Com a certeza de que a discussão encaminhada neste livro tem muito a contribuir para o aprofundamento do tema que coloca em cena, parabenizo seus autores pela iniciativa de sua publicação.

Suzana Carielo da Fonseca Programa de Pós-Graduação em Gerontologia da PUC-SP 


\title{
INTRODUÇÃO
}

\author{
José Luiz Riani Costa \\ Amarilis Maria Muscari Riani Costa
}

O título do livro, propositalmente, tem um duplo sentido. Muitas pessoas provavelmente associarão o título a um conjunto de atividades realizadas após o expediente de trabalho, popularmente conhecido como happy hour. Alguns poderão até pensar que se trata de um guia de bares e restaurantes destinados às confraternizações de final de tarde. O subtítulo deixa claro que não se trata disso, mas o que poderíamos chamar, por analogia, de happy years; ou seja, um "guia" para que o tempo da aposentadoria seja um período de anos felizes.

Este livro surgiu da necessidade sentida de divulgar a experiência acumulada em uma série de atividades vinculadas à extensão universitária voltadas à preparação para a aposentadoria, bem como em projetos de pesquisa e publicações envolvendo docentes, servidores técnico-administrativos e pós-graduandos ligados à Unesp, no câmpus de Rio Claro. ${ }^{1}$ A expectativa é que as reflexões aqui apresentadas contribuam para a implantação de programas de preparação para a aposentadoria (PPA) em insti-

1. Agradecimento à prof $\mathrm{dr}^{\mathrm{a}} \mathbf{-}$ Adelita $\mathrm{A}$. Sartori Paoli, pelo apoio constante no tempo em que esteve à frente da Vice-Diretoria do Instituto de Biociências e participou ativamente nas atividades envolvendo a preparação para a aposentadoria no câmpus. 
tuições públicas e privadas, além de colaborar com os programas já existentes.

Entende-se que a universidade, inserida em uma realidade sociocultural, deve colaborar na busca de respostas para a solução dos diferentes problemas existentes. Assim, para cumprir sua responsabilidade de promover, gerar e difundir conhecimentos, a universidade deve estabelecer uma estreita relação com a comunidade onde está inserida, incluindo a comunidade interna. Para Novo e Fôlha (2010), responsabilidade social da universidade significa, também, preocupar-se com os servidores e com o ambiente.

No caso da qualidade de vida no trabalho, por exemplo, deve ir além do cumprimento das obrigações trabalhistas, contribuindo para que seus trabalhadores, "ao chegarem no momento da aposentadoria, possam desfrutar deste período com o prazer e a alegria merecidos após tantos anos de dedicação ao trabalho na instituição" (Novo; Fôlha, 2010, p.6).

A universidade tem uma contribuição importante a dar na compreensão do processo de envelhecimento da sociedade e na formulação de propostas para o enfrentamento dos problemas identificados, por meio das atividades de ensino, pesquisa e extensão. Assim, a implantação de PPA na universidade tem um papel relevante a desempenhar, tanto na produção de conhecimento quanto na prestação de serviços à comunidade, podendo estabelecer parceria com as prefeituras de municípios da região, bem como outros órgãos públicos e empresas que não possuam seu próprio PPA.

Bressan et al. (2012) lembram que, apesar de a aposentadoria ter significado relativamente semelhante nas sociedades ocidentais, esse significado pode apresentar diferenças regionais dentro de um mesmo país, ou mesmo em uma determinada organização, em função das diferentes atividades realizadas. Dessa forma, é preciso considerar a necessidade de alternativas de serviços de suporte social. Os autores também fazem uma reflexão importante: as divisões próprias da aposentadoria (por idade, por tempo de serviço, por invalidez, por acidente de trabalho, aposentadoria especial), acrescidas ao fato de que todas essas modalidades são vivenciadas 
por indivíduos diferentes, tendo cada um suas especificidades, tornam ainda mais difícil que se tenha um único olhar.

No setor público, existem aspectos específicos no que se refere à legislação trabalhista e previdenciária, como a estabilidade no emprego e a possibilidade de proventos integrais na aposentadoria, que tendem a fazer que o servidor permaneça trabalhando no mesmo órgão ou setor por muitos anos, geralmente até chegar ao final da vida laboral. Além disso, com as mudanças nas regras da aposentadoria no setor público que vêm ocorrendo nas últimas décadas, tem-se tornado cada vez mais frequente o envelhecimento no trabalho.

\section{O caminho trilhado até o momento}

A primeira ação envolvendo esta temática, no âmbito da Unesp, particularmente no câmpus de Rio Claro, ocorreu em 2001, por meio da apresentação do trabalho intitulado "A Unesp aberta à sua própria terceira idade”, no III Seminário Unesp-Unati (Universidade Aberta à Terceira Idade), que propunha a implantação de ações voltadas à população trabalhadora que envelhecia, incluindo a preparação para a aposentadoria (Costa, A., 2001). A ideia era despertar a universidade a assumir sua responsabilidade social quanto à aposentadoria, tanto em relação aos seus próprios servidores quanto no que se refere aos demais trabalhadores de instituições públicas e privadas.

Em 2002, o tema foi retomado no trabalho "A saúde dos aposentados (e dos quase)", no I Congresso Saúde e Trabalho da Unesp, realizado no câmpus de Assis. Nessa mesma época, a relação entre envelhecimento e trabalho e a preparação para a aposentadoria foram alguns dos temas abordados na tese de doutorado Em busca da (c)idade perdida: o município e as políticas públicas voltadas à população idosa (Costa, J., 2002).

Nos anos seguintes, foi instituída uma comissão junto à Reitoria, que contou com representantes do Núcleo Local Unesp-Unati 
do câmpus de Rio Claro, com o objetivo de elaborar uma proposta de PPA a ser implantada em todas as unidades da Unesp. Infelizmente, os trabalhos foram interrompidos e a proposta não se efetivou.

Em 2004, com a participação da universidade no Conselho Municipal do Idoso, especialmente por meio do Núcleo Local Unesp-Unati, foi elaborada a Lei n.3.498, de 16 de dezembro de 2004, que instituiu a Política Municipal do Idoso de Rio Claro, incluindo artigos relacionados a essa temática (Rio Claro, 2004).

Em 2007, foi realizado o I Congresso de Preparação para a Aposentadoria no câmpus de Ilha Solteira da Unesp, com o objetivo de desencadear a reflexão sobre esse novo ciclo de vida, incluindo a formulação de um novo projeto de vida. Em 2009, aconteceu o II Congresso de Preparação para a Aposentadoria, visando criar um espaço de formação técnica e científica dos processos de envelhecimento e da aposentadoria. O evento contou com palestras e mostra de trabalhos, buscando refletir sobre os múltiplos fatores no marco da vida que é a aposentadoria, e informar sobre as possibilidades de aposentadoria na legislação brasileira, entre outros objetivos. Na ocasião, as reflexões que vinham acontecendo no câmpus de Rio Claro foram apresentadas por meio de uma conferência e apresentação de pôster.

Uma ação importante nesse processo foi desenvolvida entre os servidores da Reitoria da Unesp, constituída por um conjunto de palestras, sendo que a atividade de sensibilização ficou a cargo do grupo de Rio Claro.

A partir de então, intensificou-se a aproximação com a preparação para a aposentadoria, por meio de diferentes atividades. Em 2009, no V Congresso de Extensão Universitária da Unesp, foram apresentados temas livres relacionados a essa temática (Costa; Costa, 2009).

Em 2010, a discussão sobre o tema foi levada ao XIV Congresso da Associação Nacional de Medicina do Trabalho (Anamt), com a palestra "Envelhecimento dos trabalhadores: o caso dos servidores públicos". Ainda em 2010, aconteceu em Brasília o III Encontro Nacional de Atenção à Saúde do Servidor (Enass), 
que contou com a participação de representantes de diversos ministérios e órgãos regionais das diferentes regiões do país. Nesse evento, por proposta do grupo da Unesp/Rio Claro, aconteceram a mesa-redonda "Envelhecimento e trabalho público" e uma oficina sobre Programa de Preparação para a Aposentadoria, que estimularam a troca de experiências em relação ao tema. Como desdobramentos desse trabalho, surgiram convites para palestras em algumas universidades federais e outros órgãos públicos.

Em 2011, foram apresentados outros trabalhos na forma de tema livre no VI Congresso de Extensão Universitária da Unesp (Costa; Costa, 2011).

Em 2012, no II Encontro de Associados da Associação dos Funcionários Públicos do Estado de São Paulo (Afpesp) foi apresentada uma proposta no sentido de a entidade desenvolver ações relacionadas à preparação para a aposentadoria, o que deu origem ao Programa Nova Etapa. O assunto também foi levado ao Encontro das Associações de Servidores da Unesp, bem como aos Encontros de Formação da Pastoral da Saúde da diocese de Piracicaba.

A experiência ao longo desses anos no câmpus de Rio Claro propiciou a organização, em 2012, do Ciclo de Palestras sobre Preparação para Aposentadoria, um evento de extensão universitária que buscou criar as bases para a implantação do PPA na Unesp/ câmpus de Rio Claro. Teve também o objetivo de divulgar o conhecimento produzido pela universidade a respeito do processo de envelhecimento. Essa experiência será detalhada mais à frente.

Em 2013, a Reitoria da Unesp organizou um ciclo de palestras em dez câmpus da universidade, de modo a possibilitar a participação de servidores de todas as unidades. As palestras aconteceram mensalmente, abordando os seguintes temas: Aspectos psicossociais da aposentadoria e qualidade de vida; Rede social e apoio; Responsabilidade social, cultura, lazer e arte - Unati; Empreendedorismo, trabalho e qualidade de vida; Saúde econômica e financeira; Legislação e aposentadoria na Unesp; Atividade física e longevidade; e Longevidade e sexualidade. 
Nesse período, foram publicados diversos artigos em jornais e gravados diversos podcasts, cuja relação encontra-se nos Apêndices. Também foi publicado o capítulo "Unesp-Unati e as políticas públicas voltadas à população idosa" no livro Unati - Espaço aberto ao ensino e à criatividade (Costa; Costa; Gobbi, 2012).

\section{O Ciclo de Palestras sobre Preparação para Aposentadoria e seus desdobramentos}

Como resultado das ações anteriormente descritas, foi realizado na Unesp/câmpus de Rio Claro, o Ciclo de Palestras sobre Preparação para Aposentadoria, no período de maio a dezembro de 2012, com palestras mensais que abordaram os seguintes temas: Princípios e diretrizes do Programa de Preparação para a Aposentadoria (PPA); Aspectos previdenciários da aposentadoria; Lazer, cultura e turismo; O envelhecimento da humanidade; Os efeitos do trabalho na saúde do trabalhador e do aposentado; Aspectos psicossociais da aposentadoria; As bases legais do Programa de Preparação para a Aposentadoria (PPA); Objetivos e prioridades do PPA; Atividade física e saúde no trabalho e no pós-trabalho; A centralidade do trabalho nas sociedades humanas; e Construção de projetos de vida para o período pós-carreira. A atividade de encerramento do ciclo contou com os participantes revelando aos demais os seus talentos, o que possibilitou uma troca interessante de informações e emoções.

O público-alvo do ciclo era constituído por profissionais da área de recursos humanos/gestão de pessoas da Unesp e de instituições públicas e privadas do município e da região, trabalhadores inseridos em programas de preparação para a aposentadoria de outras instituições, idosos que participam dos projetos de extensão apoiados pelo Núcleo Local Unesp-Unati, bem como demais interessados na temática. 
A Unesp vem desenvolvendo e divulgando uma intensa produção acadêmica a respeito do processo de envelhecimento, bem como oferecendo um conjunto de projetos de extensão universitária que contribuem para a melhoria da qualidade de vida de um grande contingente de pessoas. Tal conhecimento também deve ser aplicado em benefício de seus próprios servidores, visando à manutenção da capacidade funcional e à preparação para a vida no pós-trabalho.

Foi sugerido aos diretores dos dois institutos que integram o câmpus de Rio Claro que os servidores que se encontravam a dois anos da aposentadoria fossem liberados para participar das atividades do Ciclo de Palestras, além de outros servidores, a critério das chefias dos diferentes setores, bem como os profissionais com conhecimentos técnicos que pudessem colaborar para o aprimoramento do processo. Também foi sugerida a participação dos servidores aposentados, pois estes poderiam enriquecer as reflexões e debates, bem como ajudar a enfrentar a nova situação.

A atividade também foi divulgada junto à Prefeitura Municipal de Rio Claro e demais órgãos públicos das três esferas de governo existentes no município e na região, bem como ao Conselho Municipal do Idoso, grupos de terceira idade, associações de aposentados, sindicatos de trabalhadores etc.

Em função da repercussão na mídia regional, o evento estimulou o debate sobre a importância dos programas de preparação para a aposentadoria na garantia da qualidade de vida no trabalho e no pós-trabalho, na expectativa de colaborar com as instituições públicas e privadas no cumprimento do Estatuto do Idoso nesse campo.

No câmpus de Rio Claro, paralelamente às palestras do ciclo coordenado pela Reitoria, foi criado o Projeto de Extensão PPA-Unesp/Rio Claro, incorporando o Projeto de Extensão "Cinema, Educação e Saúde", desenvolvido desde 2008, como relatado no Capítulo 8, além da proposta de um Programa de Atividades Físicas. 
Nos capítulos que se seguem, são apresentadas as reflexões levadas a cabo nesse período, bem como a fundamentação teórica das pesquisas desenvolvidas pelos autores em relação à aposentadoria.

Existem correntes de pensamento que propõem outras denominações para o conjunto de ações envolvido no processo que visa contribuir para que o desligamento do trabalho tenha minimizados os problemas decorrentes dessa fase e potencializadas as oportunidades para que a transição se dê de modo positivo, como "planejamento de aposentadoria", "orientação para a aposentadoria" e "educação para a aposentadoria", entre outros. No entanto, neste livro adota-se a denominação "programa de preparação para aposentadoria" por ser a mais utilizada e a que é referida na legislação e outros documentos oficiais.

\section{Referências bibliográficas}

BRESSAN, M. A. L. C. A significação do trabalho e da aposentadoria: o caso dos servidores da Universidade Federal de Viçosa. Viçosa, 2011. Dissertação (Mestrado em Economia Doméstica) - Universidade Federal de Viçosa.

et al. Aposentadoria e trabalho: percepções de servidores públicos de uma universidade federal. In: FRANÇA, L.; STEPANSKY, D. (Orgs.). Propostas multidisciplinares para o bem-estar na aposentadoria. Rio de Janeiro: Quartet; Faperj, 2012.

COSTA, A. M. M. R. A Unesp aberta à própria terceira idade. SEMINÁRIO UNESP-UNATI, 3, Rio Claro, 2001. Anais do...

; COSTA, J. L. R. A saúde dos aposentados (e dos quase). CONGRESSO SAÚDE E TRABALHO DA UNESP, 1, Assis, 2002. Anais do...

. Os núcleos locais Unesp-Unati e a implantação de programas de preparação para a aposentadoria. CONGRESSO DE EXTENSÃO UNIVERSITÁRIA DA UNESP, 6, Águas de Lindoia (SP), 2011. Anais do... 
COSTA, A. M. M. R.; COSTA, J. L. R. Preparação para a aposentadoria no âmbito da universidade. CONGRESSO DE PREPARAÇÃO PARA A APOSENTADORIA - PERSPECTIVAS E RESPONSABILIDADE SOCIAL, 2, Ilha Solteira (SP), 2009. Anais do...

COSTA, J. L. R. Em busca da (c)idade perdida: o município e as políticas públicas voltadas à população idosa. Campinas, 2002. Tese (Doutorado em Saúde Coletiva) - FCM, Unicamp.

; COSTA, A. M. M. R.; GOBBI, S. Unesp-Unati e as políticas públicas voltadas à população idosa. In: DEL-MASSO, M. C. S.; AZEVEDO, T. C. A. M. (Orgs.). Unati - Espaço aberto ao ensino e à criatividade. v.1. 1.ed. São Paulo: Cultura Acadêmica, 2012. p.25-42.

NOVO, L. F.; FÔLHA, F. A. S. Importância da preparação à aposentadoria: a fala de servidores aposentados da UFPEL. COLOQUIO INTERNACIONAL SOBRE GESTIÓN UNIVERSITARIA EN AMÉRICA DEL SUR, 10, Mar Del Plata, 2010.

RIO CLARO. Lei n.3.498, de 16 de dezembro de 2004, que instituiu a Política Municipal do Idoso de Rio Claro, 2004. 


\title{
1 \\ ENVELHECIMENTO E TRABALHO
}

\author{
Amarilis Maria Muscari Riani Costa \\ Paulo Fernando Moraes \\ José Luiz Riani Costa \\ Ruth Gelehrter Costa Lopes
}

\section{Envelhecimento populacional}

O Estado e a sociedade brasileiros, ainda perplexos, assistem a um processo de envelhecimento da população sem precedentes (Costa, 2002; Kalache, 2012). Além da velocidade, esse processo ocorre em um contexto em que persistem outros problemas sociais, como a pobreza e a exclusão social que, apesar dos avanços recentes, ainda não estão plenamente resolvidos.

Há diferentes maneiras de se envelhecer, o que exige que as políticas públicas voltadas ao segmento idoso considerem as demandas específicas, promovendo a igualdade de acesso à justiça social. Assim, essas políticas devem atender o princípio da equidade, que orienta a tratar diferentemente os desiguais para que tenham acesso igual ao direito, dando mais a quem mais precisa (Camarano; Pasinato, 2004; Costa; Costa; Gobbi, 2012).

Além disso, as ações voltadas à população idosa devem ter uma abordagem integrada das diversas políticas setoriais, como saúde, assistência social, previdência, educação, esporte e lazer, obedecendo ao princípio da intersetorialidade, componente importante das políticas públicas e essencial quando o foco é essa faixa etária.

Reconhecendo que nenhuma disciplina esgota todas as possibilidades de interpretação dos fenômenos da vida humana e social, 
um aspecto importante na formulação de políticas públicas voltadas à população idosa é a interdisciplinaridade, para a superação da visão fragmentada do conhecimento, incluindo o trabalho em equipe e o controle social nesse processo, desde o diagnóstico até a intervenção e a avaliação.

Embora aspectos pontuais relativos aos direitos dos idosos estejam contemplados na legislação brasileira desde o Império ${ }^{1}$ (Filizzola, 1966), foi durante os trabalhos da Assembleia Nacional Constituinte que se consolidaram as bases de uma legislação abrangente de proteção da população idosa, fruto de uma intensa mobilização de associações profissionais ligadas à gerontologia e de organizações dos próprios idosos e aposentados. Os direitos garantidos na Constituição Federal de 1988 foram aprofundados em outras legislações nas três esferas de gestão, mas grande parte da efetivação desses direitos se dá na esfera municipal.

Como as pessoas estão vivendo mais, o número de aposentados vem se tornando cada vez maior. Estudos das Nações Unidas mostram que, em 2007, havia, para cada idoso, doze pessoas na idade economicamente produtiva (de 15 a 62 anos). A previsão é de que essa proporção, em menos de cinquenta anos, seja de três para cada pessoa aposentada. "Neste sentido, o desafio de manter os padrões de saúde e independência dessa população será cada vez maior" (Bressan et al., 2012, p.200).

Segundo França (2002), ocorre um aumento da população ativa, mas esse crescimento é insuficiente se for considerado proporcionalmente ao crescimento da população idosa. Ainda segundo a autora (2002), "a faixa etária produtiva, que é responsável pelo pagamento dos custos com as crianças e os idosos, tem tido um aumento constante, ou seja, 52\% em 1960 para 58\% em 1991".

1. Em 1865, foi promulgada a Lei dos Sexagenários, que "libertou" os escravos mais idosos e, na década de 1870, foi criado o primeiro Asilo de Mendicidade, atribuindo ao Estado a responsabilidade de "defender, socorrer, proteger e amparar a velhice mendicante" (Filizzola, 1966, p.214). 
Contudo, além de esse crescimento não ser proporcional ao número de inativos, a mediana da idade das pessoas em atividade (15 a 64 anos), vem apresentando um crescimento constante a partir de 1980. Essa mediana, que era de 20 anos em 1980, deverá passar para 40 anos em 2035, podendo chegar a 46 anos em 2050 (IBGE, 2009; 2010).

O envelhecimento populacional tem trazido enormes desafios para o país, habituado a lidar com questões típicas da população jovem. Como os idosos formam um grupo populacional mais propenso a doenças crônicas e incapacitantes, o setor saúde tem sido um dos mais confrontados com os desafios trazidos por esse fenômeno, pois precisa readequar sua estrutura e organização para atender melhor a população idosa.

Assim, na sociedade brasileira tem crescido um movimento social, em grande medida encabeçado pelos próprios idosos, de luta por uma vida não só mais longa, mas também mais digna. Cabe destacar aqui a melhor articulação dos conselhos de idosos, mobilizando-se por reconhecimento de direitos garantidos no Estatuto do Idoso, como saúde, transporte público, trabalho e enfrentamento da violência e do abandono.

\section{A questão do trabalho e a população idosa}

A associação de uma série de fatores (aumento da população idosa, taxa de desemprego, desigualdade econômica e social, insuficiência da aposentadoria, inovação tecnológica acelerada etc.) vem trazendo um novo desafio ao mundo do trabalho.

O afastamento dos trabalhadores antes dos 60 anos, ou mesmo antes do tempo que lhes permita completar o tempo para a aposentadoria coloca-os à margem do processo produtivo formal e do acesso aos já escassos benefícios sociais. Criam-se amplas redes de trabalho informal e de subemprego, insuficientes para garantir os 
direitos da cidadania e prejudiciais à produção de riqueza nacional. (Neri, 2002, p.8)

Nesse cenário, é importante que os idosos também tenham direito ao trabalho, mas, lamentavelmente, algumas empresas vêm empregando pessoas idosas para diversos serviços internos e/ou externos (que por analogia poderiam receber a denominação office old), muitas vezes sem vínculo empregatício, aproveitando-se, inclusive, do tratamento especial que os idosos conquistaram com tanta luta, como passe livre no transporte coletivo, caixas exclusivos em bancos e outras instituições etc.

L. G. Gonçalves (2002), em sua dissertação de mestrado, investigou as desigualdades em saúde entre idosos em relação à inserção no mercado de trabalho, por meio de dois estudos com indivíduos residentes em dez regiões metropolitanas. Um dos estudos foi realizado com idosos do sexo masculino e o outro foi realizado com idosas, apresentando os seguintes resultados:

Em síntese, nossos resultados mostraram que um quarto dos idosos trabalhava e que a inserção no mercado de trabalho expressa diferenças relativas à idade, à renda domiciliar, à escolaridade e ao fato de ser referência domiciliar. Além disso, este estudo identificou que a melhor condição de saúde, em especial a preservação da autonomia e da mobilidade física, é um importante fator para a permanência na vida ativa nas idades mais avançadas [...]. (p.21)

A participação das mulheres idosas no trabalho foi quase três vezes menor que a dos homens idosos [...]. Assim, o grande percentual de idosas que não trabalhavam e nem eram aposentadas, não representa uma característica desta faixa etária, mas reflete e acentua uma contingência de gênero. Por outro lado, o trabalho das idosas cuidando dos netos e da casa, viabiliza a participação das mais jovens em atividades remuneradas [...]. (p.44) 
De acordo com Neri (2002, p.10), "a desvantagem para os trabalhadores mais velhos" é maior "em ocupações caracterizadas por rápida mudança tecnológica e que por isso requerem constante treinamento e reciclagem de conhecimentos e habilidades".

No entanto, há dados empíricos suficientes que contrariam a noção de que ocorre um declínio generalizado, universal e irrecuperável nas capacidades intelectuais e de trabalho dos adultos maduros. Mais que isso, há informações de que a falta de oportunidades para treinamento e para reciclagem de habilidades é a maior responsável pelo obsoletismo do trabalhador, e não a pretensa decrepitude dos adultos mais velhos. Ao contrário, ambientes de trabalho enriquecidos, inovadores e desafiadores contribuem para a manutenção e o progresso das capacidades humanas e para a satisfação de seus integrantes. (Neri, 2002, p.8)

Para a autora (2002), "o fato de os trabalhadores mais velhos serem eficientes em muitas atividades que requerem persistência, precisão, experiência, capacidade de solução de problemas práticos, pontualidade, assiduidade e cuidado", além do fato de serem mais "flexíveis e motivados a enfrentar desafios, desmentem muitos dos estereótipos correntes sobre o envelhecimento", como os que os veem "como obsoletos, improdutivos, resistentes à mudança e desmotivados" (p.10-1). Por outro lado, "empresas onde os procedimentos de trabalho permanecem inalterados por períodos mais longos, ou naquelas que precisam investir numa imagem conservadora das tradições", como "hotéis e pousadas; fábricas de remédios, fraldas e comidas para bebês; empresas de seguro e firmas de previdência privada tendem a valorizar" os trabalhadores mais velhos (p.11).

Ainda de acordo com Neri (2002), "a despeito de estarem em desvantagem educacional frente aos trabalhadores mais jovens", os trabalhadores "mais velhos são sensíveis ao treino cognitivo e capazes de generalização de novas aprendizagens", permitindo a adaptação "às mudanças tecnológicas" (p.11). Aliás, a autora des- 
taca que "ambientes desafiadores exercem influência capital sobre a continuidade de seu funcionamento intelectual". Além disso, "pessoas que envelhecem sem patologias podem apresentar alto grau de especialização cognitiva, derivada da influência da cultura, que supera as limitações decorrentes das alterações biológicas dependentes da idade" (p.16).

\section{Centralidade do trabalho}

Sendo socialmente construído, o significado do trabalho tem variado ao longo da história humana, refletindo o cenário do sistema produtivo, vigente em cada época desde quando o homem utilizava ferramentas rudimentares para conseguir o necessário para a sua sobrevivência até os dias de hoje (Cerqueira, 2012). Muitas vezes, para o senso comum, há uma ligação do trabalho com tortura, castigo, sofrimento e dor.

O trabalho é uma ação tipicamente humana. Diferentemente dos outros animais, com seu trabalho, o homem atua ativamente sobre o meio para obter os recursos de que necessita.

Na teoria marxista, a sociedade capitalista transforma em mercadoria a capacidade produtiva do trabalhador, promovendo a alienação do trabalhador, que não reconhece mais o produto do seu trabalho, tornando-se estranho a ele. O trabalhador passa a ser dependente das condições que lhe são impostas pelo modo de produção capitalista para produzir seu meio de subsistência, sem se dar conta de que reproduz, concomitantemente, "as condições de sobrevivência do sistema produtivo que o aprisiona e o explora" e que "determina o seu modo de vida e suas relações sociais" (Cerqueira, 2012, p.90).

Contudo, se por um lado o trabalho na sociedade capitalista se torna um mecanismo de alienação e exploração, por outro lado é o mantenedor da vida, instrumento de transformação da natureza e da sociedade, mediador das relações sociais e fundamental para a construção da identidade social e da afirmação da autoestima dos 
indivíduos. Por tudo isso, e por ser a fonte responsável por prover a subsistência do trabalhador e de sua família, o trabalho tende a ser o protagonista no cenário da vida das pessoas, determinando papel secundário aos outros elementos (idem, 2012).

O trabalho pode ser entendido como todo esforço, físico ou psíquico, do ser humano que, intervindo na natureza, produz um resultado (Marx, 1983; Albornoz, 1992; Chrisostomo, 2009; Zanelli et al., 2010; Roesler, 2012). Destaca-se o caráter processual do trabalho nessa relação homem-natureza, em que o homem, por meio do trabalho, põe em movimento as forças naturais que pertencem à sua corporeidade, relacionando-se com o ambiente por meio de seu corpo, por sua ação, com a finalidade de apropriar-se da matéria natural de uma forma que seja útil à sua própria vida, à sua sobrevivência. $\mathrm{O}$ trabalho está associado à transformação da natureza em produtos ou serviços. Assim, o trabalho é processo, ação e obra concluída. Por meio do trabalho, o homem atua sobre a natureza, transformando-a e, ao mesmo tempo, transformando sua própria natureza.

Segundo Zanelli et al. (2010), na sociedade contemporânea há uma centralidade da vida no trabalho. Dentro da perspectiva social, o trabalho é o principal ordenador da vida humana, pois regras, horários, atividades específicas e interações sociais são dispostas conforme as exigências que as tarefas do trabalho impõem. $O$ trabalho proporciona uma rotina de horário, exigindo a presença física do trabalhador e estabelecendo contatos sociais com a equipe de trabalho, as quais configuram um cotidiano.

Em razão da importância da presença física e psicossocial do trabalho na vida das pessoas, ao perderem o emprego, muitas ficam desorientadas, deprimidas, desestruturam-se emocionalmente, sentem-se inúteis e com a percepção, aliada a sentimentos, de que não têm contribuições úteis que possam dar. (Zanelli et al., 2010, p.23) 
Em função disso, pode-se dividir a vida de uma pessoa em três grandes etapas: a de preparação para o trabalho, com um papel destacado da família e da estrutura de ensino; a etapa do trabalho propriamente dito, que ocupa parte significativa de cada dia, durando geralmente cerca de 30 ou 35 anos; e a etapa do pós-trabalho, a aposentadoria, que, com os avanços da medicina e a melhoria da qualidade de vida, vem aumentando, podendo representar mais de trinta anos.

Outro olhar sobre o trabalho é necessário para que se possa pensar de forma diferente a relação homem e trabalho. Segundo Maar (2006), essa perspectiva tem sido pensada pela via da sociologia a partir das décadas de 1970 e 1980, como se nota no marco deixado pelo livro Adeus ao proletariado, de André Gorz, no qual é questionada a centralidade da vida no trabalho como categoria sociológica, tratando do trabalho assalariado. As relações com o trabalho produtivo vêm sendo diversificadas e modificadas desde então.

O tema da centralidade do trabalho precisa ser focalizado tendo em vista o processo de produção material da vida humana em sociedade e sua interação com os outros homens e com a natureza (Maar, 2006). O trabalho é fundamental à constituição da humanidade porque, por meio dele, busca-se atender as necessidades elementares do homem como ser social. Segundo Gorz (apud Soares; Costa, 2011), a centralidade do trabalho está no pensamento, na imaginação das pessoas, que o entendem como algo que possuem e não como algo que fazem em seu cotidiano. $\mathrm{O}$ sentido humanista emancipatório do trabalho calca-se na crítica ao economicismo, que, entre outros aspectos, instrumentaliza as relações sociais em termos de produtividade (Maar, 2006). Em outras palavras, comparada a uma máquina, em uma sociedade que repõe mão de obra a todo instante, a pessoa só se percebe útil à sociedade ao trabalhar.

A aposentadoria não é um momento único, mas um processo de rompimento com o ciclo de trabalho, com paralisação, progressiva ou repentina, de suas obrigações produtivas. Essa transição do mundo produtivo ocorre de um período de tempo totalmente 
voltado e organizado para o trabalho para um período de tempo livre e, em alguns casos, pode resultar em uma verdadeira desorientação temporal e social. Os papéis desempenhados no trabalho, como diz Erikson (1972 apud Santos, 1990), estão relacionados à noção de identidade, que compreende sempre a ideia de um processo dialético que implica tanto o sujeito como o ambiente social.

\section{Referências bibliográficas}

ALBORNOZ, S. O que é o trabalho. São Paulo: Brasiliense, 1992. BRESSAN, M. A. et al. Aposentadoria e trabalho: percepções de servidores públicos de uma universidade federal. In: FRANÇA, L.; STEPANSKY, D. (Orgs.). Propostas multidisciplinares para o bem-estar na aposentadoria. Rio de Janeiro: Quartet; Faperj, 2012.

CAMARANO, A. A.; PASINATO, M. T. Introdução. In: CAMARANO, A. A. (Org.). Os novos idosos brasileiros: muito além dos 60? Rio de Janeiro: Ipea, 2004.

CERQUEIRA, L. L. Trabalho, qualidade de vida e aposentadoria: uma análise evolutiva dos conceitos e das relações que se constroem em torno deles. Revista Científica da Unirb/Faculdade Regional da Bahia - Unirb, Salvador, v.3, n.4, abr. 2012.

CHRISOSTOMO, A. C. R. O trabalho segundo a visão de um grupo de aposentados. São Paulo, 2009. 183p. Dissertação (Mestrado em Psicologia Clínica) - Programa de Pós-Graduação em Psicologia Clínica, Pontifícia Universidade Católica de São Paulo.

COSTA, J. L. R. Em busca da (c)idade perdida: o município e as políticas públicas voltadas à população idosa. Campinas, 2002. Tese (Doutorado em Saúde Coletiva) - FCM/Unicamp.

; COSTA, A. M. M. R.; GOBBI, S. Unesp-Unati e as políticas públicas voltadas à população idosa. In: DEL-MASSO, M. C. S.; AZEVEDO, T. C. A. M. (Orgs.). Unati - Espaço aberto ao ensino e à criatividade. v.1. São Paulo: Cultura Acadêmica, 2012. p.25-42.

FILIZZOLA, M. Como emplacar 100 anos. Rio de Janeiro: O Cruzeiro, 1966. 
FRANÇA, L. H. Repensando aposentadoria com qualidade: um manual para facilitadores de programas de educação para aposentadoria. Rio de Janeiro: CRDE; Unati; UERJ, 2002.

GONÇALVES, L. G. Envelhecimento e trabalho no Brasil: diferenças de saúde e gênero. Belo Horizonte, 2002. 68f. Dissertação (Mestrado em Saúde Pública) - Faculdade de Medicina, Universidade Federal de Minas Gerais.

GORZ, A. Adeus ao proletariado: para além do socialismo. Rio de Janeiro: Forense Universitária, 1987.

INSTITUTO BRASILEIRO DE GEOGRAFIA E ESTATÍSTICA (IBGE). Censo Demográfico 2010. Disponível em: http://www. censo2010.ibge.gov.br.

- Dinâmica demográfica e a mortalidade no Brasil no período 1998-2008. Rio de Janeiro: IBGE, 2009.

KALACHE, A. Prefácio. In: FRANÇA, L.; STEPANSKY, D. (Orgs.). Propostas multidisciplinares para o bem-estar na aposentadoria. Rio de Janeiro: Quartet; Faperj, 2012.

MAAR, L. W. A dialética da centralidade do trabalho. Ciência e Cultura, São Paulo, v.58, n.4, out./dez. 2006.

MARX, K. O capital: crítica da economia política. L.1. v.1. São Paulo: Abril Cultural, 1983.

NERI, A. L. Envelhecer bem no trabalho: possibilidades individuais, organizacionais e sociais. A Terceira Idade, São Paulo, v.13, n.24, p.7-27, abr. 2002.

ROESLER, V. R. Posso me aposentar "de verdade”. E agora? Contradições e ambivalências vividas no processo de aposentadoria de bancários. Florianópolis, 2012. Tese (Doutorado em Psicologia) Universidade Federal de Santa Catarina.

SANTOS, M. de F. de S. Aposentadoria: aspectos psicológicos. São Paulo: EPU, 1990.

SOARES, D. H. P.; COSTA, A. Aposentação: aposentadoria para ação. São Paulo: Vetor, 2011.

ZANELLI, J. C.; SILVA, N.; SOARES, D. P. Orientação para aposentadoria nas organizações de trabalho: construção de projetos para o pós-carreira. Porto Alegre: Artmed, 2010. 


\title{
2 \\ Preparação para A APOSENTAdoria
}

\author{
Amarilis Maria Muscari Riani Costa \\ Pollyanna Natalia Micali \\ Oscar Gutiérrez Huamaní \\ José Luiz Riani Costa \\ Ruth Gelehrter Costa Lopes
}

No Brasil, a aposentadoria é ainda uma questão recente. No início da década de 1920, assim como ocorreu antes na Europa e nos Estados Unidos, a classe operária comandou uma luta pela proteção dos trabalhadores mais idosos. Naquela época, as pessoas viviam muito pouco depois que se aposentavam e, assim, a preocupação maior era o apoio financeiro aos mais velhos (França, 2012).

Ao afirmar que "o trabalhador deveria ter garantida a sua sustentação econômica na fase da aposentadoria", Rey et al. (1996, p.147), citando Salgado, reconhecem que esta "pode-se constituir um período de empobrecimento e até mesmo de miséria, dada a depreciação constante de seu valor e a difícil possibilidade de complementação de renda com outro trabalho remunerado".

No meio urbano, encontramos uma população marginal produzida por um modelo econômico que absorve mão de obra qualificada, que incorpora cada vez mais tecnologia avançada, ignorando contingentes migratórios formados por populações desqualificadas e migrantes, que buscam sua absorção nos grandes centros urbanos metropolitanos. Nessa população existe uma velhice urbana, em aguda carência material, o que favorece o abandono, a delinquência e a demência senis. (Dal Rio, 2002, p.62) 
Como visto no capítulo anterior, os significados conferidos ao trabalho e à aposentadoria são permeados pela lógica do sistema capitalista, no qual o indivíduo é valorizado enquanto produz segundo as relações de produção. Em muitos casos, a aposentadoria é vista como uma situação em que o indivíduo se sente desvalorizado por não mais ser participante da "população economicamente ativa" e de ser, assim, considerado improdutivo. Nesse contexto, o fato de o aposentado ser rotulado como "dependente" da sociedade pode implantar no imaginário social o estigma da inatividade, que passa a acompanhar os demais momentos da vida após a aposentadoria.

Muitas vezes, são deixados de lado valores como a experiência, a maturidade, a sabedoria adquiridas ao longo dos anos de trabalho, especialmente em uma sociedade competitiva e em permanente mudança, fazendo que o aposentado possa sentir-se desorientado, carente de perspectiva ou objetivos, caindo em um mundo fechado, rotineiro, individual e, em alguns casos, depressivo (Pont, 1997).

\section{Transição da vida centrada no trabalho para o tempo do pós-trabalho}

Segundo definição do dicionário Aurélio, aposentadoria pode ser definida como o "ato de aposentar; estado do empregado ou funcionário (civil ou militar) que, tendo atingido certa idade, certo tempo de serviço ou por motivo de saúde, é posto em inatividade e passa a receber uma pensão; reforma (para militares)" (grifo nosso).

Ainda segundo o mesmo dicionário, "inativo" significa "que não tem atividade; inerte: ficar inativo. / Paralisado, paralítico: está com uma perna inativa. / Reformado ou aposentado (falando-se de militares, empregados ou funcionários). / Bras. Servidor público aposentado, reformado, que está na inatividade" (grifo nosso).

Assim, etimologicamente, e no senso comum, a aposentadoria está associada à ideia de alguém que se retira da vida pública, que se recolhe aos seus aposentos, ao espaço privado da sua habitação, ao 
lugar do não trabalho. Mas também, em outra perspectiva, tem-se a ideia da aposentadoria como um prêmio, um reconhecimento pela dedicação ao trabalho realizado durante um longo período. É quando o trabalhador está dispensado das rotinas diárias, está "legalmente liberado de um compromisso formal" (Roesler, 2012, p.69).

Para Erbolato (2002), a aposentadoria é considerada um evento normativo da velhice, podendo representar um marco para seu início. Para a autora, a perda do papel profissional e o afastamento dos relacionamentos ligados ao contexto ocupacional são frequentemente associados a prováveis consequências estressantes.

Levando-se em consideração a centralidade do trabalho e a sua influência na constituição psíquica das pessoas, podem-se imaginar as consequências da aposentadoria na vida dos trabalhadores, considerando-se que a aposentadoria é o momento em que se deixa de trabalhar cotidianamente, não se tem mais horários prefixados (Bittencourt et al., 2011).

A aposentadoria coincide com fenômenos como "ninho vazio", período compreendido entre o momento em que o último filho deixa a casa e ocorre a morte de um dos parceiros, perda de participação social, tempo livre, entre outros (Sartori; Zilberman, 2009).

Embora a aposentadoria, muitas vezes, seja vista como algo que representa a libertação de horários e da rotina, muitos trabalhadores, ao se depararem com a realidade, não sabem o que fazer com o tempo livre (Novo; Fôlha, 2010).

Ao longo dos anos de trabalho, são criados vínculos e desenvolvidos afetos que podem tornar maiores as dificuldades do rompimento. Dessa forma, "é importante que se possa compreender e orientar essas mudanças de maneira positiva”, para que "possam ser superados os receios de se construir uma aposentadoria digna" (idem, p.4).

Como lembra Caldas (2012, p.75),

para algumas pessoas, a aposentadoria pode representar o ingresso em um grupo de inativos para os quais a vida carece de signi- 
ficado. Mas, para outras, pode ser a possibilidade de realização de novos projetos de vida. Pode ser a oportunidade para se dedicar a uma atividade intelectual, desportiva ou social, postergada por uma intensa vida de trabalho. O fato é que somos nós que atribuímos o significado que essa fase da vida terá.

O período que envolve a aposentadoria deve ser entendido como um processo de longo prazo, que se inicia muito antes de a pessoa deixar a relação formal de trabalho e se estende até um tempo depois desse momento (França; Vaughan, 2008). Esse período pode ser visto como positivo para os que estão preparados, mas pode representar uma fase de incertezas, e, assim, uma visão negativa do que poderá acontecer (Bittencourt et al., 2011).

Tem sido destacada a importância das primeiras vivências da aposentadoria na "desmistificação de preconceitos e viabilização de ações" que possam dar suporte às mudanças sociais que ocorrem nesse período (Vasques-Menezes, 2012, p.187).

Não se pode esquecer que essa fase de transição pode ser diferente de uma pessoa para outra, "na forma que acontece e nas consequências que apresenta, pois essas podem variar de acordo com o passado do aposentado, suas condições de saúde prévias ao processo, e as circunstâncias envolvendo a aposentadoria em si" (Bittencourt et al., 2011, p.34).

No entanto, a busca das condições e variáveis de um envelhecimento bem-sucedido, que tenha qualidade de vida, incluindo aspectos físicos, psicológicos e sociais, não é apenas uma questão ou um ideal pessoal e social. Trata-se, também, de um desafio para a ciência, para o Estado e para a sociedade (Neri, 1993).

Outro aspecto importante a ser considerado é a qualidade de vida na velhice, devendo-se reconhecer que, para a promoção da boa qualidade de vida na idade madura, é preciso ir além dos limites da responsabilidade pessoal. Para Neri (2001), qualidade de vida na velhice envolve aspectos socioculturais, incluindo os biológicos, psicológicos e sociais, na interação entre pessoas que vivenciam processos de mudança em uma sociedade em mudança. 
Assim, a avaliação da qualidade de vida na velhice implica abordar múltiplos critérios, envolvendo determinantes ou indicadores relacionados à longevidade, saúde biológica, saúde mental, satisfação, controle cognitivo, competência social, produtividade, atividade, eficácia cognitiva, status social, renda, continuidade de papéis familiares e ocupacionais, e continuidade de relações informais em grupos primários (principalmente rede de amigos) (Neri, 1993). Avaliar qualidade de vida envolve a comparação entre as condições disponíveis e as desejáveis (Neri, 2001).

A bibliografia tem demonstrado o impacto da aposentadoria na vida dos trabalhadores. Para Bressan (2011, p.43),

a saída do mundo do trabalho na aposentadoria traz diversas implicações para os sujeitos e aponta para a responsabilidade social do governo e das organizações de trabalho, no sentido de apontar a preparação dos servidores para que esse desligamento não se torne experiência negativa para eles, visto que o trabalho e a aposentadoria podem apresentar sentidos e significados diferentes para os envolvidos.

Nesse cenário, é necessário refletir a respeito da importância de um programa efetivo de preparação para a aposentadoria que acompanhe o servidor durante sua carreira na instituição, para abrir outras perspectivas além do trabalho e, consequentemente, preparar essa pessoa para o desligamento.

\section{Programas de preparação para aposentadoria}

Os programas de preparação para aposentadoria (PPA) surgiram por volta de 1950, nos Estados Unidos, e, geralmente, disponibilizam informações específicas sobre as questões que os trabalhadores vivenciam no período da aposentadoria, incluindo os recursos socioculturais e serviços da comunidade disponíveis a esse segmento da sociedade. 
No âmbito internacional, a Organização Internacional do Trabalho (OIT, 1992), em documento elaborado por ocasião da "Oficina Internacional do Trabalho - A OIT e as pessoas de idade avançada", propôs que os países deveriam adotar medidas relativas à preparação para a aposentadoria, além de facilitar a continuidade do trabalho para as pessoas idosas.

A legislação brasileira, por meio da Lei n.8.842, de 4 de janeiro de 1994, que instituiu a Política Nacional do Idoso, determinou que os programas de preparação para a aposentadoria deveriam acontecer "com antecedência mínima de dois anos antes do afastamento" (Brasil, 1994). Mais tarde, em 2003, o Estatuto do Idoso (Lei n.10.741, de 1o de outubro de 2003), em seu art. 28, diz:

o Poder Público criará e estimulará programas de [...] preparação dos trabalhadores para a aposentadoria, com antecedência mínima de 1 (um) ano, por meio de estímulo a novos projetos sociais, conforme seus interesses, e de esclarecimento sobre os direitos sociais e de cidadania. (Brasil, 2003)

Os programas existentes visam tornar "menos traumática a transição da vida ativa para a de aposentado" (Rey et al., 1996, p.148), tendo como princípios e diretrizes, entre outros, a participação opcional, a observação do contexto cultural, a participação da família no programa e a definição de temas e atividades em conjunto com os trabalhadores. Os programas exitosos contam com "compromisso da empresa em tornar o trabalho efetivo, por meio do engajamento dos diversos níveis hierárquicos” (idem, p.149).

De acordo com Rey et al. (1996, p.148), por meio de programas de preparação para aposentadoria, o trabalhador está sendo mais esclarecido quanto a seus direitos e possibilidades de vida futura, afastando o receio de passar tão somente a "sobreviver", negando a si próprio maior possibilidade de vida. Observam, no entanto, que, enquanto "no Brasil os programas são postos em execução somente próximo ao momento da aposentadoria, ou seja, um ou dois anos antes de o trabalhador completar o tempo legal para deixar o ser- 
viço", "nos países desenvolvidos esses programas são implantados com antecedência de dez anos" (p.149).

Esse tema tem sido motivo de atenção de diferentes profissionais, ora se voltando para uma categoria ou empresa específica, ora envolvendo toda a comunidade (Moragas, 1997; Papaléo Netto, 1996; Costa, 2001).

Dal Rio (2002, p.65), ao desenvolver pesquisa sobre o "tempo do pós-trabalho", observou que este era "caracterizado pelos depoentes como uma nova etapa" dedicada, "em parte, às atividades comunitárias, voltadas para ajudar o próximo”. Para a autora, aparentemente, essa "decisão é tomada para atender a valores religiosos, a necessidades pessoais de crescimento e para dar continuidade ao trabalho interrompido, às vezes precocemente, com a aposentadoria. Há aqueles que denotam uma forma de retribuir o que receberam, passarem adiante o seu legado profissional ou mesmo exercerem a cidadania" (p.66).

Uma ação voluntária está ligada à solidariedade, que na natureza humana é a capacidade de agir em benefício do outro, mas, mesmo sem se dar conta, o voluntário espera usufruir algo em troca. Ser solidariamente ativo abre a possibilidade de continuar o processo de realização e aperfeiçoamento enquanto ser humano, preocupado consigo e com o próximo. Propicia, ao mesmo tempo, uma inserção na comunidade e no mundo, vencendo o individualismo e o isolamento, fatores muito presentes no pós-trabalho e na velhice. Evitá-los, também, deve ter sido uma das causas da busca de outra atividade, que compensasse, inclusive, a perda de prestígio decorrente da saída do mundo produtivo. (Dal Rio, 2002, p.67)

França (2012), baseando-se em diversos pesquisadores, ressalta que é mais comum o estresse na fase que antecede a aposentadoria e na imediatamente após o fato. A autora afirma que os aposentados podem, principalmente, viver um período de maior bem-estar após dois anos de transição, sendo importante investigar 
os aspectos que poderiam garantir o bem-estar nessa nova etapa de vida.

Segundo Butler (2002 apud França, 2012), são cinco os aspectos correlacionados ao bem-estar no envelhecimento:

O primeiro é financeiro, seguido dos relacionamentos sociais (amizade e sistema de apoio social); intimidade (relacionamento próximo e íntimo com pessoas que se preocupem umas com as outras); físico (dieta e exercício) e um senso de propósito. No senso de propósito estão inseridas a segunda carreira, o voluntariado, um projeto pessoal, uma atividade cultural e esportiva, um tipo de aprendizagem, ou outra atividade que ofereça um sentido para a vida. (França, 2012, p.40)

Zanelli et al. (2010, p.133) enfatizam que o objetivo maior do PPA é:

agir proativamente em fatores que se manifestam com maior intensidade nos momentos que antecedem a aposentadoria, de modo a reduzir ansiedades próprias a tal fase e servir de facilitador na elaboração de novos planos, como também na reelaboração de projetos de vida.

Embora a atenção aos servidores que estão próximos à aposentadoria seja da maior urgência, esse tema deve ser tratado ao longo da vida funcional, desde sua entrada na instituição, como parte integrante do plano de carreira do servidor.

No Brasil, essa proposta é um pouco mais recente, sendo implementada na década de 1970, através da iniciativa do Sesc no estado de São Paulo. Em seu início, o programa no Sesc era composto por dois módulos de atividades teórico-práticas e apontou melhoras, como o engajamento a novas atividades mesmo antes da aposentadoria. Netto e Netto (2008) resgatam informações da Associação Brasileira das Entidades Fechadas de Previdência Complementar (Abrapp, 2003; 2004) de que aproximadamente oitenta instituições 
do país chegaram a desenvolver algum tipo de trabalho com funcionários que se encontravam perto da aposentadoria. Os autores destacam que no início dos anos 1990 houve um processo de retração do programa de preparação para aposentadoria por conta da instabilidade econômica vigente no Brasil porque houve um incentivo às aposentadorias voluntárias e um firme propósito de enxugar o contingente de trabalhadores nas empresas e viabilizar essas ações, integrando um contexto de privatizações e consolidação do modelo neoliberal de Estado mínimo.

O processo de transição para o pós-trabalho pode beneficiar-se da implantação de PPA, visando destacar os aspectos positivos dessa nova fase da vida. Tais atividades podem ser consideradas verdadeiros antídotos contra depressão e outras insatisfações de um tempo ocioso, pois favorecem a incorporação de novas opções de identidade social e de reforço da autoestima.

Essas ações permitem ao empregado que está prestes a se aposentar fazer uma transição paulatina entre sua vida laboral e sua vida pós-aposentadoria. Incluem-se nessas ações o desenvolvimento de novas atividades ligadas a cultura, lazer, esportes, trabalhos manuais, filantropia, entre outros.

Para a adequada execução do PPA, é importante o desenvolvimento de ações multidisciplinares, incluindo educadores, assistentes sociais, profissionais de educação física, gerontólogos, psicólogos, fisioterapeutas, médicos, enfermeiros, entre outros.

\section{Referências bibliográficas}

\section{ASSOCIAÇÃO BRASILEIRA DAS ENTIDADES FECHADAS} DE PREVIDENNCIA COMPLEMENTAR (Abrapp). Complementar. Aposentadoria com qualidade, responsabilidade social da empresa. Fundos de Pensão, n.292, ano XXIII, p.41-4, mar. 2004.

. Os riscos da transição para aposentadoria. Fundos de Pensão, n.287, ano XXII, p.37-40, set. 2003. 
BITTENCOURT, B. M. et al. Para além do tempo de emprego: o sentido do trabalho no processo de aposentadoria. Revista Ciências da Administração, v.13, n.31, p.30-57, set./dez. 2011.

BRASIL. Lei n.10.741, de 1ㅇ de outubro de 2003, que cria o Estatuto do Idoso e dá outras providências, 2003.

Lei n. 8.842, de 4 de janeiro de 1994, que dispõe sobre a Política Nacional do Idoso, 1994.

BRESSAN, M. A. L. C. A significação do trabalho e da aposentadoria: o caso dos servidores da Universidade Federal de Viçosa. Viçosa, 2011. Dissertação (Mestrado em Economia Doméstica) - Universidade Federal de Viçosa.

CALDAS, C. Promoção de saúde na aposentadoria. In: FRANÇA, L.; STEPANSKY, D. (Orgs.). Propostas multidisciplinares para o bem-estar na aposentadoria. Rio de Janeiro: Quartet; Faperj, 2012.

COSTA, A. M. M. R. A Unesp aberta à própria terceira idade. SEMINÁRIO UNESP-UNATI, 3, Rio Claro (SP), 2001. Anais do...

DAL RIO, M. C. Trabalho voluntário como promoção da integração social do idoso. Terceira Idade, São Paulo: Sesc, n.13, v.24, p.5772, 2002.

ERBOLATO, R. M. P. L. Relações sociais na velhice. In: FREITAS et al. (Orgs.). Tratado de Geriatria e Gerontologia. Rio de Janeiro: Guanabara Koogan, 2002.

FRANÇA, L. Envelhecimento dos trabalhadores nas organizações: estamos preparados? In: ; STEPANSKY, D. (Orgs.). Propostas multidisciplinares para o bem-estar na aposentadoria. Rio de Janeiro: Quartet; Faperj, 2012.

FRANÇA, L. H. F. P.; VAUGHAN, G. Ganhos e perdas: atitudes dos executivos brasileiros e neozelandeses frente à aposentadoria. Psicologia em Estudo, Maringá, v.13, n.2, p.207-16, abr./jun. 2008.

MORAGAS, R. M. Gerontologia social: envelhecimento e qualidade de vida. São Paulo: Paulinas, 1997.

NERI, A. L. Palavras-chave em Gerontologia. Campinas: Alínea, 2001. Qualidade de vida no adulto maduro: interpretações teóricas e evidências de pesquisa. In: (Org.). Qualidade de vida e idade madura. Campinas: Papirus, 1993. 
NETTO, F. S.; NETTO, J. P. P. Programas de Preparação para a Aposentadoria - PPA: responsabilidade social das organizações. 2008. Disponível em: http://www.aedb.br/seget/arquivos/artigos 08/254_254_SeGET_-_PPA_e_RS_-_final.pdf .

NOVO, L. F.; FÔLHA, F. A. S. Importância da preparação à aposentadoria: a fala de servidores aposentados da UFPEL. COLOQUIO INTERNACIONAL SOBRE GESTIÓN UNIVERSITARIA EN AMÉRICA DEL SUR, 10, Mar Del Plata, 2010.

ORGANIZAÇÃO INTERNACIONAL DO TRABALHO (OIT). La OIT y las personas de edad avanzada: actividades y servicios que la Organización Internacional del Trabajo puede ofrecer para mejorar la situación de las personas de edad avanzada. Ginebra: Oficina Internacional Del Trabajo, 1992.

PAPALÉO NETTO, M. Gerontologia. São Paulo: Atheneu, 1996.

PONT, G. P. Tercera edad, actividad física y salud. Barcelona: Paidotribo, 1997.

REY, B. F. et al. A preparação para a aposentadoria e a implantação de programas nesta área. Revista Gerontologia, v.IV, 1996.

ROESLER, V. R. Posso me aposentar "de verdade". E agora? Contradições e ambivalências vividas no processo de aposentadoria de bancários. Florianópolis, 2012. Tese (Doutorado em Psicologia) Universidade Federal de Santa Catarina.

SARTORI, A. C.; ZILBERMAN, M. L. Revisando o conceito de síndrome do ninho vazio. Rev. Psiq. Clín., v.36, n.3, p.112-21, 2009.

VASQUES-MENEZES, I. Orientação para o trabalho em situação de aposentadoria. In: FRANÇA, L.; STEPANSKY, D. (Orgs.). Propostas multidisciplinares para o bem-estar na aposentadoria. Rio de Janeiro: Quartet; Faperj, 2012.

ZANELLI, J. C.; SILVA, N.; SOARES, D. H. P. Orientação para aposentadoria nas organizações de trabalho: construção de projetos para o pós-carreira. Porto Alegre: Artmed, 2010. 


\title{
3 \\ SaÚde, enVelHeCimento e APOSENTADORIA'
}

\author{
Jessica Rodrigues Pereira \\ Paulo Fernando Moraes \\ Úrsula Virgínia Pereira \\ José Luiz Riani Costa
}

O envelhecimento normal apresenta mudanças biológicas universais e de caráter não patológico que são inerentes ao processo, como alterações hormonais, osteomusculares, cutâneas, sensoriais etc. O envelhecimento normal também pode apresentar uma diminuição da velocidade dos processos mentais, sem representar perda das funções cognitivas. Felizmente, com a disseminação de informações e implementação de políticas públicas voltadas à promoção da saúde, há um expressivo número de pessoas experimentando o envelhecimento saudável e bem-sucedido (Neri, 2002). Chaimowicz (1997) adverte que o ritmo e a intensidade dessas alterações dependem de características individuais, como a herança genética, e de fatores ambientais, ocupacionais, sociais, culturais etc. aos quais o indivíduo esteve exposto ao longo da vida.

Mas, muitas vezes, o envelhecimento está associado a mudanças patológicas ou a doenças associadas à idade, em função da vulnerabilidade a fatores extrínsecos e intrínsecos. Em muitos casos, mesmo diagnosticados com uma ou mais doenças, como

1. Agradecimento a Larissa Riani Costa Tavares e Luiz Augusto Riani Costa pela colaboração na revisão do capítulo. 
hipertensão arterial, diabetes, artropatias etc., muitos idosos dizem sentir-se saudáveis, especialmente em função do controle de tais doenças e ausência de incapacidades. Apesar de a probabilidade de desenvolver certas doenças aumentar com a idade, envelhecer não é sinônimo de adoecer (Neri, 2002). No entanto, há uma parcela de pessoas que experimentam o envelhecimento associado a perdas físicas e cognitivas em um período relativamente curto (idem, 2002).

As doenças comumente associadas ao envelhecimento compreendem as cardiovasculares (doença aterosclerótica, hipertensão arterial etc.), as respiratórias (bronquite crônica, asma, enfisema e infecções respiratórias), as músculo-esqueléticas (artrose/osteoartrose/osteoartrite, dores lombares etc.), as neurológicas (doença de Parkinson, doença de Alzheimer, outras patologias neuropsiquiátricas), as metabólicas (diabetes, obesidade, osteoporose etc.) e as sensoriais (catarata, glaucoma, retinopatia diabética e presbiacusia) (Mazo et al., 2001).

Com relação às causas de morte na população idosa, predominam as doenças do aparelho circulatório, seguidas das neoplasias e doenças do aparelho respiratório. No primeiro grupo, destacam-se a doença cerebrovascular e a cardiopatia isquêmica. Entre as neoplasias, as mais frequentes no sexo masculino são as de pulmão, estômago e de próstata, sendo que, no sexo feminino, predominam as neoplasias de mama, do estômago e do colo uterino. Entre as doenças do aparelho respiratório, destacam-se a doença pulmonar obstrutiva crônica (DPOC) e a pneumonia (Cabrera; Andrade; Wanjngarten, 2007).

Lima e Costa et al. (2000) realizaram estudo sobre a saúde da população idosa, com base em bancos de dados nacionais de mortalidade e de internações hospitalares, e, no que se refere às causas de morte, chegaram a dados semelhantes aos descritos anteriormente. Com relação às internações hospitalares, o estudo apontou que as principais causas entre os idosos foram "as doenças do aparelho circulatório e as doenças do aparelho respiratório, correspondendo de forma consistente a cerca da metade das internações hospitalares" (p.38). 
Em relação à saúde bucal, as mudanças na demografia têm exigido maior atenção para o diagnóstico precoce do câncer bucal e da doença periodontal, entre outras patologias, além das tradicionais ações de restauração e de fornecimento de próteses (Costa, J., 2001). Mais informações sobre a saúde bucal e sua relação com os distúrbios de alimentação e nutrição são apresentadas no Capítulo 7 .

Birman (1995, p.39) chama a atenção para o fato de o idoso ser, frequentemente, "levado a um processo de "desnarcisação", algumas vezes associado à ideia de que não há "qualquer possibilidade de horizonte de futuro". Nesse sentido, o autor propõe uma releitura da psicopatologia da terceira idade que permita estudar os "efeitos simbólicos que podem ser produzidos na velhice quando impõe para o sujeito a inexistência de um projeto futuro".

$\mathrm{O}$ autor afirma que existem três formas de o idoso "lidar e manejar o impasse de sua condição": a depressão, quando a pessoa "revisita o passado sem ter qualquer possibilidade de retificá-lo"; a paranoia, quando faz "acusações dirigidas [...] aos outros, principalmente para as pessoas mais próximas, dos fracassos que a existência lhe produziu", e a mania, caracterizada por "modalidades de travestismo juvenil [...] que pretendem exibir uma juventude que não é reconhecida pelos outros" (Birman, 1995, p.40-1).

A questão da saúde mental, embora não se constitua em uma causa de morte importante, representa um grande sofrimento para a população idosa. Além dos quadros demenciais, com destaque para a doença de Alzheimer, que geralmente ocorre após os 65 anos de idade, e a demência vascular, associada a hipertensão arterial e diabetes, deve-se registrar que "depressão, ansiedade e transtornos psicóticos, têm também alta prevalência. Os índices de suicídio atingem seus picos, especialmente entre homens idosos. $\mathrm{O}$ uso indevido de substância, inclusive álcool e medicamentos, também tem alta prevalência, embora seja quase sempre ignorado" (OPAS/ OMS, 2001, p.104).

A prevalência da Doença de Alzheimer vem apresentando um rápido crescimento, em todo o mundo, com maior intensidade nos países subdesenvolvidos. Além do tratamento farmacológico, 
que vem apresentando novidades promissoras, destaca-se o tratamento não farmacológico, por meio de exercícios físicos e treinamento cognitivo. Em relação a essa modalidade terapêutica, a Unesp/câmpus de Rio Claro desenvolve, desde 2006, um Projeto de Extensão cuja experiência foi relatada no livro Vivências sobre a Doença de Alzheimer na Unesp: diálogo entre ensino, pesquisa e extensão (Costa; Andrade; Stein, 2014).

O documento "Política Nacional de Redução da Morbimortalidade por Acidentes e Violências" (Ministério da Saúde, 2002, p.7) afirma que "os acidentes e as violências no Brasil configuram um problema de saúde pública de grande magnitude e transcendência, que tem provocado forte impacto na morbidade e na mortalidade da população". Os acidentes e as violências aparecem reunidos na Classificação Internacional de Doenças (CID-10), sob a denominação "causas externas", englobando todos os tipos de lesões, como ferimentos, fraturas, queimaduras, intoxicações, afogamentos, entre outros. Embora tenham maior frequência em outras faixas etárias, os acidentes e as violências também têm chamado a atenção entre os idosos.

Segundo o Ministério da Saúde (2002, p.22), "a violência contra os idosos existe e manifesta-se sob diferentes formas: abuso físico, psicológico, sexual, abandono e negligência”. Some-se a essas formas de violência, o abuso financeiro e a autonegligência. A negligência "é uma forma de violência presente tanto em nível doméstico quanto institucional, levando muitas vezes ao comprometimento físico, emocional e social, gerando, em decorrência, aumento dos índices de morbidade e mortalidade". A expressão "maus-tratos contra os idosos" é utilizada para designar "ações únicas ou repetidas que causam sofrimento ou angústia”, incluindo também a omissão em situações "em que haja expectativa de confiança".

Debert (1999, p.83) cita uma pesquisa de Baptista e Juvêncio, realizada "nas Delegacias de Polícia de Proteção aos Idosos, em São Paulo", que mostrou "que a violência nelas denunciada é cometida, sobretudo, por parentes que residem na mesma unidade doméstica que os idosos". 
O documento alerta para o fato de os idosos mais vulneráveis serem os que apresentam dependência física ou mental, "sobretudo quando apresentam déficits cognitivos, alterações do sono, incontinência e dificuldades de locomoção, necessitando, assim, de cuidados intensivos em suas atividades da vida diária”. Com relação ao agressor, a situação é mais complicada quando este é dependente econômico do idoso e/ou "quando o cuidador consome abusivamente álcool ou drogas, apresenta problemas de saúde mental ou se encontra em estado de elevado estresse na vida cotidiana" (Ministério da Saúde, 2002, p.22).

Além disso, geralmente as violências não são corretamente diagnosticadas em função de uma série de fatores, incluindo "falta de informação e preparo dos profissionais de saúde para enfrentar esses eventos, descrédito para com os relatos dos idosos por parte dos familiares e destes profissionais, além de constrangimento do idoso em acusar pessoas de sua família”.

Com relação aos acidentes, "as quedas, causadas pela instabilidade visual e postural, comuns à idade, representam os principais acidentes entre os idosos. Um terço desse grupo que vive em casa e a metade dos que vivem em instituições sofrem pelo menos uma queda anual. A fratura de colo de fêmur é a principal causa de hospitalização por queda”. Segundo o documento, "cerca de metade dos idosos que sofrem esse tipo de fratura falece dentro de um ano; a metade dos que sobrevivem fica totalmente dependente do cuidado de outras pessoas [...] por um longo período" (ibidem, p.22).

Matsudo e Matsudo (2000, p.12) afirmam que as quedas "que geralmente acontecem por anormalidades do equilíbrio, fraqueza muscular, desordens visuais, anormalidades do passo, doença cardiovascular, alteração cognitiva e consumo de alguns medicamentos" podem ser prevenidas, ao menos em parte, através de diferentes exercícios físicos adaptados a diferentes patologias, como doença de Alzheimer e doença de Parkinson. A Unesp/ câmpus de Rio Claro desenvolve programas de exercícios físicos voltados a essas importantes doenças que acometem especialmente a população idosa, conforme descrito por Coelho et al. (2013). 
O Ministério da Saúde (2002, p.23) chama a atenção para a relação entre os acidentes sofridos pelos idosos nas áreas urbanas com os riscos presentes no ambiente doméstico e em outros de "âmbito público (barreiras arquitetônicas, sistemas de transporte coletivos inadequados, criminalidade)".

\section{O processo de envelhecimento e seus desdobramentos no âmbito da saúde}

Não há uma exata definição de envelhecimento bem-sucedido, principalmente devido à heterogeneidade do processo de envelhecimento (Teixeira; Neri, 2008). Envelhecer bem é uma questão de valores particulares, porém alguns elementos podem ser levados em consideração quando se trata de envelhecimento bem-sucedido. São eles: a) alta capacidade funcional cognitiva e motora; b) baixa probabilidade para doenças e incapacidades relacionadas ao envelhecimento; e c) engajamento ativo com a vida (Rowe; Kahn, 1997).

Uma das características marcantes no processo de envelhecimento é o declínio da capacidade funcional, que inclui flexibilidade, força, agilidade, coordenação motora, equilíbrio e resistência aeróbia. Esses componentes constituem variáveis afetadas diretamente por alterações neurológicas e musculares (Gobbi; Villar; Zago, 2005).

A Política Nacional de Saúde da Pessoa Idosa (Brasil, 2006) fundamenta a ação do setor saúde na atenção integral à população idosa, em conformidade com a Lei Orgânica da Saúde, com a Política Nacional do Idoso e com o Estatuto do Idoso. Entre seus objetivos estão a promoção do envelhecimento saudável, a manutenção e a melhoria da capacidade funcional dos idosos, a prevenção de doenças e a recuperação da saúde. Inclui, ainda, a capacitação de recursos humanos especializados.

Outro aspecto a ser considerado é a funcionalidade cognitiva do idoso, que deve ser preservada, pois está relacionada à sua saúde e qualidade de vida (Yassuda et al., 2006). 
Conceituar saúde não é uma tarefa fácil, pois não representa a mesma coisa para todas as pessoas, principalmente quando se consideram os âmbitos social, econômico, cultural e político, fazendo que a conceituação dependa da classe social, época, local etc. (Scliar, 2007).

Um dos primeiros conceitos de saúde, elaborado pela Organização Mundial da Saúde (OMS), em 1946, estabelece que "saúde é o estado de completo bem-estar físico, mental e social, e não meramente a ausência de doença ou incapacidade”. Assim, entendeu-se que a saúde seria composta por três dimensões básicas: bem-estar físico, mental e social (Almeida Filho, 2000; Patrick; Erikson, 1993; Robine, 1999).

Outro conceito de saúde que merece destaque é o contido no art. 196 da Constituição Federal, que indica que "a saúde é direito de todos e dever do estado, garantido mediante políticas sociais e econômicas que visem a redução do risco de doenças e outros agravos e ao acesso universal e igualitário às ações e serviços para sua promoção, proteção e recuperação". Este conceito foi complementado pela Lei n. 8.080/90 que, em seu art. 3o diz que "os níveis de saúde expressam a organização social e econômica do país, tendo a saúde como determinantes e condicionantes, entre outros, a alimentação, a moradia, o saneamento básico, o meio ambiente, o trabalho, a renda, a educação, a atividade física, o transporte, o lazer e o acesso aos bens e serviços essenciais (Redação dada pela Lei n.12.864/2013).

O envelhecimento saudável leva em consideração que alguns processos do envelhecimento são, até certo ponto, modificáveis, o que faz que seja necessária uma abordagem multidimensional e individual relacionada a aspectos biológicos, físicos e sociais (Gardner, 2006).

Levando em consideração a perspectiva dos próprios idosos, há uma grande variabilidade de definições, mas, em geral, um envelhecimento saudável inclui as dimensões físicas, sociais, econômicas, entre outras (Cupertino; Rosa; Ribeiro, 2007). 
Por outro lado, quando se leva em consideração a evolução de métodos diagnósticos e terapêuticos de algumas doenças, entre elas, as crônico-degenerativas, observa-se que há um aumento em idosos com enfermidades múltiplas, e para esses idosos é necessário que se encontrem opções para manutenção de sua autonomia e independência, e não somente o aumento da longevidade (Jacob Filho, 2006).

É importante destacar que condutas baseadas no risco relativo podem levar a concentrar as ações nos comportamentos de médicos e de pacientes, em detrimento de ações que atuem sobre as causas.

\section{O envelhecer com saúde}

A preocupação com o envelhecer com saúde surge principalmente devido ao crescimento significativo da população idosa, ligado ao aumento de expectativa de vida proporcionado pela evolução da ciência, especialmente em relação à prevenção, ao diagnóstico e ao tratamento de doenças (Garuffi et al., 2011; IBGE, 2010).

Esse crescimento reflete-se em uma maior preocupação com a qualidade de vida. A prática regular de atividades físicas é um importante componente para se envelhecer com saúde; porém, com o passar dos anos, o idoso tende a praticar menos atividades físicas programadas regularmente, sendo esse o principal motivo da diminuição da capacidade funcional, além da probabilidade de aumento de sintomas depressivos, estresse e algumas doenças crônicas (Sereniki; Vital, 2008; Vital et al., 2012).

Em relação à saúde da população idosa, a OMS destaca alguns desafios para a saúde pública: Como manter a independência e a vida ativa nessa fase da vida? Como manter ou melhorar a qualidade de vida para essa população? E como fazer que políticas de prevenção e promoção de saúde voltadas aos idosos ganhem força? (Costa; Veras, 2003). 
Para proporcionar uma melhor qualidade de vida para o idoso em aspectos cognitivos, motores e afetivos, o exercício físico sempre foi considerado um importante fator; juntamente com outros componentes de um estilo de vida ativo, proporciona uma melhor qualidade de vida, com melhoras funcionais e na mobilidade do idoso (Garuffi et al., 2011).

Para a promoção e a manutenção de um envelhecimento saudável, são recomendados quatro componentes fundamentais da atividade física, para benefícios na saúde: exercícios aeróbios, fortalecimento muscular, exercícios de flexibilidade e equilíbrio (ACSM, 2011).

A prática regular de exercícios físicos promove o controle e a diminuição da gordura corporal, aumentando a massa muscular e a densidade óssea; melhora na capacidade de flexibilidade; fortalecimento de tecido conectivo; aumento do volume de sangue e ventilação pulmonar, diminuição da frequência cardíaca em repouso e ativo, controle da pressão arterial; melhora nos níveis de HDL e diminuição no LDL, triglicérides, colesterol total, níveis de glicose; diminuição dos riscos de doenças cardiovasculares, osteoporose, obesidade, câncer de cólon e de útero (Matsudo, 2009).

As alterações não são apenas metabólicas e antropométricas. Há também consideráveis alterações psicossociais, como melhora no autoconceito, autoestima, imagem corporal, humor, tensão muscular, insônia. Pode-se observar, ainda, diminuição de riscos de depressão, estresse e ansiedade, podendo ocorrer diminuição do consumo de medicamentos e incrementos na socialização. Com a prática de exercícios físicos também pode haver prevenção ou retardo do declínio das funções cognitivas (Matsudo, 2009).

\section{A aposentadoria no processo de envelhecimento}

Aposentadoria e envelhecimento são dois processos que costumam estar relacionados, pois os sujeitos se aposentam ao envelhecer. É possível que, para muitos, aposentar-se signifique ter 
envelhecido, pois a chegada da aposentadoria concretiza o momento em que se percebe que o tempo passou e é necessário finalizar o ciclo de trabalho.

Uma das características do envelhecimento é a redução da capacidade de manter o equilíbrio homeostático quando submetido a condições de sobrecarga funcional, acarretando maior vulnerabilidade e maior incidência de processos patológicos, que podem levar à morte (Papaléo Netto, 1996). O organismo humano, desde a sua concepção até a morte, passa por diversas fases: desenvolvimento, puberdade, maturidade ou estabilização e envelhecimento. Ainda segundo Papaléo Netto (1996), é fácil reconhecer algumas manifestações do envelhecimento, além de cabelos brancos e rugas, como o aumento de ligações cruzadas de colágeno e a redução das capacidades máximas de trabalho e resistência.

Segundo documento do Ministério da Saúde,

A Organização Pan-Americana da Saúde (Opas) define envelhecimento como "um processo sequencial, individual, acumulativo, irreversível, universal, não patológico, de deterioração de um organismo maduro, próprio a todos os membros de uma espécie, de maneira que o tempo o torne menos capaz de fazer frente ao estresse do meio ambiente e, portanto, aumente sua possibilidade de morte". (Brasil, 2006)

O processo de envelhecimento deve ser compreendido em sua totalidade, incluindo os aspectos orgânico e funcional, bem como as implicações na vida social. Assim, conforme Brêtas (2003), é preciso considerar que o envelhecimento é um processo complexo, pluridimensional, revestido por perdas e aquisições individuais e coletivas, fenômenos inseparáveis e simultâneos. Por mais que o ato de envelhecer seja individual, o ser humano vive na esfera coletiva e, como tal, sofre as influências da sociedade. A vida é social e culturalmente construída.

Segundo Emiliano (2005), o ato de aposentar-se pode mudar o comportamento dos sujeitos diante das relações sociais, alterando 
as percepções estruturadas no decorrer da vida, principalmente por estar atrelado à dificuldade de desvinculação das relações do ambiente de trabalho. Quando o indivíduo perde essa comunicação com o ambiente de trabalho, com a chegada da aposentadoria, seu status na sociedade também tende a diminuir e a família tem um papel importante para o equilíbrio pessoal do indivíduo e sua adaptação social (Santos, 1990).

O afastamento do trabalho provocado pela aposentadoria talvez seja, segundo França (1999), a perda mais importante da vida social das pessoas, pois pode resultar em outras perdas futuras, que tendem a afetar a sua estrutura psicológica. As consequências negativas percebidas com a ocorrência da aposentadoria são a diminuição da renda familiar, a ansiedade ante o vazio deixado pelo trabalho e o aumento na frequência a consultas médicas (França, 1999). Os sujeitos, ao envelhecer, nem sempre encontram papéis que os gratifiquem e possibilitem pertencimento social (Wolff, 2009) como havia no período em que trabalhavam.

Assim, a aposentadoria envolve perdas de vínculos, status ocupacional e, por vezes, renda. Conforme resultado da pesquisa "Idosos no Brasil", na velhice ocorre em geral uma queda de renda (Neri, 2007).

Por outro lado, há oportunidade para uma vida religiosa mais atuante, a tentativa de realizar sonhos, como viajar com amigos, frequentar grupos de convivência, realizar passeios, participar de jogos voltados ao público idoso etc.

A busca de atividades físicas ou de lazer no maior período livre de que o aposentado passa a dispor pode ser uma ocupação interessante do tempo e possibilitar uma melhor preparação para essa nova etapa da vida. Cabe ressaltar que seus benefícios podem minimizar as doenças relacionadas ao trabalho e também prevenir problemas de saúde e fatores de risco, como estresse e ansiedade (Santos, 1990).

Há estudos que indicam que a aposentadoria é um processo de transição que interfere no aumento do engajamento em atividades físicas regulares (Barnett; Van Sluijs; Ogilvie, 2012) e que a moti- 
vação para a prática de atividade física se baseia na crença de que o aposentado supera a barreira "falta de tempo", frequentemente referida por pessoas inseridas no mercado de trabalho (Caudroit; Stephan; Scanff, 2011).

Por outro lado, outro estudo realizado com 785 participantes aposentados da European Prospective Investigation into Cancer (Epic - Norfolk), no período de 2002 a 2006, mostra que houve declínio na atividade física geral com a aposentadoria. Em muitos casos, a aposentadoria foi associada ao aumento médio no tempo de visualização de TV, tendo o maior acréscimo ocorrido entre os trabalhadores manuais (Barnett et al., 2014).

Uma revisão sistemática, abrangendo os anos de 1980 a 2010, investigou a transição para a aposentadoria e as mudanças na atividade física, bem como sua relação com a classe socioeconômica e com os preditores dessas mudanças (Barnett; Van Sluijs; Ogilvie, 2012). Os autores utilizaram dezenove bases de dados e chegaram à seleção de igual número de estudos. Todos os estudos usaram a ocupação profissional para definir o nível de atividade física e dois estudos utilizaram os bens familiares como fator adicional. Três estudos relatam associação positiva entre atividade física e nível elevado de grau ocupacional do aposentado. Um estudo não encontrou declínio em trabalhadores sedentários, mas um significante declínio em trabalhadores manuais. O principal resultado foi o aumento da atividade física de lazer após a aposentadoria no grupo com maior nível socioeconômico (idem, 2012).

Em outra revisão sistemática realizada pelo mesmo grupo, identificou-se a tendência ao engajamento em atividades físicas recreacionais, que propiciam, além dos benefícios para a saúde, oportunidades para socialização, mudanças pessoais e ingresso em uma nova rotina de amizades e convívio social. Porém, essa adesão a atividades recreacionais é menor entre os aposentados pertencentes a grupos ocupacionais mais baixos, sendo necessários estudos futuros para compreender a questão (Barnett; Guell; Ogilvie, 2012). 
A aposentadoria também tem sido associada a estilos saudáveis de vida, como parar de fumar, diminuição no consumo de álcool e aumento no tempo de atividade física de lazer (Sjösten et al., 2012).

Torna-se um dever dos profissionais que trabalham com idosos o apoio ao envelhecimento ativo na aposentadoria, minimizando perdas e agravos à saúde. Para a Organização Mundial da Saúde (OMS, 2005), o envelhecimento ativo é um processo no qual ocorre a "otimização das oportunidades de saúde, participação e segurança, com o objetivo de melhorar a qualidade de vida à medida que as pessoas ficam mais velhas". Essa definição refere-se tanto a indivíduos quanto a grupos populacionais, permitindo que as pessoas percebam o seu potencial para a busca de oportunidades para a conquista do bem-estar considerando sua participação na sociedade de acordo com suas necessidades, desejos e capacidades, ao mesmo tempo que são garantidos segurança e cuidados adequados para seu alcance (OMS, 2005).

Bobbio (1997), após escrever sobre diversos temas relativos à vida humana, escreveu sobre o envelhecimento, quando ele mesmo experimentou os efeitos do avançar da idade. Para ele, o mundo dos velhos é o mundo da memória, do passado, sendo que muitos não dedicam seus pensamentos "àquilo que está por vir". Esta pode ser a tendência para uma parcela das pessoas que se aposentam, mas é possível modificar isto por meio de uma série de iniciativas que envolvem o próprio indivíduo, a família, a sociedade e o Estado, incluindo diversos elementos que serão vistos nos capítulos seguintes.

\section{Referências bibliográficas}

AMERICAN COLLEGE OF SPORTS MEDICINE (ACSM). GARBER C. E. et al. Quantity and Quality of Exercise for Developing and Maintaining Cardiorespiratory, Musculoskeletal, and Neuromotor Fitness in Apparently Healthy Adults: Guidance for Prescribing Exercise. Medicine $\mathcal{E}$ Science in Sports $\mathcal{E}$ Exercise, 
Hagerstown, Position Stand from the American College of Sports Medicine and the American Heart Association 2010, v.43, n.7, p.1.334-59, 2011.

ALMEIDA FILHO, N. O conceito de saúde: ponto-cego da epidemiologia? Rev. Bras. Epidemiol., v.3, n.1-3, 2000.

BARBOSA, R. B. O Projeto Carmen no Brasil. Promoção da Saúde, Ministério da Saúde, ano 1, n.2, nov./dez. 1999.

BARNETT, I. et al. Changes in Household, Transport and Recreational Physical Activity and Television Viewing Time Across the Transition to Retirement: Longitudinal Evidence from the Epic Norfolk Cohort. J. Epidemiol. Community Health, v.68, n.8, p.74753, 2014.

; GUELL, C.; OGILVIE, D. The Experience of Physical Activity and the Transition to Retirement: a Systematic Review and Integrative Synthesis of Qualitative and Quantitative Evidence. International Journal of Behavioral Nutrition and Physical Activity, v.9, n.97, p.1-10, 2012.

; VAN SLUIJS, E.; OGILVIE, D. Physical Activity and Transitioning to Retirement: a Systematic Review. American Journal of Preventive Medicine. Phyladelphia, v.43, n.3, p.329-36, 2012.

BIRMAN, J. Futuro de todos nós: temporalidade, memória e terceira idade na psicanálise. In: VERAS, R. (Org.). Terceira idade: um envelhecimento digno para o cidadão do futuro. Rio de Janeiro: Relume-Dumará, 1995. p.29-48.

BOBBIO, N. O tempo da memória: de senectude e outros escritos autobiográficos. Rio de Janeiro: Campus, 1997.

BRASIL. Cadernos de Atenção Básica - Envelhecimento e saúde da pessoa idosa. 192p. Ministério da Saúde. Secretaria de Atenção à Saúde. Departamento de Atenção Básica. Brasília: Ministério da Saúde, 2006.

. Presidência da República, Casa Civil. Lei n.10.741, de 1ํo de outubro de 2003. Estatuto do Idoso. Brasília, DF, 2003.

Plano de Ação Governamental Integrado para o Desenvolvimento da Política Nacional do Idoso. Brasília, DF: Ministério da Previdência e Assistência Social; Secretaria de Assistência Social, 1996. 
BRÊTAS, A. C. P. Cuidadores de idosos e o Sistema Único de Saúde. Revista Brasileira de Enfermagem, Brasília, v.56, n.3, p.298-301, maio./jun., 2003.

CABRERA, M. A. S.; ANDRADE, S. M.; WANJNGARTEN, M. Causas de mortalidade em idosos: estudo de seguimento de nove anos. Geriatria E Gerontologia, 1(1), p.14-20, 2007.

CAUDROIT, J.; STEPHAN, Y.; SCANFF, C. L. Social Cognitive Determinants of Physical Activity Among Retired Older Individuals: an Application of the Health Action Process Approach. British Journal of Health Psychology, Oxford, n.16, p.404-17, 2011.

CHAIMOWICZ, F. A saúde dos idosos brasileiros às vésperas do século XXI: problemas, projeções e alternativas. Revista de Saúde Pública, São Paulo, v.31, n.2, p.180-200, 1997.

COELHO, F. G. M. et al. (Orgs.). Exercício físico no envelhecimento saudável e patológico: da teoria à prática. 1.ed. Curitiba: CRV, 2013.

COSTA, J. L. R.; ANDRADE, L. P.; STEIN, A. M. (Orgs.). Vivências sobre a Doença de Alzheimer na Unesp: diálogo entre ensino, pesquisa e extensão. 1.ed. São Paulo: Cultura Acadêmica, 2014.

COSTA, J. F. R. Saúde bucal na terceira idade. In: Livro de resumos do III Seminário Unesp-Unati. Rio Claro, 2001. p.49.

COSTA, M. F. L.; VERAS, R. Saúde pública e envelhecimento. Cad. Saúde Pública, Rio de Janeiro, 19(3), p.700-1, maio/jun., 2003.

Cupertino, A. P. F. B.; ROSA, F. H. M.; RIBEIRO, P. C. C. Definição de envelhecimento saudável na perspectiva de indivíduos idosos. Psicologia: Reflexão e Crítica, 20(1), p.81-6, 2007.

DEBERT, G. G. A reinvenção da velhice: socialização e processos de reprivatização do envelhecimento. São Paulo: Edusp, 1999.

EMILIANO, N. Aposentadoria, o idoso e a família. 2005. Disponível em: http://www.portaldafamilia.org/artigos/artigo368.shtml. Acesso em: 20 mar. 2015.

FRANÇA, L. Preparação para a aposentadoria: desafios a enfrentar. In: VERAS, R. (Org.). Terceira idade: alternativas para uma sociedade em transição. Rio de Janeiro: Relume Dumará; Unati, 1999.

GARDNER, P. J. Envelhecimento saudável: uma revisão das pesquisas em língua inglesa. Movimento, Porto Alegre, v.12, n.2, p.69-92, maio/ago. 2006. 
GARUFFI, M. et al. Atividade física para promoção da saúde de idosos com doença de Alzheimer e seus cuidadores. Revista Brasileira de Atividade Física E Saúde, v.16, n.1, p.80-3, 2011.

GOBBI, S.; VILLAR, R.; ZAGO, A. S. Bases teórico-práticas do condicionamento físico. Rio de Janeiro: Guanabara Koogan, 2005.

HEIMANN, L. et al. O município e a saúde. São Paulo: Hucitec, 1992. INSTITUTO BRASILEIRO DE GEOGRAFIA E ESTATÍSTICA (IBGE). Censo Demográfico 2010. Disponível em: http://www. censo2010.ibge.gov.br.

JACOB FILHO, J. Atividade física e envelhecimento saudável. Rev. Bras. Educ. Fís. Esp., São Paulo, v.20, supl. n.5, p.73-7, set. 2006.

LIMA E COSTA, M. F. F. et al. Diagnóstico da situação de saúde da população idosa brasileira: um estudo da mortalidade e das internações hospitalares públicas. Informe Epidemiológico do SUS, v.9, n.1, p.23-41, 2000.

MATSUDO, S. M. M. Envelhecimento, atividade física e saúde. BIS - Boletim do Instituto de Saúde, n.47, p.76-9, 2009.

MATSUDO, V. K. R.; MATSUDO, S. M. M. Evidências da importância da atividade física nas doenças cardiovasculares e na saúde. Revista Diagnóstico e Tratamento, v.5, n.2, p.10-7, 2000.

MAZO, G. Z.; LOPES, M. A.; BENEDETTI, T. B. Atividade física e o idoso: concepção gerontológica. Porto Alegre: Sulina, 2001.

MINISTÉRIO DA SAÚDE. Política Nacional de Redução da Morbimortalidade por Acidentes e Violências. Brasília, 2002.

NERI, A. L. Idosos no Brasil: vivências e desafios e expectativas na terceira idade. São Paulo: Fundação Perseu Abramo, Edições Sesc-SP, 2007. 288p.

. Envelhecer bem no trabalho: possibilidades individuais, organizacionais e sociais. A Terceira Idade, São Paulo, v.13, n.24, p.727, abr. 2002.

NOVO, L. F.; FÔLHA, A. F. S. Importância da preparação à aposentadoria: a fala dos servidores aposentados da UFPEL. COLOQUIO INTERNACIONAL SOBRE GESTIÓN UNIVERSITÁRIA EN AMÉRICA DEL SUR, 10, Mar Del Plata, 2010. Anais do..., p.1-14. 
ORGANIZAÇÃO MUNDIAL DA SAÚDE (OMS). Envelhecimento ativo: uma política de saúde. World Health Organization. 60p. Brasília: Organização Pan-Americana da Saúde, 2005.

ORGANIZAÇÃO PAN-AMERICANA DA SAÚDE (OPAS)/ ORGANIZAÇÃO MUNDIAL DA SAÚDE (OMS). Relatório sobre a saúde no mundo: 2001. Saúde Mental: Nova Concepção, Nova Esperança, 2001.

PAPALÉO NETTO, M. Gerontologia. São Paulo: Atheneu, 1996.

PATRICK, D.; ERIKSON, P. Health Status and Health Policy: Quality of Life in Health Care. New York: Oxford University Press, 1993.

ROBINE, J. M. Measurement of States of Health in Populations: Dimensions and Levels. In: SAYERS, B. Health Assessment: Complexity, Trends and Opportunities. Geneva: WHO Global Advisory Committee for Health Research, 1999. (Appendix III).

ROWE, J.; KAHN, R. Successful Aging. The Gerontologist, n.37(4), p.433-40, 1997.

SANTOS, M. de F. de S. Aposentadoria: aspectos psicológicos. São Paulo: EPU, 1990.

SCLIAR, M. História do conceito de saúde. Physis: Rev. Saúde Coletiva, Rio de Janeiro, n.17(1), p.29-41, 2007.

SERENIKI, A.; VITAL, M. A. B. F. A doença de Alzheimer: aspectos fisiopatológicos e farmacológicos. Rev. Psiquiatr., Rio Grande do Sul, Porto Alegre, v.30, n.1, supl., 2008.

SJÖSTEN, N. et al. Change in Physical Activity and Weight in Relation to Retirement: the French GAZEL Cohort Study. BMJ Open, Londres, v.2, n.(e000522), p.1-11, 2012.

TEIXEIRA, I. N. D. O.; NERI, A. L. Envelhecimento bem-sucedido: uma meta no curso da vida. Psicol., USP, São Paulo, v.19, n.1, mar. 2008.

VITAL, T. M. et al. Depressive Symptoms and Level of Physical Activity in Patients with Alzheimer's Disease. Geriatrics and Gerontology International, Tokyo, v.12, n.4, p.637-42, 2012.

WOLFF, S. H. Vivendo e envelhecendo: recortes de práticas sociais dos núcleos de vida saudável. São Leopoldo: Editora Unisinos, 2009. 
62 JOSÉ L. RIANI COSTA • AMARILIS M. M. R. COSTA • GILSON FUZARO JUNIOR

WORLD HEALTH ORGANIZATION (OMS). Envelhecimento ativo: uma política de saúde. 60p. World Health Organization, Brasília: Organização Pan-Americana da Saúde, 2005.

YASSUDA, M. S. et al. Treino de memória no idoso saudável: benefícios e mecanismos. Psicol. Reflex. Crit., Porto Alegre, v.19, n.3, 2006. 


\title{
4 \\ ASPECTOS PSICOSSOCIAIS DA APOSENTADORIA
}

\author{
Carla Andrezza Andreatto \\ Amarilis Maria Muscari Riani Costa \\ Lais Scarpari \\ Ruth Gelehrter Costa Lopes
}

A Organização Mundial da Saúde (OMS) destaca que, embora a taxa de aposentados tenha aumentado por consequência do aumento da expectativa de vida, a taxa de aposentados ativos tende a diminuir gradativamente ao longo dos anos (OMS, 2005).

Do ponto de vista psicossocial, é necessário que sejam analisadas as atitudes dos trabalhadores diante de suas perdas e de seus ganhos, bem como os fatores individuais, sociais, familiares e econômicos da pessoa no processo da transição para a aposentadoria, de modo que o enfrentamento das perdas contemple planejamento e intervenções (Andreatto et al., 2013; França, 2004). Essa transição pode incluir diferentes tipos de trabalho, voluntário ou remunerado com carga horária reduzida, pois se acredita que o trabalho esteja inteiramente relacionado à identidade do indivíduo (França; Vaughan, 2008).

Para muitos, essa transição pode desencadear ansiedade, podendo estar associada, ao menos em parte, à falta de planejamento e suporte diante dessa nova fase da vida. Assim, faz-se necessária a implementação de PPA nas organizações, bem como propostas de planejamento de vida futura para esses indivíduos (Bossé; Aldwin; Levenson, 1991). Esses programas devem oferecer um espaço para 
a discussão dos aspectos positivos, tais como benefícios da prática de atividade física e da adoção de estilo de vida que promova a saúde, a prevenção de problemas físicos ou emocionais e a discussão de como a aposentadoria pode afetar o cônjuge ao longo do tempo, bem como a estruturação da vida após a aposentadoria, a fim de torná-la aprazível e significativa (Monteiro, 2001; Andreatto et al., 2013).

O fator tempo é usado pelos aposentados considerando dois padrões de vida comuns após a aposentadoria: o estilo de vida focado na família e o de investimento equilibrado. O primeiro estilo consiste de atividades acessíveis e com baixo custo, girando em torno da família e do lar, como assistir televisão, receber visitas de familiares e de amigos, conversar, ir a restaurantes, jogar cartas e outros entretenimentos. O segundo estilo normalmente é visto em indivíduos com nível de instrução mais elevado, que dividem seu tempo entre os eixos familiar, trabalho e lazer (Papalia; Olds, 2000). É importante destacar que esses fatores podem sofrer mudanças com a idade. No estudo de Kelly, Steinkamp e Kelly (1986), os aposentados mais jovens que estavam mais satisfeitos com sua qualidade de vida eram os que viajavam e participavam de eventos culturais regularmente, porém, após os 75 anos, as atividades familiares e domésticas traziam mais satisfação.

Diversos indivíduos que costumavam pintar nos fins de semana ou cuidar do jardim se esforçam para tornar essas atividades um hobby ou ofício, tornando-se essencial à sua vida após a aposentadoria (Mannell, 1993). Esse estilo de vida é chamado de lazer sério, dominado por atividades que exigem habilidade, atenção e comprometimento, sendo que os aposentados que o adotam tendem a ter plena satisfação na função (Kelly, 1994).

Os afro-americanos, após a aposentadoria, tendem a ser mais inclinados a atividades produtivas ou úteis, como costura, jardinagem e pescaria, quando comparados a pessoas brancas. Uma hipótese para esse quadro é que a discriminação racial, associada à pobreza, tenha excluído muitas atividades de lazer de suas vidas (Brown; Tedrick, 1993). 
A maior disponibilidade de tempo permite o exercício de novos papéis em relação a diferentes questões da comunidade. Dal Rio (2002) observou que o tempo do pós-trabalho é caracterizado por alguns como uma nova etapa, na qual poderiam se dedicar a atividades comunitárias. Para a autora, aparentemente, essa decisão é tomada, entre outros fatores, para atender a valores religiosos e a necessidades pessoais de crescimento. Para algumas pessoas, o trabalho voluntário seria uma forma de exercer a cidadania e de retribuir o que receberam ao longo da vida, além de passar adiante sua experiência profissional. No entanto, o investimento em relações interpessoais, bem como a preocupação com o bem-estar do próximo (não familiar) não constituem, ainda, um papel social específico.

A maioria dessa população trabalha com populações de todas as idades, sendo que mais da metade está envolvida em trabalhos religiosos, dentro de igrejas e sinagogas (Papalia; Olds, 2000). Os trabalhos voluntários adquiriram status elevado, sendo que a população de idosos mais bem instruídos de hoje tem mais a contribuir e mais interesse nesse assunto (Chambre, 1993).

Um exemplo de trabalho voluntário para os aposentados é a Pastoral da Pessoa Idosa, que tem um caráter ecumênico, atuando em diversas partes do país, abordando temas como saúde, nutrição, educação, direitos, cidadania, organização comunitária e outros de interesse desse público. Uma forma de criar as condições para a implantação da Pastoral da Pessoa Idosa é incluir ações voltadas à população idosa na Pastoral da Saúde.

Existem diferentes caminhos para uma aposentadoria significativa e aprazível, conquistadas em duas vertentes em comum: realizar atividades compensadoras e ter relacionamentos compensadores (Papalia; Olds, 2000). Para muitos idosos, ambas são consideradas como sendo uma extensão de uma história desenvolvida durante toda a trajetória de uma longa vida (Kelly, 1994).

Ter uma relação agradável com as pessoas que nos rodeiam e saber enfrentar as adversidades da vida são algumas das características de quem vive de bem com a vida. Isto é importante para nossa 
qualidade de vida em qualquer idade, especialmente no processo de envelhecimento.

Para a OMS, qualidade de vida é:

a percepção do indivíduo de sua posição na vida, no contexto da cultura e sistema de valores nos quais ele vive e em relação aos seus objetivos, expectativas, padrões e preocupações.

Fica claro que esse conceito depende de cada pessoa, mas existem algumas coisas que são comuns a muitos, como o exercício dos direitos garantidos na Constituição e nas leis, o acesso a moradia digna, alimentação, atenção à saúde, entre outros. Também é evidente que a qualidade de vida depende de muitos fatores, incluindo elementos de avaliação, tanto positivos como negativos.

Assim, uma pessoa que apresenta uma doença crônica que exige o uso contínuo de medicamentos e desfruta de algumas coisas agradáveis, pode referir uma qualidade de vida excelente, se tiver o apoio da família e de amigos e se puder contar com as ações e serviços que necessitar dos diversos setores da administração pública.

Em função disso, muitos setores governamentais e não governamentais vêm unindo esforços para garantir que, além de aumentar a quantidade de anos de vida, seja possível, também, aumentar a qualidade com que se vive esses anos.

\section{Redes de suporte social}

As relações sociais de uma pessoa têm características de uma rede que se desenvolve ao longo de sua vida (Capitanini, 2000). Pode-se dizer que essa rede tem dois grandes componentes: a rede formal e a rede informal, sendo que a primeira compreende os equipamentos públicos e seus profissionais, enquanto a informal inclui familiares, amigos, colegas de trabalho e vizinhos (Neri, 2001; Domingues, 2011). 
Capitanini (2000), ao discutir os conceitos de suporte social e rede de suporte social, faz referência a diversos autores, revelando sua amplitude. Uma das concepções inclui as ações que levam uma pessoa a acreditar que é cuidada, amada, estimada e valorizada, bem como pertencente a uma rede de relações e obrigações comuns e mútuas, ou de relações que envolvem dar e receber. Tais redes permitem que as pessoas mantenham sua identidade social, recebam ajuda e estabeleçam contatos sociais (idem, 2000).

Batistoni (2007) destaca que a rede de suporte social pode representar a garantia de acesso a recursos, materiais ou não, e tende a influenciar comportamentos (como atividades físicas, dieta e socialização), além de atuar como amortecedor de estresse e fator de prevenção da depressão entre idosos. Nessa rede, a qualidade dos contatos sociais tem um papel protetor mais importante que a quantidade. Quando a rede social é satisfatória, as possíveis perdas econômicas decorrentes da aposentadoria podem ser compensadas.

A família é um componente importante da rede informal, mas o convívio com os filhos e netos nem sempre caracteriza uma velhice bem-sucedida (Debert, 1999). Em alguns casos, os amigos e vizinhos podem ser mais importantes que a interação com filhos e netos (Deps, 1993). Os grupos religiosos também podem representar um componente significativo da rede de suporte social do idoso (Goldstein, 1993).

A rede de relações sociais pode apresentar uma diminuição no processo de envelhecimento, particularmente com a aposentadoria. Assim, a rede de suporte social do idoso, apesar de depender da história anterior de integração social, pode ser construída, por livre escolha, buscando atender suas necessidades afetivas específicas, especialmente junto a outros idosos, pois compartilham diversas experiências, valores e significados, além de possuírem necessidades parecidas (Neri, 2001).

Nesse sentido, a participação em grupos de terceira idade ou associações de aposentados pode ser uma opção interessante na remodelagem da rede de suporte social (Costa; Lopes, 2014). 


\section{O protagonismo da população idosa}

Uma forma interessante de ampliar a rede de suporte social é o exercício do protagonismo da população idosa, incluindo a participação na formulação e implementação de políticas públicas que garantam seus direitos, o que vem merecendo destaque em alguns organismos internacionais.

A participação social na vida política é uma das opções de atividades que podem ser exercidas pelos aposentados, especialmente por meio de conselhos e conferências, entendidos como formas de controle social de diferentes políticas públicas.

O Plano de Ação Internacional para o Envelhecimento, mais conhecido como Plano de Madri, foi elaborado na II Assembleia Mundial do Envelhecimento, promovida pela Organização das Nações Unidas (ONU), realizada em Madri/Espanha, em 2002, atualizando um documento de 1982, produzido na I Assembleia realizada em Viena (SEDH, 2007).

No Plano de Madri, o conceito de "participação" extrapola a atuação de representantes da população idosa nos espaços de formulação e implementação de políticas públicas de seu interesse. Inclui a contribuição social e econômica dos idosos, inclusive os "cuidados prestados aos membros da família, o trabalho produtivo de subsistência, a manutenção dos lares e a realização de atividades voluntárias na comunidade" que comumente não são medidos em termos econômicos. Também é considerada a participação em atividades culturais, esportivas e recreativas que contribuem para aumentar e manter o bem-estar pessoal, bem como reflexos na economia local. O plano destaca que "as organizações de idosos constituem um meio importante para facilitar a participação mediante a realização de atividades de promoção e o fomento da interação entre as gerações” (SEDH, 2007).

O Plano de Madri aborda a "participação de idosos nos processos de tomada de decisões em todos os níveis", indicando as seguintes medidas: 
a) incorporar as necessidades de idosos e as questões que os preocupam aos processos de tomada de decisões em todos os níveis;

b) estimular, caso ainda não as haja, a criação de organizações de idosos, em todos os níveis, entre outras coisas para representá-los nos processos de tomada de decisões;

c) adotar medidas para permitir igual e plena participação dos idosos, particularmente das mulheres idosas, na tomada de decisões em todos os níveis. (SEDH, 2007)

Outro documento internacional importante para o protagonismo da população idosa é o Envelhecimento ativo: uma política de saúde, elaborado pela OMS (2005), com o objetivo de "dar informações para a discussão e formulação de planos de ação que promovam um envelhecimento saudável e ativo".

Segundo o documento, "envelhecimento ativo" deve ser entendido como "o processo de otimização das oportunidades de saúde, participação e segurança, com o objetivo de melhorar a qualidade de vida à medida que as pessoas ficam mais velhas" (ibidem).

Dessa forma, a Política do Envelhecimento Ativo está estruturada em três pilares básicos: saúde, participação e segurança. A ação nesses três pilares requer desenvolvimento do conhecimento, em que estão incluídas avaliação, pesquisa, vigilância e disseminação dos resultados das pesquisas. Fator relevante é a divulgação dos resultados das pesquisas, que devem ser "compartilhados em linguagem clara, e em formatos práticos e acessíveis, com os governantes, as organizações não governamentais que representam os idosos, o setor privado e o público em geral" (ibidem).

Para a OMS (2005), a expressão "envelhecimento ativo" aplica-se tanto a indivíduos quanto a grupos populacionais, permitindo que as pessoas percebam o seu potencial para o bem-estar físico, social e mental ao longo do curso da vida. Nessa visão, as pessoas participam da sociedade de acordo com suas necessidades, desejos e capacidades e ao mesmo tempo têm garantidos meios para sua proteção, segurança e cuidados adequados, quando necessários. 
Nesse conceito, a palavra "ativo" não se refere apenas à capacidade de estar fisicamente ativo ou de fazer parte da força de trabalho, mas sim à participação contínua nas questões que lhe dizem respeito, como os aspectos sociais, econômicos, culturais, espirituais e civis. Assim, os idosos aposentados ou que apresentam alguma doença ou incapacidade podem continuar a ter uma vida útil entre seus familiares, amigos e comunidades.

Para alcançar a meta de "obtenção da melhor qualidade de vida possível, pelo maior tempo possível e para o maior número de pessoas possível", a OMS vem promovendo iniciativas de treinamento e de pesquisa para ampliar as bases de conhecimento sobre gerontologia e geriatria. Também tem incentivado iniciativas interdisciplinares eintersetoriais, especialmente nos países em desenvolvimento, para dar conta dos "índices rápidos e sem precedentes da população que está envelhecendo, dentro de um contexto de pobreza predominante e problemas de infraestrutura não solucionados" (OMS, 2005). Para a entidade, cabe aos países e às administrações locais a definição de objetivos com metas realistas e a implementação de políticas e programas adaptados a cada realidade.

Em suma, para efetivação do controle social são necessárias diversas ações integradas, incluindo: criação de conselhos, proposição de ações, monitoramento das políticas, formação de lideranças, renovação dos conselheiros, engajamento dos movimentos sociais e participação ativa dos gestores públicos (Costa et al., 2014).

A universidade tem um papel fundamental nesse processo, desde a formação de profissionais qualificados, passando pela produção de conhecimento e a colaboração no processo de educação permanente dos profissionais em atividade e dos conselheiros, até a participação direta de docentes, servidores e alunos nos conselhos e conferências.

Outro aspecto a observar é que a participação dos aposentados não deve se restringir às políticas que digam respeito à própria população idosa, mas também ao conjunto da sociedade. Algumas organizações de aposentados desempenham um papel importante na luta por melhores condições de vida dos próprios idosos e dos 
demais segmentos da população, por meio da participação nos conselhos de saúde, de educação, de assistência social, entre outros, nas três esferas de gestão.

As organizações de idosos e de aposentados podem ser incluídas no âmbito dos novos movimentos sociais, na medida em que, sem representar uma classe social, são grupos sociais com contornos mais ou menos definidos, que defendem interesses coletivos, às vezes bastante localizados, mas com possibilidade de ser universalizados (Santos, 1999).

A Lei n.8.842/94 indica também que devem ser viabilizadas "formas alternativas de participação, ocupação e convívio do idoso, que proporcionem sua integração às demais gerações" (Brasil, 1994).

A questão intergeracional é relevante, pois muitas ações voltadas aos idosos podem ajudar na afirmação da identidade desse segmento populacional, mas podem, por outro lado, reforçar a discriminação, ao manter os idosos isolados dos demais segmentos da sociedade. Enfim, deve-se evitar a "inclusão segregadora", constituindo guetos, concretos ou virtuais.

\section{Aposentadoria e a tarefa de cuidar de alguém}

Em alguns casos, a aposentadoria pode estar atrelada ao papel de cuidar de um ente familiar, podendo ser uma criança com deficiência, um adulto com sequela de acidente ou um idoso. Esses idosos que se tornam cuidadores num contexto familiar no qual ninguém mais dispõe de tempo para desempenhar tal tarefa, deixam de dispor do seu tempo de lazer e descanso para cumprir uma empreitada que pode ter, em média, sessenta horas semanais (Haley, 1997). Existem estudos que relacionam o ato de cuidar de um idoso a sobrecarga física, estresse e sintomas depressivos.

Segundo Alvarenga et al. (2009), a aposentadoria é caracterizada como um momento de mudanças que pode repercutir de maneira positiva ou negativa. No caso de idosos que têm o empenho 
de cuidar de alguém, essa situação pode estar relacionada a aspectos negativos, uma vez que a sobrecarga de cuidar de alguém é evidenciada em muitos estudos, principalmente quando relacionada a alguma doença grave.

Observações não sistematizadas têm mostrado que muitas pessoas se aposentam para cuidar de um familiar, ou, estando aposentadas, assumem a condição de cuidador. Uma pesquisa que envolveu servidores aposentados de uma universidade pública paulista identificou como um dos motivos para a definição do momento da aposentadoria a tarefa de "cuidar de alguém" (Costa, 2014). Em alguns casos, o trabalhador se vê na contingência de antecipar a data da aposentadoria para exercer a tarefa de cuidar de algum membro da família, especialmente o cônjuge. Nesses casos, além da redução do valor dos proventos, a pessoa que se aposenta não tem tempo hábil para se preparar para essa transição.

Ainda que a tarefa de cuidar não seja o motivo da aposentadoria, esta surge com frequência depois da aposentadoria, especialmente em função do "tempo livre" que o aposentado tem para "desfrutar". Às vezes, o cuidado é eventual ou pontual, como acompanhante da internação hospitalar de um familiar ou amigo.

Os cuidadores de idosos, em sua maioria, são mulheres (esposas ou filhas), com idade de 50 anos ou mais. Quando o cuidado de um dos cônjuges é assumido pelo outro, pode ocorrer uma confusão entre os papéis, especialmente nos casos de demência, o que tende a influenciar negativamente na vida afetiva do casal.

A tarefa de cuidar de idosos, especialmente quando estes apresentam comprometimentos motores ou cognitivos importantes, pode representar uma sobrecarga, levando ao desgaste físico e emocional, com repercussões na sua saúde. Em função disso, é importante que as políticas públicas voltadas à população idosa incluam ações destinadas ao apoio dos cuidadores, especialmente o cuidador é também um idoso.

Porém, outra linha de pesquisa tem sido proposta nas últimas duas décadas, identificando adaptações positivas, tanto físicas como psicológicas, no cuidador (Fredman et al., 2006; 2008; Sena; 
Gonçalves, 2008). Por ter que desempenhar diversas atividades e passar por situações muito específicas, o cuidado pode exercer uma influência positiva na saúde física do cuidador.

Um fator que pode auxiliar o entendimento dessa resposta positiva do processo de cuidar é a resiliência, entendida como a capacidade de enfrentamento de uma situação delicada com pouco impacto e sem prejuízo significativo na saúde do cuidador.

Dessa forma, as instituições poderiam organizar ou disponibilizar acesso a informações, com o objetivo de apoiar e orientar os trabalhadores, aposentados ou não, que estejam exercendo o papel de cuidador, bem como incluir na programação do PPA conteúdos relativos ao cuidado, tendo em vista a possibilidade de assumir esse papel no pós-trabalho.

\section{Referências bibliográficas}

ALVARENGA, L. N. et al. Repercussões da aposentadoria na qualidade de vida do idoso. Rev. Esc. Enferm. USP, v.43, n.4, p.796802, 2009.

ANDREATTO, C. A. A. et al. Envelhecimento psicossocial. In: COELHO, F. G. D. M.; GOBBI, S. et al. (Orgs.). Exercício físico no envelhecimento saudável e patológico: da teoria à prática. v.1. cap.2. Curitiba: CRV, 2013. p.52-3.

BATISTONI, S. S. T. Sintomas depressivos entre idosos: estudo prospectivo de suas relações com variáveis sociodemográficas e psicossociais. Campinas, 2007. Tese (Doutorado em Educação) Faculdade de Educação da Unicamp.

BOSSÉ, R.; ALDWIN, C. M.; LEVENSON, M. R. How Stressful is Retirement? Findings Form the Normative Aging Study. Psychological Science, Boston, v.46, n.1, p.9-14, 1991.

BRASIL. Lei n.8.842, de 4 de janeiro de 1994, que dispõe sobre a Política Nacional do Idoso, 1994.

BROWN, M. B.; TEDRICK, T. Outdoor Leisure Involvements of Black Older Americans: an Exploration of Ethnicity and Margina- 
lity. Activities, Adaptation and Aging, New York, v.17, n.3, p.5565, 1993.

CAPITANINI, M. E. S. Sentimentos de solidão, bem-estar subjetivo e relações sociais em idosas vivendo sós. Campinas, 2000. Dissertação (Mestrado em Psicologia Educacional) - Faculdade de Educação, da Unicamp.

CHAMBRE, S. M. Volunteerism by Elders: Past Trends and Future Prospects. The Gerontologist, v.33, 1993.

COSTA, A. M. M. R. O significado da aposentadoria para os servidores públicos: o caso de uma universidade. São Paulo, 2014. 112p. Dissertação (Mestrado em Gerontologia) - Pontifícia Universidade Católica de São Paulo (PUC-SP).

; LOPES, R. G. C. Rede de suporte social na velhice: para além da família e dos amigos. Revista Portal de Divulgação, n.40, ano IV, mar./abr./maio 2014. Disponível em: www.portaldoenvelhe cimento.org.br/revista.

et al. O papel do controle social nas políticas públicas para idosos no Brasil. Revista Portal de Divulgação, n.42, ano V, set./ out./nov. 2014. Disponível em: www.portaldoenvelhecimento. org.br/revista.

DAL RIO, M. C. Trabalho voluntário como promoção da integração social do idoso. Terceira Idade, São Paulo: Sesc, n.13, v.24, p.5772, 2002.

DEBERT, G. G. A reinvenção da velhice: socialização e processos de reprivatização do envelhecimento. São Paulo: Edusp, 1999.

DEPS, V. L. Atividade e bem-estar psicológico na maturidade. In: NERI, A. L. (Org.). Qualidade de vida e idade madura. Campinas: Papirus, 1993.

DOMINGUES, M. A. R. et al. Mapa mínimo de relações do idoso: análise de reprodutividade. Revista Kairós Gerontologia, São Paulo, 14(6), p.153-66, dez. 2011.

FRANÇA, L. H. Attitudes Towards Retirement: a Cross-Cultural Study Between New Zealand and Brazilian Executive. New Zealand: The Universit of Auckland, Departament of Psychology, 2004. 
FRANÇA, L. H.; VAUGHAN, G. Ganhos e perdas: atitudes dos executivos brasileiros e neozelandeses frente à aposentadoria. Psicologia em Estudo, Maringá, v.13, n.2, 2008.

FREDMAN, L.; CAULEY, J. A.; SATTERFIELD, S. et al. Caregiving, Mortality, and Mobility Decline: the Health, Aging, and Body Composition (Health ABC) Study. Archives of Internal Medicine, v.168, n.19, p.2.154-62, 2008.

; BERTRAND, R. M.; MARTIRE, L. M. et al. Leisure-time Exercise and Overall Physical Activity in Older Women Caregivers and Non-Caregivers from the Caregiver-SOF Study. Preventive Medicine, v.43, n.3, p.226-9, 2006.

GEORGE, L. K. Depressive Disorders and Symptoms in Later Life. Generations, v.17, n.1, 1993.

GOLDSTEIN, L. L. Desenvolvimento do adulto e religiosidade: uma questão de fé. In: NERI, A. L. (Org.). Qualidade de vida e idade madura. Campinas: Papirus, 1993. p.83-108.

HALEY, W. The Family Caregiver's Role in Alzheimer's Disease. Neurology, 48(5), p.25-9, 1997.

KELLY, J. R. Recreation and Leisure. In: MONK, A. (Ed.). The Columbia Retirement Handbook. New York: Columbia University Press, 1994.

; STEINKAMP, M.; KELLY, J. Later Life Leisure: How They Play in Peoria. The Gerontologist, v.26, 1986.

MANNELL, R. High Investment Activity and Life Satisfaction: Commitment, Serious Leisure, and Flow in the Daily Lives of Older Adults. In: KELLY, J. (Ed.). Activity and Aging. Newburg Park, CA: Sage, 1993.

MONTEIRO, C. A. Geossistema: a história de uma procura. São Paulo: Contexto, 2001.

NERI, A. L. Palavras-chave em Gerontologia. Campinas: Alínea, 2001. ORGANIZAÇÃO MUNDIAL DA SAÚDE (OMS). Envelhecimento ativo: uma política de saúde. Brasil: Organização Pan-Americana da Saúde, 2005.

PAPALIA, D.; OLDS, S. Desenvolvimento psicossocial na terceira idade. In: . Desenvolvimento humano. 7.ed. Porto Alegre: Artmed, 2000. 
SANTOS, B. de S. Pela mão de Alice: o social e o político na pós-modernidade. São Paulo: Cortez, 1999.

SECRETARIA ESPECIAL DOS DIREITOS HUMANOS (SEDH). Plano de Ação Internacional sobre o Envelhecimento, 2002. Organização das Nações Unidas. Brasília: SEDH, 2007.

SENA, E. L. S.; GONÇALVES, L. H. T. Vivências de familiares cuidadores de pessoas idosas com doença de Alzheimer: perspectiva da filosofia de MerleauPonty. Texto E Contexto Enfermagem, v.17, n.2, p.232-40, 2008. 


\title{
5 \\ ATIVIDADE FísICA E APOSENTADORIA'
}

\author{
Pollyanna Natalia Micali \\ Paula Secomandi Donadelli \\ Paulo Fernando Moraes \\ Reisa Cristiane de Paula Venancio
}

Um dos componentes mais importantes de um Programa de Preparação para Aposentadoria (PPA), no que se refere à saúde dos futuros aposentados, é o relacionado à atividade física. Além de palestras, dinâmicas em grupo e rodas de conversa sobre o tema que possibilitem o acesso aos conhecimentos disponíveis, é importante que a organização ofereça um programa regular de atividades físicas.

A aposentadoria, muitas vezes, é caracterizada pelas perdas que ocorrem nessa fase, e também pela mudança abrupta na rotina diária. Outras mudanças podem acontecer, como o afastamento das amizades vinculadas ao ambiente de trabalho, a diminuição na renda e alteração de outros fatores que podem comprometer a qualidade de vida do trabalhador (França; Vaughan, 2008). Por outro lado, a maior disponibilidade de tempo livre possibilita ao indivíduo realizar coisas que antes não conseguia como, por exemplo, praticar exercícios físicos e, consequentemente, aumentar o nível de atividade física nos domínios do lazer e doméstico. Um dos instrumentos para avaliar o nível de atividade física é o Questionário

1. Agradecimento a Larissa Riani Costa Tavares e Luiz Augusto Riani Costa pela colaboração na revisão do capítulo. 
Internacional de Atividade Física (IPAQ) (Miilunpalo, 2001; Bauman et al., 2009).

A atividade física (AF) é definida como qualquer movimento corporal produzido em consequência de contração muscular que leve a um aumento do gasto calórico; dessa forma, andar, sentar, bordar, costurar podem ser consideradas atividades físicas. Já o exercício físico é uma subcategoria da AF, caracterizado por ser planejado, estruturado, repetitivo e utilizado como meio para melhora de alguma aptidão física (Caspersen; Powell; Christenson, 1985; Confef, 2002; Hoffman; Harris, 2002).

A relação entre a $\mathrm{AF}$, saúde, qualidade de vida e envelhecimento é campo de estudo dos profissionais de saúde, que consensualmente atribuem à adoção de um estilo de vida ativo um fator imprescindível para um envelhecimento bem-sucedido (Matsudo; Matsudo; Barros Neto, 2001).

Os benefícios obtidos pela prática de AF regular têm sido amplamente descritos em pesquisas científicas, abrangendo aspectos biológicos, psicológicos e sociais. Virtuoso Júnior et al. (2012) destacam que a prática de AF regular reduz o risco da incapacidade funcional em pessoas idosas, mantendo-as independentes para a realização das atividades do dia a dia. Segundo a OMS (WHO, 2010), a inatividade física é o quarto principal fator de risco da mortalidade global mundial.

Diante disso, sugere-se que os PPAs incluam a AF como uma das alternativas disponíveis para essa nova fase da vida, possibilitando aos aposentados a aquisição ou manutenção de um estilo de vida fisicamente ativo.

Neste capítulo também serão apresentados alguns resultados de dissertações de mestrado e projetos em andamento envolvendo essa temática, desenvolvidos na Unesp, junto ao Programa de Pós-Graduação em Ciências da Motricidade, bem como trabalhos apresentados em congressos e outros eventos.

Tendo em vista os capítulos anteriores, pode-se observar que o período da aposentadoria também vem acompanhado do envelhecimento natural, caracterizado por alterações anatômicas e 
funcionais que acontecem em ritmos e intensidades diferentes, dependendo de fatores pessoais internos (especialmente genéticos) e externos (ambientais, ocupacionais, sociais etc.) (Costa; Costa; Gobbi, 2012).

Um estudo de revisão que avaliou a adaptação à aposentadoria identificou evidências de que vários fatores, como ter filhos dependentes financeiramente, perder o parceiro durante a transição, aposentar-se mais cedo do que o esperado e aposentar-se por problemas de saúde são condições que afetam negativamente a saúde física e a adaptação à aposentadoria. Por outro lado, ter boa saúde física e mental, aposentar-se por decisão própria, usufruir de bom status financeiro, engajar-se em lazer e trabalho formal ou voluntário, ter planejado a aposentadoria, aposentar-se para fazer outras atividades, ter boa relação conjugal e estar insatisfeito com o trabalho ou desempregado antes da aposentadoria são condições favoráveis ao ajustamento após a aposentadoria (Wang; Henkens; Van Solinge, 2011).

Uma atitude saudável e que ajuda o indivíduo a se adaptar mais facilmente a essa realidade é a prática regular de atividades físicas. Segundo Slingerland, Van Lenthe e Jukema (2007) e Santos et al. (2001), há fortes evidências de que essa prática na aposentadoria diminui as doenças crônicas, o risco de quedas, melhora a capacidade funcional e a mobilidade, tornando o indivíduo mais independente. Matsudo (2009) destaca que, além de diminuir o risco de quedas, há uma diminuição na frequência e na gravidade das lesões por quedas, relacionadas ao aumento da força muscular de membros inferiores e coluna vertebral, melhora no tempo de reação, promoção de sinergia motora das reações posturais, velocidade de andar, mobilidade e flexibilidade.

Como principais efeitos metabólicos estão o aumento do volume de sangue circulante, da resistência física em 10\%-30\%, da ventilação pulmonar, diminuição da frequência cardíaca em repouso e no trabalho submáximo. Ocorre ainda o controle da pressão arterial, melhora nos níveis de colesterol HDL (lipoproteínas de alta densidade) e diminuição dos níveis de triglicérides, colesterol 
total e LDL (lipoproteínas de baixa densidade), e de glicose. A AF promove, ainda, a diminuição de marcadores inflamatórios associados às doenças crônicas não transmissíveis, colaborando na diminuição do risco de doença cardiovascular, acidente vascular cerebral tromboembólico, hipertensão arterial, diabetes tipo 2, osteoporose, obesidade, câncer de cólon e câncer de útero (Matsudo, 2009).

Nos efeitos psicossociais há melhora do humor, da autoestima e da imagem corporal, bem como redução da tensão muscular, da insônia, da ansiedade e da depressão. Também previne ou retarda o declínio das funções cognitivas (Peluso; Andrade, 2005; Matsudo, 2009).

A redução de sintomas depressivos e da ansiedade por meio da prática regular do exercício físico pode ser explicada pelo aumento da liberação de hormônios e neurotransmissores, como catecolaminas, hormônio adrenocorticotrófico (ACTH), vasopressina, beta-endorfina, dopamina, serotonina e pela ativação de receptores específicos e diminuição da viscosidade sanguínea, propiciando um efeito tranquilizante e analgésico, obtendo um resultado relaxante pós-esforço (Cheik et al., 2003).

Apesar de todos esses benefícios advindos da prática regular de AF, 31,3\% da população mundial e 49,2\% da população brasileira não atingem as recomendações mínimas de prática de $\mathrm{AF}$ (WHO, 2010; Hallal; Andersen; Bull, 2012). Isso é preocupante, considerando que a $\mathrm{AF}$ pode ser uma ferramenta de promoção à saúde e de enfrentamento das doenças crônicas não transmissíveis (Duncan; Silva; Polanczyk, 2012). O monitoramento dessa prática, bem como de seus fatores associados, é de extrema importância.

De acordo com dados do Vigitel (2014), apenas 35,3\% dos entrevistados disseram dedicar pelo menos 150 minutos do seu tempo livre na semana com AF, bem como aponta que $52 \%$ da população adulta do país apresenta excesso de peso.

Zantinge et al. (2013) afirmam que a AF regular é uma eficaz ferramenta, pois ajuda na saúde física e mental do indivíduo. Especialmente entre os idosos, é constatada a diminuição do risco de 
institucionalização, do uso de serviços de saúde e de medicamentos, gerando menos gastos à saúde pública.

A recomendação de AF para os aposentados, em geral, segue as mesmas recomendações para os idosos. Ela é fundamentada em quatro pilares: atividade aeróbia, fortalecimento muscular, flexibilidade e equilíbrio.

De acordo com Matsudo (2009), as atividades aeróbias, como caminhada, bicicleta e natação, devem ser realizadas por $30 \mathrm{mi}$ nutos, com intensidade moderada, 5 vezes por semana. $O$ fortalecimento muscular deve ser realizado duas ou três vezes por semana, em dias não consecutivos. Deve-se executar uma série de 8 a 15 repetições e de 8 a 10 exercícios diferentes priorizando grandes grupos musculares.

Os exercícios de flexibilidade devem ser executados por, no mínimo, 10 minutos nos dias que forem realizadas as atividades aeróbias e o fortalecimento muscular. Orienta-se ficar na posição estática por 10 a 30 segundos em cada posição, e repetir 3 a 4 vezes cada movimento. Por fim, recomenda-se que os exercícios de equilíbrio sejam realizados 3 vezes por semana (Matsudo, 2009).

O Ministério da Saúde incluiu as práticas corporais/atividades físicas no âmbito da Política Nacional de Promoção da Saúde (Brasil, 2006). Também incluiu os profissionais de educação física na composição dos Núcleos de Apoio à Saúde da Família (NASF), bem como apoiou a implantação de academias da saúde. Além disso, a ANS vem estimulando a adoção de um estilo de vida ativo, incluindo bonificações aos usuários que praticam regularmente AF.

Slingerland, Van Lenthe e Jukema (2007) relatam que, quando o indivíduo se aposenta, há uma queda no nível de $\mathrm{AF}$, já que muitos deles realizam trabalhos manuais e se deslocam para o trabalho caminhando ou pedalando, o que contribui substancialmente para um maior nível de atividade física do indivíduo. Em contrapartida, eles afirmam que a pressão e as limitações do tempo são as principais barreiras para a prática regular de AF.

Por isso, a ideia de aliar essa prática a um PPA é fundamental, já que diversas pesquisas apontam que a inatividade física, combi- 
nada a outros fatores de risco, contribui para a ocorrência de um conjunto de doenças crônicas, como: diabetes, osteoporose, câncer de cólon, de pulmão e de próstata e, sobretudo, doenças cardiovasculares (Zaitune et al., 2007).

No Brasil, muitos programas de PPA citam a prática regular como uma estratégia importante, mas poucos realizam algum tipo de intervenção ou desenvolvem alguma ação específica para que os indivíduos sejam realmente mais ativos.

Em 2006, foi criado o PPA da Universidade Federal de Santa Catarina, no qual cinquenta funcionários foram convidados a participar de nove encontros, para tratar de assuntos relevantes como expectativas pós-aposentadoria, relação familiar, empreendedorismo, saúde, AF, entre outros (Soares; Costa; Rosa 2007).

Segundo Soares, Costa e Rosa (2007), em relação à AF, realizou-se uma palestra informativa sobre esportes, com a presença de um especialista convidado, a apresentação de técnicas sobre a correta realização de atividades físicas, bem como propostas para o início da prática esportiva, inclusive com as alternativas existentes dentro da própria universidade, como o Núcleo de Estudos da Terceira Idade (Neti). Também foi realizada uma dinâmica de grupo para discussão sobre atividades de lazer, com foco nas possibilidades para a região. Em ambas as situações, tanto no esporte, como no lazer, discutiu-se a importância da inserção social promovida pela prática de atividades físicas.

Tendo em vista a importância do tema e poucos resultados na literatura, estão sendo desenvolvidos alguns projetos de pesquisa pela Unesp, como um estudo de base populacional, de caráter epidemiológico, que está sendo realizado na cidade de Rio Claro, incluindo aposentados, a fim de verificar, por meio de questionários, o nível de AF, a qualidade de vida, condições socioeconômicas, condições de saúde e as barreiras enfrentadas para iniciar ou continuar a prática de AF. Os resultados poderão nortear a implantação de novos programas que atendam de forma mais abrangente as reais necessidades dessa população, além de melhorar a aderência a esses programas. 
Outro trabalho de mestrado em andamento é a implantação de um projeto-piloto de preparação para a aposentadoria para servidores da Prefeitura de Limeira (SP). Nesse projeto foram feitas intervenções com $A F$, duas vezes por semana, palestras educativas e dinâmicas em grupo, uma vez por semana, abordando assuntos relevantes, como envelhecimento, doenças crônicas, depressão, nutrição, importância da AF, qualidade de vida, expectativas relacionadas à aposentadoria, empreendedorismo e voluntariado. Um dos objetivos específicos do projeto é incentivar que esses servidores introduzam essa prática regularmente na sua rotina e proporcionar a eles um envelhecimento bem-sucedido. Foram realizadas avaliações físicas e psicológicas antes do início e após o término da intervenção, para analisar o efeito nos servidores participantes, em comparação com um grupo que não participou das atividades. Os resultados preliminares indicam que houve mudança significativa no nível de AF dos servidores, bem como na coordenação motora dos mesmos. Também houve melhora nos níveis de força de membros superiores e inferiores, na flexibilidade e na resistência aeróbia. Um achado positivo desta pesquisa foi que o follow-up realizado 6 meses após o término da intervenção, revelou que $80 \%$ dos servidores do grupo intervenção continuavam praticando exercícios físicos 3 vezes por semana. Devido a todas estas mudanças, a qualidade de vida dos servidores melhorou em diversos aspectos quando analisadas qualitativamente. Outros resultados estão sendo analisados para posterior divulgação.

$\mathrm{Na}$ Austrália foi realizado por Holt, Jancey e Lee (2014) um estudo em vilas de aposentados. Essas vilas são comuns no país e estão crescendo, visto que o número de idosos também é crescente. Nesse estudo, cerca de 400 pessoas, divididas em 20 grupos de 20 indivíduos cada, sendo 10 no grupo intervenção e 10 no grupo controle, foram analisadas durante 6 meses. Para os indivíduos do grupo intervenção, foram oferecidas cartilhas explicativas falando da importância da $\mathrm{AF}$ e recomendando que os indivíduos pratiquem 150 minutos semanais de atividades físicas moderadas. Nessa cartilha, também foram apresentados conteúdos sobre 
hábitos alimentares saudáveis. Esse estudo ainda estava em andamento por ocasião da publicação mas será importante para fornecer informações sobre facilitadores de barreiras para construir hábitos saudáveis e também podem contribuir para que os órgãos públicos pensem em estratégias para facilitar esse processo.

Existem na literatura alguns estudos com essa temática realizados em outros países, porém existem limitações para a comparação dos resultados, devido aos diferentes hábitos e culturas, além da utilização de diferentes instrumentos de avaliação.

Em outro estudo, Lahti et al. (2011) concluíram que indivíduos que se aposentam aumentam a frequência da prática esportiva no lazer e diminuem a inatividade física. Esses resultados apontam que esse momento de transição para a aposentadoria é o ideal para que sejam feitas ações que estimulem a prática regular, bem como as AF no lazer.

Soares, Costa e Rosa (2007) afirmam que é necessário um novo olhar para os aposentados em virtude do aumento da expectativa de vida, trazida principalmente pelos avanços da medicina. É preciso preparar esse idoso para que ele viva mais vinte ou trinta anos com qualidade.

Estudos indicam maior adesão à $\mathrm{AF}$ por adultos no período de aposentadoria, melhorando a saúde e bem-estar devido à nova rotina e à possibilidade de interação social, enfatizada entre as mulheres, e às mudanças pessoais, enfatizada entre os homens (Barnett; Guell; Ogilvie, 2012).

Segundo Barnett, Van Sluijs e Ogilvie (2012), o principal resultado após uma revisão sistemática do tema abrangendo trinta anos, entre 1980 a 2010, é que a AF no lazer aumentou depois da transição para a aposentadoria no grupo de maior nível econômico. Também se investigou se outras mudanças variavam com a classe socioeconômica.

Em outra revisão sobre o assunto, Barnett, Guell e Ogilvie (2012) realizaram uma síntese de resultados quantitativos e qualitativos. Os resultados dessa revisão permitiram perceber que esse engajamento tende a ocorrer mais em atividades de recreação, que 
incluem expectativas dos benefícios de saúde, padrões de $\mathrm{AF}$ ao longo da vida, oportunidades para socialização, mudanças pessoais e desejos para uma nova rotina.

Para entender como ocorre o processo de envelhecimento de professores, a Unesco (2004) desenvolveu uma pesquisa com professores no Brasil, identificando que 17,8\% praticam AF diariamente, $15,3 \%$ realizam AF de três a quatro vezes por semana, $18,7 \%$ de uma a duas vezes por semana e $13,7 \%$ a cada quinze dias. Os que disseram nunca realizar atividade física somaram 34,5\%.

Moraes (2014), em sua dissertação de mestrado, desenvolvida junto ao Programa de Pós-Graduação em Ciências da Motricidade, da Unesp, buscou entender melhor o processo de envelhecimento ativo de um grupo de indivíduos participantes de um programa de $\mathrm{AF}$ da Unati/Esalq/USP, especialmente os professores aposentados, caracterizando o grupo em relação: 1) ao índice de aptidão funcional geral (IAFG); 2) ao nível de atividade física; 3) à qualidade de vida em três domínios: capacidade funcional, limitação por aspectos físicos e vitalidade, e também a atividade física na aposentadoria dos professores do grupo.

Fizeram parte dessa pesquisa 47 participantes, com média de idade de 70,21 anos $( \pm 5,58)$ e peso 67,88 $( \pm 9,63)$. Os resultados socioeconômicos da amostra apontaram um melhor nível econômico dos professores em relação aos demais participantes.

Isto leva à associação com o estudo de Barnett, Van Sluijs e Ogilvie (2012), que relacionou os resultados de outros estudos sobre a pós-aposentadoria e o status socioeconômico concluindo que o aposentado com esse indicador mais elevado realiza mais AF no lazer no período de aposentadoria.

Entre os resultados encontrados quanto ao IAFG do grupo estudado, a maioria $(46,94 \%)$ está classificada como fraco ou muito fraco, não havendo diferenças significativas entre professores e não professores quanto ao IAFG. Nas capacidades físicas específicas, observou-se ligeira vantagem para os professores nos componentes da capacidade funcional da American Alliance for Health, Physical Education, Recreation and Dance - AAHPERD (agilidade, equi- 
líbrio dinâmico e resistência aeróbia). Os professores aposentados do grupo estudado apresentam-se mais ativos no cotidiano que os demais, pois o nível de AF nos domínios doméstico e lazer, avaliados pelo IPAQ, foram significativamente maiores. Quanto aos três domínios avaliados no questionário SF-36 (capacidade funcional, limitação por aspectos físicos e vitalidade), a vitalidade foi significativamente menor entre os professores do grupo.

A conclusão observada no estudo de Moraes (2014) foi a tendência de as professoras e professores aposentados buscarem um envelhecimento ativo, preconizado pela OMS (2005), que se caracteriza pelo aumento da expectativa de vida saudável e a qualidade de vida para todas as pessoas que estão envelhecendo, inclusive as que são frágeis, fisicamente incapacitadas e que requerem cuidados.

Em uma pesquisa realizada com aposentados residentes no município de Rio Claro, procurou-se investigar o nível de atividade física e a qualidade de vida, por meio de um estudo epidemiológico, de base populacional. Foi observado que as mulheres aposentadas não atingiram os níveis de AF recomendados (150 minutos semanais) no tempo livre, diferentemente dos homens, que atingiram estes níveis. Em relação à qualidade de vida, observou-se que os aposentados apresentaram pior qualidade de vida quando comparados a não aposentados no domínio capacidade funcional, indicando uma influência da aposentadoria no nível de AF e qualidade de vida. Dessa forma, devem ser incentivados e implantados PPAs em empresas e instituições, com apoio das políticas públicas de saúde, a fim de minimizar estes efeitos durante o processo de aposentadoria e nas etapas posteriores (Micali, 2015).

A inclusão da prática regular de AF é importante em todas as idades, porém, à medida que envelhecem, as pessoas tendem a ser mais inativas. Nesse contexto, pessoas maiores de 65 anos fisicamente ativas, ao serem comparadas com as fisicamente inativas, apresentam melhores rendimentos na aptidão cardiorrespiratória, menor risco para o desenvolvimento de doenças incapacitantes, além de taxas menores de várias doenças crônicas não transmissí- 
veis (WHO, 2010), além do convívio e da interação social. Novos estudos e programas de PPA ainda precisam ser realizados para preencher as lacunas sobre essa temática.

Diante dos relatos apresentados e da afirmação de diversos autores baseados em estudos experimentais e epidemiológicos (transversais e longitudinais), existem evidências de que a atividade física tem implicações sobre a qualidade e a expectativa de vida. Estudos com pessoas idosas indicam que tanto o exercício aeróbio, feito regularmente, quanto o treinamento de força, têm efeito positivo sobre a saúde, não havendo evidências da superioridade de uma forma de atividade sobre as outras (Ministério da Saúde, 2002; Santarem, 2002; Deps, 1993).

Para o homem primitivo, a atividade física era parte integrante do seu dia a dia, mas, com a evolução da tecnologia, tanto no trabalho como na vida doméstica, houve uma progressiva redução das atividades físicas, especialmente para alguns grupos de pessoas (Costa; Gobbi, 2002).

Para Santarem (2002, p.9), como as "pessoas idosas costumam apresentar graus variáveis de processos degenerativos articulares e vasculares, exigindo maiores cuidados na prática esportiva e nos programas de exercícios terapêuticos ou de condicionamento físico", é importante que as atividades iniciais sejam suaves e que a progressão ocorra lentamente, especialmente se os idosos forem sedentários há muitos anos.

Deps (1993, p.65) lembra que, "para ser significativa, a atividade física deve trazer satisfação” e que, para que seja prazerosa, "deve-se levar em consideração a motivação ou as circunstâncias em que foi gerada”. Nesse sentido, as atividades sociais relacionadas às atividades físicas também têm "efeitos preventivos e terapêuticos sobre as reações ao estresse e à doença”. 


\section{Referências bibliográficas}

BARNETT, I.; GUELL, C.; OGILVIE, D. The Experience of Physical Activity and the Transition to Retirement: a Systematic Review and Integrative Synthesis of Qualitative and Quantitative Evidence. International Journal of Behavioral Nutrition and Physical Activity, v.9, n.97, p.1-10, 2012.

;VAN SLUIJS, E.; OGILVIE, D. Physical Activity and Transitioning to Retirement: a Systematic Review. American Journal of Preventive Medicine, Phyladelphia, v.43, n.3, p.329-36, 2012.

BAUMAN, A. et al. The International Prevalence Study on Physical Activity: Results from 20 Countries. International Journal of Behavioral Nutrition and Physical Activity, v.6, n.21, 2009.

CASPERSEN, C. J.; POWELL, K. E.; CHRISTENSON, G. M. Physical Activity, Exercise and Physical Fitness. Public Health Reports, v.100, n.2, p.126-31, 1985.

CHEIK, N. et al. Efeitos do exercício físico e da atividade física na depressão e ansiedade em indivíduos idosos. R. Bras. Cie. Mov., 11(3), p.45-52, 2003.

CONSELHO FEDERAL DE EDUCAÇÃO FÍSICA (Confef). Resolução n.046/2002. Dispõe sobre a Intervenção do Profissional de Educação Física. Diário Oficial da União, Brasília, 19 mar. 2002, 53, seção 1, p.134.

COSTA, J. L. R.; COSTA, A. M. M. R.; GOBBI, S. Unesp-Unati e as políticas públicas voltadas à população idosa. In: DEL-MASSO, M. C. S.; AZEVEDO, T. C. A. M. (Orgs.). Unati - Espaço aberto ao ensino e à criatividade. 1.ed. São Paulo: Cultura Acadêmica, 2012.

; GOBBI, S. Atividade física e saúde. CONGRESSO SAÚDE E TRABALHO DA UNESP, 1, Assis, São Paulo, 2002. p.49.

DEPS, V. L. Atividade e bem-estar psicológico na maturidade. In: NERI, A. L. (Org.). Qualidade de vida e idade madura. Campinas: Papirus, 1993.

DUNCAN, B. B.; SILVA, O. B.; POLANCZYK, C. A. Prevenção clínica das doenças cardiovasculares. In: DUNCAN, B. B.; SCHMIDT, M. I.; GIUGLIANI, E. R. J. (Orgs.). Medicina am- 
bulatorial: condutas de atenção primária baseadas em evidências. 3.ed. Porto Alegre: Artmed, 2012.

FRANÇA, L. H.; VAUGHAN, G. Ganhos e perdas: atitudes dos executivos brasileiros e neozelandeses frente à aposentadoria Psicologia em Estudo, n.13(2), p.207-16, 2008.

HALLAL, P. C.; ANDERSEN, L. B.; BULL, F. C. Global Physical Activity Levels: Surveillance Progress, Pitfalls, and Prospects. Lancet, 380(9838), p.247-57, 2012.

HOFFMAN, S. J.; HARRIS, J. C. Cinesiologia: o estudo da atividade física. São Paulo: Artmed, 2002.

HOLT, A. M.; JANCEY, J.; LEE, A. H. A Cluster-Randomised Controlled Trial of a Physical Activity and Nutrition Programme in Retirement Villages: a Study Protocol. BMJ Open, v.4, n.9, e005107, 2014.

INTERNACIONAL PHYSICAL ACTIVITY QUESTIONNAIRE (IPAQ). Disponível em: http://www.ipaq.ki.se. Acesso em: set. 2014.

LAHTI, J. et al. Changes in Leisure-Time Physical Activity after Transition to Retirement: a Follow-up Study. International Journal of Behavioral Nutrition and Physical Activity, n. 8, p.36, 2011.

MATSUDO, S. M. M. Envelhecimento, atividade física e saúde. BIS - Bol. Inst. Saúde, São Paulo, n.47, abr. 2009.

; MATSUDO, V. K. R.; BARROS NETO, T. L. Atividade física e envelhecimento: aspectos epidemiológicos. Rev. Bras. Med. Esporte, Niterói, v.7, n.1, 2001.

MICALI, P. N. Nivel de atividade física e qualidade de vida em aposentados residentes no município de Rio Claro - SP. 2014. Dissertação (Mestrado em Ciências da Motricidade) - Unesp.

MIILUNPALO, S. Evidence and Theory Based Promotion of Health-Enhancing Physical Activity. Public Health Nutr., v.4, n.2B, p.725-8, 2001.

MINISTÉRIO DA SAÚDE. Atividade física é fundamental. Revista de Hipertensão E Diabetes, ano 1, n.2, abr. 2002.

MORAES, P. F. Envelhecimento ativo de professores de um programa de atividades físicas da Unati/Esalq/USP. 2014. Dissertação (Mestrado em Ciências da Motricidade) - Unesp. 
ORGANIZAÇÃO DAS NAÇÕES UNIDAS PARA A EDUCAÇÃO, CIÊNCIA E CULTURA (Unesco). O perfil dos professores brasileiros: o que fazem o que pensam o que almejam: pesquisa nacional Unesco. São Paulo: Moderna, 2004.

ORGANIZAÇÃO MUNDIAL DA SAÚDE (OMS). Envelhecimento ativo: uma política de saúde. World Health Organization. 60p. Brasília: Organização Pan-Americana da Saúde, 2005.

PELUSO, M. A. M.; ANDRADE, L. H. S. G. Physical Activity and Mental Health: the Association between Exercise and Mood. Clinics, n.60, p.61-70, 2005.

SANTAREM, J. M. Bases fisiológicas do exercício profilático e terapêutico. FM-USP, 2002. Disponível em: http://docslide.com.br/ documents/bases-fis-do-ex-profilatico-e-terapeutico.html.

SANTOS, L. D. et al. Eficácia da atividade física na manutenção do desempenho funcional do idoso: uma revisão da literatura. Rev. Fisioter. Bras., v.2, p.169-76, 2001.

SLINGERLAND, A. S.; VAN LENTHE, F. J.; JUKEMA, J. W. Aging, Retirement, and Changes in Physical Activity: Prospective Cohort Findings from the GLOBE Study. Am. J. Epidemiol., 165, p.1.356-63, 2007.

SOARES, D. H. P.; COSTA, A. B.; ROSA, A. Aposenta-Ação: programa de preparação para aposentadoria. Estud. interdiscip. envelhec., Porto Alegre, v.12, p.143-61, 2007.

VIGITEL. Vigilância de fatores de risco e proteção para doenças crônicas por inquérito telefônico. Ministério da Saúde, Secretaria de Vigilância em Saúde, Departamento de Vigilância de Doenças e Agravos não Transmissíveis e Promoção de Saúde. Brasília: Ministério da Saúde, 2014.

VIRTUOSO JÚNIOR, J. S. et al. Atividade física como indicador preditivo para incapacidade funcional em pessoas idosas. Rev. Latino-Am. Enfermagem, v.20, n.7, p.1-7, mar./abr. 2012.

WANG, M.; HENKENS, K.; VAN SOLINGE, H. Retirement Adjustment: a Review of Theoretical and Empirical Advancements. American Psychologist, 66(3), p.204-13, 2011.

WORLD HEALTH ORGANIZATION (WHO). Global Recommendations on Physical Activity for Health. Suíça, 2010. 55p. 
Disponível em: http://whqlibdoc.who.int/publications/2010/ 9789241599979_eng.pdf?ua=1>. Acesso em: mar. 2015.

ZAITUNE, M. P. A. et al. Fatores associados ao sedentarismo no lazer em idosos. Cad. Saúde Pública, Rio de Janeiro, 23(6), p.1.329-38, jun. 2007.

ZANTINGE, E. M. et al. Retirement and a Healthy Lifestyle: Opportunity or Pitfall? A Narrative Review of the Literature. European Journal of Public Health, 2013. 


\title{
6 \\ ENVELHECIMENTO, NOVAS TECNOLOGIAS E APOSENTADORIA
}

\author{
Elisangela Gisele do Carmo \\ Marisa Silvana Zazzetta
}

O cenário mundial mostra um perfil demográfico com grande contingente de idosos, o que configura uma realidade associada a inúmeros desafios presentes e futuros. Desde seu nascimento, o indivíduo mantém uma relação ativa com o mundo e é na vida cotidiana, ou seja, na vida de todos os dias, segundo Heller (1991), que se depara, nos seus cenários mais imediatos, com os objetos fabricados e construídos pelo homem para satisfazer as necessidades cotidianas. A expectativa é que o homem adulto consiga dominar a manipulação de tais objetos. No mundo atual, grande parte desses objetos está associada a novas tecnologias e sua manipulação pode representar um desafio para uma parcela dos idosos.

O mundo contemporâneo é confrontado a cada instante com a rapidez das mudanças tecnológicas. As tecnologias, por sua vez, influenciam as relações sociais e familiares, exigindo o acompanhamento e adaptação a mudanças, bem como a apropriação e desenvolvimento de habilidades para manipular tecnologias.

Os diferentes perfis de idosos são um alvo constante para a utilização das novas tecnologias, denominadas tecnologias de informação e comunicação (TICs), devido à facilidade que elas promovem no relacionamento interpessoal. A Pesquisa Nacional por Amostra de Domicílios (PNAD), realizada em 2013, mostra que há um crescimento significativo de idosos que acessam a internet no Brasil, 
correspondendo a 9,4\% de aumento nessa população, superando a média total de 2,9\% (IBGE, 2013).

Dias (2012) afirma que os sistemas que trazem informações como forma de atualizar e produzir conhecimento são imperativos no processo ensino-aprendizagem e proporcionam a maior facilidade da inclusão digital dos idosos. Além disso, Oliveira (2003) reflete que as TICs têm uma função também técnica e administrativa em diversos setores, sendo a disseminação da internet parte essencial da vida e do trabalho dos indivíduos.

De acordo com Pirola, Velho e Vermelho (2012), as novas tecnologias proporcionam aos idosos maior atualização, independência e convívio social através da utilização das redes sociais para fazer novas amizades, bem como encontrar familiares que moram longe. Os mesmos autores afirmam, ainda, que o lado positivo dessa relação entre idosos e redes sociais é que, diferentemente dos jovens, os idosos "constroem laços mais fortes, porque os canais de comunicação diminuem a dispersão na frente da internet, tornando gratificante o uso de alguma rede social, com a qual se identifique mais”. Essa afirmação é reforçada por Szabo (2012), que mostra a relação dos idosos com as novas tecnologias, identificando essa relação, através da rede social Facebook, como sendo a de maior destaque nessa faixa etária, frequentemente acessada por mulheres idosas de até 80 anos.

Outro estudo realizado por Jantsch et al. (2012) analisa a interação dos idosos com a internet, mostrando que existe uma relação positiva, principalmente para aqueles que possuem mobilidade reduzida e utilizam a internet como aliada, para contatos com amigos e familiares, reafirmando a contribuição que a rede social Facebook desempenha nesse processo, minimizando sentimentos de abandono e solidão.

A tecnologia promove no cotidiano dos idosos uma infinidade de possibilidades que colaboram na satisfação das mais diferentes necessidades; essa tecnologia inclui não somente as TICs, mas também as que trazem maior integração do idoso em seu meio ambiente, como dispositivos tecnológicos para monitoramento da saúde, ajuda 
na mobilidade, geolocalização, entre outros. No entanto, para usufruir de seus benefícios, essas tecnologias deveriam estar acessíveis financeiramente para todos os usuários. O exemplo do acesso digital demonstra essa realidade, pois uma importante parcela da população idosa não tem essa oportunidade por falta de recursos financeiros para aquisição de tais produtos ou falta de acesso ao aprendizado das tecnologias (Maciel; Pessin; Tenório, 2012).

Para o idoso que usufrui de uma boa renda com a aposentadoria e busca acompanhar as mudanças na realidade, as tecnologias desempenham o papel de trazer novas formas de aprender e conhecer novas possibilidades. $\mathrm{O}$ idoso que adentra ao mundo das TICs é um indivíduo que se mostra apto a aprender, demonstrando que a fase de aposentadoria é também de readaptação e aceitação das novas aprendizagens (Sá; Almeida, 2012).

No idoso, a existência de distúrbio cognitivo, problemas físicos decorrentes de doenças que comprometem a motricidade, exclusão social ou aspectos educacionais e culturais podem influenciar o acesso e uso de tecnologias (Goldman, 2006). Uma das barreiras para o uso de novas tecnologias é a falta de preparo dos idosos para operar as tecnologias, por não compreenderem, por exemplo, os manuais de usuário, devido ao tamanho das letras ou, ainda, pelas condições de escolaridade.

Estudo de Mattos e Chagas (2008) mostra que pessoas de menor poder aquisitivo não conseguem acompanhar a evolução tecnológica, principalmente no Brasil, em que existem grandes disparidades sociais. Dessa forma, essa exclusão pode explicar o porquê de muitos idosos não disporem de computador ou tablet, mas sim o telefone celular, que em comparação com os outros aparelhos é um bem de consumo mais acessível em termos financeiros. A opção pelo celular também pode ser explicada, conforme cita Anjos (2012), pois "o celular proporciona o contato independentemente de onde estiver, possibilitando que se comunique com pessoas e com o mundo". Esse fato é comprovado pela PNAD (IBGE, 2013), que demonstra no Brasil, um percentual total de 23,5\% de usuários de telefone celular acima de 50 anos. 
Torna-se necessária a inserção do idoso no mundo digital, ampliando suas fontes de informação, contatos e conhecimento. Nesse sentido, a implementação de políticas públicas que priorizem o acesso e as oportunidades dos idosos às TICs é necessária. O acesso a novas tecnologias, especialmente na fase da aposentadoria, possibilita usufruir de novas oportunidades tecnológicas em seu tempo livre, antes ocupado pelo trabalho e, portanto, o acesso a redes sociais seria como um elo de comunicação ao interagir com as pessoas, retomando seu convívio social, trazendo consigo novas oportunidades de participação em grupos, efetuar novos contatos, oportunizar novas formas de recreação, busca de informação, conhecimentos e aprendizados desenvolvendo novos hábitos de vida.

Há uma preocupação com a possibilidade de o uso das novas tecnologias aumentar o sedentarismo entre os aposentados, merecendo novos estudos.

Em um recente estudo realizado com pré-aposentados e aposentados residentes em um município no interior do estado de São Paulo, constatou que os pré-aposentados apresentam um autoconceito maior com relação as novas tecnologias, em relação aos aposentados. Outros achados do mesmo estudo enfatizam que a utilização das TICs favorece o acesso a mais informações, principalmente referentes a saúde e atividade física, e que o acesso às redes sociais proporciona uma melhora significativa nas condições de saúde psíquica e na qualidade de vida desta população (Carmo, 2016).

Além das TICs, existem tecnologias que podem apoiar o indivíduo em sua velhice e proporcionar um envelhecimento ativo. Cabe lembrar que, hoje, muitos equipamentos e aparelhos domésticos vêm incorporando novas tecnologias, que podem dificultar seu uso por pessoas que não tiveram possibilidade de informação, como fogões, fornos micro-ondas, máquinas de lavar roupa, máquinas de lavar louças, televisores, DVD players etc.

Para que haja um uso adequado das novas tecnologias, é importante que o Programa de Preparação para Aposentadoria (PPA) inclua palestras a respeito do tema e disponibilize cursos de 
inclusão digital e uso da internet. Também é importante que as ações e serviços oferecidos à população idosa, no âmbito de diferentes políticas públicas, incluam essas medidas.

\section{Tecnologias assistivas}

Tecnologias assistivas são dispositivos técnicos que contribuem na socialização e melhoria das atividades de vida diária, a fim de resguardar a integridade e a autonomia dos idosos (Carmo, 2012).

Em condições ideais, o idoso deve ser capaz de levar uma vida independente em sua própria casa; no entanto, muitas vezes, devido a complicações de doenças crônicas, novas estratégias devem ser procuradas. Assim, frequentemente, a assistência e o cuidado tornam-se necessários.

No mundo atual, em países desenvolvidos surgem a cada dia tecnologias inovadoras como suporte e apoio para tornar a vida do idoso mais autônoma e independente. Tais tecnologias de cuidado trazem como alternativa os robôs de assistência e os sistemas robóticos chamados de exoesqueletos e de mobilidade pessoal. Além disso, há uma infinidade de dispositivos tecnológicos que se propõem a melhorar a vida no ambiente doméstico, como a alta tecnologia das casas inteligentes, denominadas Smart Homes (Carmo, 2012)

Os robôs de assistência ou sociais têm a tarefa de estimulação cognitiva e interação, além de desempenharem diversas atividades dentro da casa do idoso, como suporte de comunicação, ajuda na manipulação de objetos, apoio na mobilidade, bem como proporcionar companhia e por vezes cuidado.

Grande parte dos robôs produzidos atualmente se destina a idosos cognitivamente saudáveis. Muitos desses robôs têm funções variadas para colaborar na saúde mental e física dos idosos. Alguns robôs possuem corpo humanoide, como é o caso do NAO, Romeo, Pepper (Aldebaran Robotics, 2014). Existem também robôs que 
não possuem aspecto humanoide, como o Giraff, Matilda, iCat, Care-O-bot 3, S65 P37, R1T1 (Nestorov et al., 2014; The University of Salford, 2013; Giraff Technologies AB, 2014; DMS Company, 2014; La Trobe University, 2011; Robinson; Macdonald; Broadbent, 2014; Fraunhofer IPA, 2014). Outros sistemas robóticos são denominados exoesqueletos, como The Honda Walk Assist Device, o Walk Assist Robot, HAL. Esses dispositivos possuem a função de melhorar o caminhar e minimizar o impacto causado pela assimetria do andar, aumentando a força muscular e melhorando a independência nas atividades da vida diária (AVD) (Cyberdyne Inc., 2013; Honda Motor Co., 2013; Toyota Motor Corporation, 2013). Também existem os dispositivos de transporte pessoal robóticos, como U3-X Personal Mobility e o UNI-CUB, Winglet e o i-REAL, com os modelos i-Swing e i-Unit (Toyota Motor Corporation, 2007; Honda Motor Co., 2013).

Como visto ao longo do capítulo, as tecnologias têm um grande potencial de beneficiar os idosos, porém, por se tratar de máquinas, ainda permanece o desafio de identificar o momento de serem aprimoradas, adaptadas, descartadas ou consertadas, bem como desenvolver mecanismos que minimizem as falhas, entre outros aspectos. É importante refletir que o homem sempre se utilizou de ferramentas para alcançar objetivos específicos e desenvolveu ao longo da sua evolução opções que melhoraram sua vida de forma eficaz. A automação de tarefas foi uma estratégia utilizada pelo homem para facilitar seu cotidiano. $\mathrm{Na}$ atualidade, tal processo exige o olhar cuidadoso para que as tecnologias não se tornem desumanas e que as máquinas não acabem por robotizar as relações sociais e a sociedade como um todo. Mediar o uso das inovações é o desafio, pois o advento de tecnologias e robôs pode vir a beneficiar idosos e auxiliar a evitar a exclusão e a solidão. 


\section{Referências bibliográficas}

ALDEBARAN ROBOTICS. Pepper. 2014. Disponível em: https:// www.aldebaran.com/en/a-robots/who-is-pepper. Acesso em: out. 2014.

Robot NAO. Who is NAO? 2014. Disponível em: https:// www.aldebaran.com/en/humanoid-robot/nao-robot. Acesso em: set. 2014.

Romeo. Disponível em https://www.aldebaran.com/en/ robotics-company/projects. Acesso em: out. 2014.

ANJOS, T. P. Descomplicando o uso do telefone celular pelo idoso: desenvolvimento de interface de celular com base nos princípios de usabilidade e acessibilidade. Santa Catarina, 2012. 179p. Dissertação (Mestrado) - Programa de Pós-Graduação em Engenharia de Produção e Sistemas, Centro Tecnológico, Universidade Federal de Santa Catarina (UFSC). Disponível em http://repositorio.ufsc. br/xmlui/handle/123456789/100596. Acesso em: mar. 2014.

CARMO, E. G. Envelhecimento e novas tecnologias: a inclusão digital e tecnológica na preparação para a aposentadoria e sua influência na qualidade de vida. Rio Claro, 2016. 173f. Dissertação (Mestrado em Ciências da Motricidade) - Departamento de Educação Física, Unesp/câmpus Rio Claro-SP. Disponível em: http://repositorio. unesp.br/bitstream/handle/11449/136183/carmo_eg_me_rcla_ par. pdf? sequence $=3 \&$ is Allowed $=\mathrm{y}$.

. Tecnologias assistivas para idosos com Doença de Alzheimer. São Carlos, 2012. 150f. Trabalho de Conclusão de Curso (Graduação em Gerontologia) - Departamento de Gerontologia, Universidade Federal de São Carlos (UFSCar).

CYBERDYNE INC. What`s HAL? 2013. Disponível em: http:/ / www. cyberdyne.jp/english/products/HAL/. Acesso em: nov. 2013.

DIAS, I. O uso das tecnologias digitais entre os seniores: motivações e interesses. Sociologia, Problemas e Práticas, Oeiras, n.68, jan. 2012.

DMS COMPANY. Project Robot. 2014. Disponível em: http:// www.projectrobot.org/\#!project/cngp. Acesso em: nov. 2014. 
FRAUNHOFER IPA. Care-O-bot3. 2014. Disponível em: http:// www.care-o-bot.de/en/care-o-bot-3/application.html. Acesso em: out. 2014.

GIRAFF TECHNOLOGIES AB. Giraff. Disponível em: http:// www.giraff.org/?lang=en. Acesso em: out. 2014.

GOLDMAN, S. N.Virtu@lidade: as delícias e as agruras da internet para idosos. Olinda: Elógica, 2006.

HELLER, A. Sociología de la vida cotidiana. 3.ed. Península: Barcelona, 1991.

HONDA MOTOR CO. Walking Assist. 2013. Disponível em: http://world.honda.com/Walking-Assist/. Acesso em: nov. 2014. HONDA MOTOR CO. Unicub. 2013. Disponível em: http:// world.honda.com/UNI-CUB/. Acesso em: nov. 2014.

INSTITUTO BRASILEIRO DE GEOGRAFIA E ESTATÍSTICA (IBGE). Pesquisa Nacional por mostra de Domicílios (PNAD). 2013. Disponível em: http://www.ibge.gov.br/home/estatistica/ populacao/trabalhoerendimento/pnad2013. Acesso em: mar. 2014. JANTSCH, A. et al. As redes sociais e a qualidade de vida: os idosos na era digital. IEEE-RITA, v.7, n.4, nov. 2012.

LA TROBE UNIVERSITY. Research Centre for Computers, Communication and Social Innovations (RECCSI). Matilda the robot can read emotions. 2011. Disponível em: http://www.latrobe. edu.au/news/articles/2011/article/matilda-the-robot-can-reademotions.

MACIEL, P. C. S.; PESSIN, G.; TENÓRIO, L. C. Terceira idade e novas tecnologias: uma relação de possibilidades e desafios. CONGRESSO INTERNACIONAL INTERDISCIPLINAR EM SOCIAIS E HUMANIDADES. Niterói: Aninter-SH/PPGSD-UFF, 3-6 set. 2012.

MATTOS, F. A. M.; CHAGAS, G. J. N. Desafios para a inclusão digital no Brasil. Perspectivas Ciências da Informação, Belo Horizonte, v.13, n.1, 2008.

NESTOROV, N. et al. Aspects of Socially Assistive Robots Design for Dementia Care. INTERNATIONAL SYMPOSIUM ON COMPUTER-BASED MEDICAL SYSTEMS (CBMS), 27, New York, 27-29 maio 2014. p.396-400. 
OLIVEIRA, J. P. M. Sistemas de informação e sociedade. Ciência e Cultura, São Paulo, v.55, n.2, abr. 2003.

PIROLA, A. R.;VELHO, A. P. M.;VERMELHO, S. C. S. D. Redes sociais na promoção da saúde do idoso: aspectos bibliográficos e de usabilidade. MOSTRA INTERNA DE TRABALHOS DE INICIAÇÃO CIENTÍFICA, 6, Maringá (PR), 2012. Anais Eletrônico da... Maringá: Cesumar, 2012.

ROBINSON, H.; MACDONALD, B.; BROADBENT, E. The Role of Healthcare Robots for Older People at Home: a Review. International Journal of Social Robotics, v.6, n.4, p.575-91, nov. 2014.

SÁ, M. E. G.; ALMEIDA, V. L. A inclusão dos idosos no mundo digital através das novas tecnologias da informação e comunicação. NTICs, v.6, n.1, mar. 2012.

SZABO, A. Exploring the Adoption Process of Facebook by the Older Generation. Amsterdam, 2012. 69f. Dissertação (Mestrado) Curso de Marketing, Departamento de Amsterdam Business School, Universidade de Amsterdam. Disponível em: http://dare. uva.nl/cgi/arno/show.cgi?fid=364387. Acesso em: mar. 2015.

THE UNIVERSITY OF SALFORD. Salford PhD Student Develops Revolutionary Elderly Care Robot. 2013. Disponível em: http://www.salford.ac.uk/news/salford-phd-student-developsrevolutionary-elderly-care-robot. Acesso em: ago. 2013.

TOYOTA MOTOR CORPORATION. i-REAL, i-Unit, i-Swing. 2007. Disponível em: http://www.toyota.com.hk/innovation/ personal_mobility/i-real.aspx. Acesso em: nov. 2013.

. Partner Robot Family. WalkAssistRobot. [s.d.] Disponível em: http://www.toyota-global.com/innovation/partner_robot/ family_2.html. Acesso em: nov. 2013. 


\title{
7 \\ AlimentaÇÃo E NUTRIÇÃo NO ENVELHECIMENTO E NA APOSENTADORIA ${ }^{1}$
}

\author{
Gilson Fuzaro Junior \\ Elisangela Gisele do Carmo \\ Raiana Lídice Mór Fukushima \\ Paula Secomandi Donadelli \\ José Felipe Riani Costa
}

Ao longo de todo o processo de envelhecimento, diversos fatores influenciam a saúde. Entre esses aspectos que contribuem para um estilo de vida saudável, a atividade física e a nutrição se mostram fundamentais e colaboram de maneira significativa para a saúde e a qualidade de vida (Lunn, 2007). O padrão alimentar e o perfil nutricional sofreram mudanças ao longo da história, o que se evidencia pela redução da desnutrição e aumento significativo da obesidade, considerado um dos graves problemas de saúde pública. Esse aumento está diretamente relacionado ao aumento do consumo de calorias e baixa prática de atividades físicas (Batista Filho et al., 2008). Neste capítulo, serão abordados, mais especificamente, os aspectos nutricionais relacionados a envelhecimento $\mathrm{e}$ aposentadoria, bem como a influência da saúde bucal nesse processo.

1. Agradecimento a Danielle Conte Alves pela colaboração na revisão do capítulo. 


\section{Nutrição e envelhecimento}

Como já explanado em outros capítulos, a expectativa de vida vem aumentando, porém, esse adicional de anos de vida não está necessariamente vinculado a um envelhecimento saudável. Esse processo é de fundamental importância para que os "novos" anos conquistados sejam gozados com saúde. Assim, devem acontecer em condições que garantam a manutenção da autonomia e independência dos indivíduos, minimizando as possibilidades da não participação na sociedade (Lima; Silva; Galhardoni, 2008).

Por outro lado, sabe-se também que diversas doenças que se manifestam na população idosa estão intimamente relacionadas com problemas nutricionais ou alimentares, como: níveis alterados de colesterol e triglicérides, obesidade, diabetes, hipertensão arterial, doenças cardiovasculares e outras. Esse quadro reflete-se no perfil de saúde da população brasileira, caracterizado pela predominância das doenças crônicas, responsáveis por 70\% das mortes no país (Schimidt et al., 2011). Entre idosos, 75\% têm pelo menos uma doença crônica e 64\% duas ou mais (IBGE, 2009).

Outro aspecto importante nesse processo é a alteração na composição e localização da gordura, concentrando-se na região abdominal, o que potencializa riscos de doença e morte em comparação a pessoas que possuem uma distribuição periférica. Essa distribuição mais centralizada da gordura pode aumentar os riscos de desenvolver diabetes mellitus do tipo 2 e doenças cardiovasculares (Lunn, 2007).

A partir desse quadro, evidencia-se a necessidade de estudos dos fatores que incidem sobre a prevalência das doenças crônicas não transmissíveis associadas à idade, assim como ter um melhor domínio sobre o real papel da nutrição na promoção e manutenção da independência e autonomia dos idosos (Da Cruz et al., 2004).

Além dos aspectos abordados nos capítulos anteriores a respeito do processo de envelhecimento, merecem destaque os distúrbios nutricionais comumente verificados em idosos, considerados muitas vezes, de forma equivocada, como normais, mas que podem 
afetar suas necessidades energéticas e a saúde geral (Malafaia, 2008).

Entre as alterações que ocorrem no processo de envelhecimento, as que interferem na alimentação e nutrição são:

- Alterações sensoriais. A diminuição das sensações do paladar, olfato, audição, visão e tato podem reduzir o apetite e o prazer pela comida, levando à redução na ingestão de alimentos, o que, a longo prazo, representa um dos fatores da desnutrição. Essas alterações podem ser devidas a vários fatores, como: diminuição das papilas gustativas e terminações nervosas, uso de prótese dentária, uso de medicações, intervenções médicas e cirúrgicas ou ainda ocasionadas por determinadas doenças neurodegenerativas (Harris, 2005).

- Baixa secreção salivar (xerostomia). De acordo com estudos sobre o processo do envelhecimento, a produção e o fluxo salivar encontram-se diminuídos em idosos. Além disso, os idosos utilizam múltiplas medicações, como diuréticos e anti-inflamatórios, que favorecem a redução salivar, prejudicando a saúde oral, facilitando a perda dentária, inflamação de gengivas ou da mucosa oral (Phillipi et al., 1999; Bós, 2007). Entre as funções da saliva, destacam-se: umidificação dos alimentos para facilitar a mastigação, remoção de resíduos alimentares ao redor dos dentes e ação tampão, neutralizando a ação bacteriana.

- Sistema digestivo. Existem evidências de que o envelhecimento influencia o seu pleno funcionamento. Nesse período, ocorre a diminuição da produção de ácido gástrico e pepsina que podem fazer que haja uma redução na biodisponibilidade de vitamina B12, ácido fólico, cálcio e ferro. Outros fatores importantes são a diminuição da secreção pancreática e da sensibilidade da vesícula biliar, que podem interferir na digestão de gorduras e proteínas, produzindo efeitos negativos (Lunn, 2007). Idosos apresentam menor superfície de absorção quando comparados a adultos jo- 
vens, o que ocorre pela diminuição da superfície interna do intestino, conjuntamente com uma menor produção das enzimas digestivas. Parece haver, atualmente, consenso na literatura que um dos únicos nutrientes cuja absorção não se altera, ou até se mostra aumentada entre os idosos, é a de açúcar. Com o avançar da idade, há uma tendência de crescimento da ocorrência de constipação intestinal, geralmente relacionada a sedentarismo e baixa ingestão de fibras e líquidos. Também ocorre o aumento da incidência de neoplasia (Bós, 2007).

- Taxa metabólica basal (TMB). A TMB mede a quantidade mínima de energia necessária para manter as funções fisiológicas em repouso (Westerterp, 2001) e, por diversos fatores, diminui com a idade. Entre esses fatores podem ser citados: diminuição da massa magra, concomitante ao aumento da massa gorda, alterações nos fluidos e temperatura corporal, alterações hormonais, estresse, genética e inatividade física (Poehlman et al., 1990; McArdle; Kattch; Kattch, 1996; Lunn, 2007).

Portanto, pode-se dizer, em síntese, que, com o envelhecimento, mudanças fisiológicas, metabólicas e na capacidade funcional podem resultar em alterações nas necessidades nutricionais (Sousa, V. et al., 2009). Nesse sentido, Najas, Andreazza e Souza (1994) destacam a importância de uma dieta equilibrada em carboidratos, proteínas e gorduras para os idosos. $\mathrm{O}$ atendimento das necessidades de vitaminas e minerais é também essencial, pois esses nutrientes atuam como reguladores de diversas funções no organismo, agindo como antioxidantes, retardando efeitos do envelhecimento e o aparecimento de doenças.

A ingestão de proteínas é importante para o organismo devido à necessidade da presença de aminoácidos para importantes funções estruturais, motoras, metabólicas, hormonais e imunológicas. A ingestão de proteínas pelos idosos deve ser adequada e suficiente para diminuir a perda muscular relacionada com a idade, porém 
deve-se ter em consideração que a ingestão elevada de proteínas pode facilitar os distúrbios renais, que são mais frequentes nessa faixa etária (Sousa, V. et al., 2009).

Vários alimentos têm sido relacionados tanto à ocorrência quanto à prevenção de doenças crônicas. Estudo de Fung et al. (2001) relata o efeito antioxidante das vitaminas A, E e C na prevenção do câncer e de doenças cardiovasculares. A vitamina A desempenha papel importante na visão, crescimento e desenvolvimento ósseo, sistema imunológico e reprodução. A vitamina C é um antioxidante solúvel, envolvido na biossíntese de colágeno e carnitina. A vitamina $\mathrm{E}$ também tem função antioxidante no organismo (Marucci; Alves; Gomes, 2007).

Outro micronutriente de extrema importância é o zinco, que está relacionado com a síntese e degradação dos macronutrientes, sistema imunológico e cicatrização. Pode haver uma ligeira deficiência devido a alterações no paladar e olfato, que ocasionam a diminuição da ingestão de alimentos ricos nesse nutriente (Novaes et al., 2005). A efetividade da suplementação de zinco é controversa na literatura, devendo cada caso ser avaliado individualmente.

Participante direto do transporte de oxigênio e gás carbônico, respiração celular e sistema imune, o ferro é um micronutriente fundamental na alimentação dos seres humanos (Marucci; Alves; Gomes, 2007).

O cálcio é um mineral constituinte de ossos e dentes, sendo 99\% desse mineral utilizado na função estrutural do organismo humano. O restante está presente em funções metabólicas como: contração muscular, estabilidade de membrana celular, liberação ou ativação de enzimas intra e extracelulares, transmissão de impulsos nervosos, coagulação sanguínea, entre outras (Marucci; Alves; Gomes, 2007).

Um importante complemento no metabolismo do cálcio é a vitamina $\mathrm{D}$, que precisa do sol para ser ativada. Idosos frequentemente apresentam deficiência dessa vitamina, principalmente pela diminuição da exposição ao sol e ingestão insuficiente de alguns alimentos (Marucci; Alves; Gomes, 2007). Em idosos, a exposição 
ao sol diminuída e a pele envelhecida aumentam o tempo de conversão da vitamina D para sua forma ativa (Sambrook; Cooper, 2006).

Uma doença muito importante no envelhecimento, e que está relacionada com esses dois últimos nutrientes citados (cálcio e vitamina D), é a osteoporose, caracterizada pela diminuição progressiva da massa óssea, levando à diminuição da resistência óssea e a um maior risco de fraturas. A osteoporose é mais frequente em mulheres idosas, já que, no climatério, a diminuição dos níveis hormonais aumenta as perdas de massa óssea (Kenny; Prestwood, 2000).

Entre os vários fatores que influenciam a perda da massa óssea, destacam-se, no idoso, os níveis séricos inadequados de vitamina D, responsáveis pela diminuição das condições funcionais dos músculos, justificando maior ocorrência de quedas e fraturas. A exposição ao sol diminuída e a pele envelhecida aumentam o tempo de conversão da vitamina $\mathrm{D}$ para sua forma ativa pela luz ultravioleta. Esse quadro de déficit de vitamina $\mathrm{D}$ resulta na redução da absorção de cálcio. Tais fatores, juntamente com uma dieta pobre em cálcio e vitamina $D$, contribuem para o agravamento desse quadro (Sambrook; Cooper, 2006).

\section{Influência da saúde bucal do idoso na alimentação e nutrição}

É importante lembrar que problemas odontológicos, além de interferir na estética e na fala, são fatores que interferem de modo significativo na alimentação, contribuindo diretamente para o aumento de desnutrição do idoso (Frank; Soares, 2002). Entre as várias alterações bucais, a mais importante e significativa é a redução do número de dentes, que afeta a eficiência da mastigação e da digestão, bem como predispõe a doenças gastrointestinais (Marques, 2006). O declínio da saúde oral em idosos está relacionado ao aumento de cárie dental, às infecções periodontais e à diminuição da saliva (Monjon; Budtz-Jorgensen; Rapin, 1999). 
Outro fator importante a ser considerado é a deficiência na higiene oral, que contribui para o desenvolvimento das referidas doenças. A higiene oral deficiente ou inadequada pode ser atribuída à diminuição da destreza manual, da percepção sensorial, da motivação e da capacidade cognitiva (Wong; McMillan, 2005). A frequência com que ocorrem as doenças bucais, o estado de conservação dos dentes e a prevalência da perda de dentes são reflexos, principalmente, da condição de vida do idoso e do seu acesso às ações e serviços em saúde bucal e geral, com forte componente social (Campos; Monteiro; Ornelas, 2000).

Uma pesquisa nacional sobre saúde bucal, denominada "Projeto SB Brasil 2010”, apontou que os indivíduos na faixa etária de 35 a 44 anos possuem, em média, 17 dentes cariados, perdidos ou obturados. Já entre os indivíduos com 65 a 74 anos, a média de dentes cariados, perdidos ou obturados é de 28. Destaca-se o fato de que, enquanto no grupo de 35 a 44 anos cerca de $45 \%$ dos dentes atacados por cárie foram extraídos, no grupo de 65 a 74 anos essa proporção chega a 92\%. Nessa mesma faixa etária, 63\% usam prótese dentária total (dentadura) e aproximadamente 24\% necessitam desse tipo de prótese em pelo menos um maxilar (Brasil, 2012).

Analisando-se os resultados dos levantamentos nacionais sobre saúde bucal realizados em 2003 e 2010, observa-se a melhora em alguns índices, evidenciando uma redução do ataque de cárie em diferentes faixas etárias. No entanto, a falta de dentes permanece sendo um problema de grande relevância, especialmente na população idosa. Nos últimos anos, tem ocorrido uma ampliação progressiva na produção de próteses dentárias totais no SUS, viabilizada pela implantação de Centros de Especialidades Odontológicas (CEO) e Laboratórios Regionais de Próteses Dentárias (LRPD) (Brasil, 2012). No que se refere aos planos privados de saúde, o fornecimento da prótese dentária total não faz parte da cobertura mínima obrigatória. Contudo, desde junho de 2010, as operadoras de planos privados de saúde são obrigadas a fornecer próteses odontológicas unitárias (fixadas sobre o remanescente da 
raiz do dente) para os beneficiários de planos com cobertura odontológica contratados após 1998 (ANS, 2010; ANS, 2013).

\section{Nutrição e aposentadoria}

Ao refletir sobre essa temática, cabe a indagar: por que é importante investigar a nutrição de indivíduos na aposentadoria, se nessa faixa etária suas escolhas sobre alimentos e padrões de refeições já estão definidos? Há quem advogue que seria mais importante realizar intervenções para influenciar as escolhas dos mais jovens. No entanto, a aposentadoria pode ser um momento oportuno para promover mudanças positivas nos hábitos alimentares. Vale lembrar que muitos trabalhadores habituaram-se a tomar refeições no local de trabalho, o que se altera com a aposentadoria. Outro fato importante é uma possível queda na renda, alterando o padrão de compra de alimentos.

Os padrões alimentares também podem sofrer influências, conforme estudo de Dunneram et al. (2013), que demonstrou que ocorrem modificações nos hábitos alimentares no período de pré-aposentadoria e que elas são intensificadas no período de pós-aposentadoria, dependendo de diversos determinantes, como: gênero, estado civil, renda, tabagismo, prática de atividade física e índice de massa corporal.

De acordo com dados da Pesquisa Nacional de Saúde 2013 (PNS 2013), observa-se uma tendência de elevação no consumo recomendado de hortaliças e frutas entre as faixas etárias de 18 a 29 anos (34,1\%), 30 a 59 anos (37,9\%) e 60 a 64 anos (42,5\%) (Brasil, 2015). Contudo, nota-se uma tendência de queda em tal consumo na faixa etária de 65 a 74 anos (40,6\%) e entre os indivíduos com 75 anos ou mais (36,1\%). A PNS 2013 indica ainda uma queda no consumo regular de doces entre as faixas etárias de 18 a 29 anos (29,6\%), 30 a $59 \operatorname{anos}(19,4 \%), 60$ a $64 \operatorname{anos}(16,6 \%)$ e 65 a 74 anos $(16,4 \%)$. No entanto, nota-se uma tendência de elevação no consumo regular de doces nas pessoas com 75 anos ou mais $(19,4 \%)$. Ou seja, as pessoas 
com 75 anos ou mais declaram um menor consumo de hortaliças e frutas e um maior consumo de doces, em comparação à faixa etária imediatamente anterior, de 65 a 74 anos (Brasil, 2015).

No que se refere ao consumo declarado de sal, a PNS 2013 sugere uma tendência progressiva de redução do consumo com o avançar da idade. A proporção mais elevada de consumo de sal ocorre na faixa etária de 18 a 29 anos (18\%) e a menor proporção ocorre entre as pessoas com 75 anos ou mais (6,9\%) (Brasil, 2015).

Estudo realizado por A. Sousa et al. (2011), com o objetivo de avaliar o perfil sociodemográfico e nutricional de servidores idosos em período de pré-aposentadoria da Universidade Federal do Maranhão (UFMA), identificou que $52 \%$ apresentavam doenças crônicas não transmissíveis (DCNT), 56\% apresentavam excesso de peso e $76 \%$ possuíam risco elevado para desenvolver DCNT. Além disso, a frequência de consumo alimentar foi inadequada para vários grupos alimentares: saladas (58\%), frituras (90\%), embutidos (84\%), biscoitos doces (64\%) e refrigerantes (58\%).

Alvarenga et al. (2009) observaram que as mudanças no estilo de vida social em decorrência da aposentadoria podem levar a um quadro de falta de apetite ou desinteresse pela alimentação. Alguns estudos identificaram relação entre a prevalência da obesidade e o envelhecimento, fase que geralmente coincide com o processo de aposentadoria. Sendo assim, os idosos aposentados, principalmente os sedentários, estão mais sujeitos à obesidade e, consequentemente, a um maior risco de desenvolver as doenças crônico-degenerativas como o diabetes mellitus tipo 2 e as doenças do sistema cardiovascular (Alvarenga et al., 2009; Gomes et al., 2006; Gigante et al., 1997).

Um estudo longitudinal sueco evidenciou que o consumo de doces e itens alimentares semelhantes aumentou após a aposentadoria (Steen et al., 1988), o que pode contribuir com o aumento no ganho de peso e massa gorda nessa faixa etária e, consequentemente, uma elevação na incidência de doenças associadas.

Lauque, Nourashemi e Soleilhavoup (1998), analisando mudanças na ingestão de nutrientes após a aposentadoria, através de 
um estudo longitudinal, encontraram que o consumo de álcool e pão aumentou. Esses resultados podem ser justificados, uma vez que o pão é uma comida rápida e de fácil acesso, enquanto a ingestão de álcool pode aumentar por conta do maior tempo livre ou pelo surgimento de doenças como depressão. No entanto, a PNS 2013 indica uma tendência progressiva de redução do consumo declarado de álcool com o avançar da idade (Brasil, 2015).

Ainda sobre o estilo de dieta na aposentadoria, um estudo de McGuiness citado por Lara et al. (2014) afirma que aposentados, ao obterem uma alimentação à base de vegetais, grãos, cereais integrais, relataram melhor qualidade de vida. Além disso, os benefícios da ingestão diária de frutas e vegetais repercutem na saúde dos aposentados, conforme o estudo de Lara et al. (2014).

Forman-Hoffman et al. (2008) afirmam que existe diferença nos hábitos alimentares na aposentadoria se comparados com os de pessoas que ainda estão na fase produtiva do trabalho, sendo que as mulheres são mais propensas a procurar hábitos mais saudáveis que os homens.

Assim, no momento de transição para a aposentadoria, recomenda-se a inclusão de ações que busquem orientar sobre uma alimentação mais saudável, na tentativa de incorporar hábitos que favoreçam a saúde. Uma boa fonte para essa discussão é o Guia alimentar para a população brasileira, elaborado pelo Ministério da Saúde, cujas recomendações foram sintetizada nos "Dez Passos para uma Alimentação Adequada e Saudável” (Brasil, 2014). Tendo em vista que no momento da aposentadoria as pessoas tendem a se preocupar mais com sua saúde atual e futura, seria de extrema importância motivá-las a participar de programas de cuidados preventivos, como forma de incentivar hábitos alimentares e estilos de vida saudáveis. Uma atividade que pode ser incluída no Programa de Preparação para Aposentadoria (PPA) é um curso de culinária, especialmente se voltado para a alimentação saudável e de baixo custo, além de palestras que abordem tais conteúdos. 


\section{Referências bibliográficas}

AGENAIA NACIONAL DE SAÚDE SUPLEMENTAR (ANS). Resolução Normativa - RN n.211, de 11 de janeiro de 2010. Atualiza o Rol de Procedimentos e Eventos em Saúde, fixa as diretrizes de atenção à saúde e dá outras providências. Diário Oficial da República Federativa do Brasil, Brasília, 12 jan. 2010, p.31, Seção 1. AGÊNCIA NACIONAL DE SAÚDE SUPLEMENTAR (ANS). Resolução Normativa - RN n.338, de 21 de outubro de 2013. Atualiza o Rol de Procedimentos e Eventos em Saúde; fixa as diretrizes de atenção à saúde; revoga as Resoluções Normativas - RN n.211, de 11 de janeiro de 2010, RN n.262, de 1ํ de agosto de 2011, RN n.281, de 19 de dezembro de 2011 e a RN n.325, de 18 de abril de 2013; e dá outras providências. Diário Oficial da República Federativa do Brasil, Brasília, 22 out. 2013, p.51, Seção 1.

ALVARENGA, L. N. et al. Repercussões da aposentadoria na qualidade de vida do idoso. Rev. Esc. Enferm., USP, v.43, n.4, p.796802, 2009.

BATISTA FILHO, M. et al. Anemia e obesidade: um paradoxo da transição nutricional. Cadernos de Saúde Pública, Rio de Janeiro, v.24, supl. 2, 2008.

BÓS, A. J. G. Características fisiológicas do processo do envelhecimento. In: BUSNELLO, F. M. Aspectos nutricionais no processo de envelhecimento. São Paulo: Atheneu, 2007. p.3-15.

BRASIL. Guia alimentar para a população brasileira. Ministério da Saúde, Secretaria de Atenção à Saúde, Departamento de Atenção Básica. 2.ed. 156p. Brasília: Ministério da Saúde, 2014. Disponível em: http://bvsms.saude.gov.br/bvs/publicacoes/guia_alimentar _populacao_brasileira_2ed.pdf.

- Ministério da Saúde. Departamento de Informática do SUS (Datasus). Pesquisa Nacional de Saúde (PNS). 2013. Disponível em: http://www2.datasus.gov.br/DATASUS/index.php?area=0207. Acesso em: 3 mai. 2015.

Secretaria de Atenção à Saúde. Secretaria de Vigilância em Saúde. SB Brasil 2010: Pesquisa Nacional de Saúde Bucal: resultados principais. Brasília: Ministério da Saúde, 2012. 
BRASIL. Ministério da Saúde. Guia Alimentar da População Brasileira.

CAMPOS, M. T. F. S.; MONTEIRO, J. B. R.; ORNELAS, A. P. R. C. Fatores que afetam o consumo alimentar e a nutrição do idoso. Rev. Nutrição, 13(3), p.157-65, 2000.

DA CRUZ, I. B. M. et al. Prevalência de obesidade em idosos longevos e sua associação com fatores de risco de morbidades cardiovasculares. Rev. Assoc. Med. Bras., 50(2), p.172-7, 2004.

DUNNERAM, Y. et al. Determinants of Eating Habits Among Pre-Retired and Post-Retired Mauritians. International Journal of Nutrition and Food Sciences, 2(3), p.109-15, 2013.

FORMAN-HOFFMAN, V. L. et al. Retirement and Weight Changes Among Men and Women in the Health and Retirement Study. J. Gerontol. B. Psychol. Sci. Soc. Sci., 63(3), S146-S153, 2008.

FRANK, A. A.; SOARES, E. A. Nutrição no envelhecer. São Paulo: Atheneu, 2002.

FUNG, T. T. et al. Association Between Dietary Patterns and Plasma Biomarkers of Obesity and Cardiovascular Disease Risk. Am. J. Clin. Nutr., 73, p.61-7, 2001.

GIGANTE, D. P. et al. Prevalência de obesidade em adultos e seus fatores de risco. Rev. Saúde Pública, v.31, n.3, 1997.

GOMES, M. B. et al. Prevalência de sobrepeso e obesidade em pacientes com diabete mellitus do tipo 2 no Brasil: estudo multicêntrico nacional. Arq. Bras. Endocrinol. Metab., v.50, n.1, p.136-44, 2006.

HARRIS, N. G. Nutrição no envelhecimento. In: MAHAN, L. K.; SCOTT-STUMP, S. Krause: alimentos, nutrição \& dietoterapia. São Paulo: Roca, 2005. p.304-23.

INSTITUTO BRASILEIRO DE GEOGRAFIA E ESTATÍSTICA (IBGE). Sobre a condição de saúde dos idosos: indicadores selecionados Indicadores sociodemográficos e de saúde no Brasil, Rio de Janeiro, n.25, 2009. (Série de Estudos e Pesquisas Informação Demográfica e Socioeconômica.)

KENNY, A. M.; PRESTWOOD, K. M. Osteoporosis. Pathogenesis, Diagnosis and Treatment in Older Adults. Rheum. Dis. Clin. North Am., 26(3), p.569-91, 2000. 
LARA, J. et al. Effectiveness of Dietary Interventions Among Adults of Retirement Age: a Systematic Review and Meta-Analysis of Randomized Controlled Trials. BMC Medicine, p.12-60, abr. 2014. LAUQUE, S.; NOURASHEMI, F.; SOLEILHAVOUP, C. A Prospective Study of Changes on Nutritional Patterns 6 Months Before and 18 Months After Retirement. J. Nutr. Health Aging, 2, p.88-91, 1998.

LIMA, A. M. M. de; SILVA, H. S. da; GALHARDONI, R. Envelhecimento bem-sucedido: trajetórias de um constructo e novas fronteiras. Interface - Comunicação, Saúde, Educação, Botucatu (SP), v.12, n.27, p.795-807, 2008. Disponível em: www.scielo.br/ scielo.php? script $=$ sci_arttext $\&$ pid $=\mathrm{S} 1414-32832008000400010$. Acesso em: 18 mar. 2015.

LUNN, J. Nutrição e envelhecimento saudável. Nutrição em Pauta, São Paulo, n. 85, p.5-9, 2007.

MALAFAIA, G. As consequências das deficiências nutricionais, associadas à imunossenescência, na saúde do idoso. Arquivos Brasileiros de Ciência da Saúde, Ouro Preto (MG), v.33, n.3, p.168-76, 2008.

MARQUES, A. C. L. Relação da higiene bucal com a sensibilidade gustativa e nutrição em idosos. São José dos Campos, 2006. Dissertação (Mestrado) - Universidade Estadual Paulista.

MARUCCI, M. F. N.; ALVES, R. P.; GOMES, M. M. B. C. Nutrição na geriatria. In: SILVA, S. M. C. S.; MURA, J. D. P. (Orgs.). Tratado de alimentação, nutrição E dietoterapia. São Paulo: Roca, 2007. p.400-16.

McARDLE, W. D.; KATCH, F. I.; KATCH, V. C. Energy Physiology: Energy, Nutrition and Human Performance. 4.ed. Baltimore: Williams and Wilkins, 1996.

MONJON, P.; BUDTZ-JORGENSEN, E.; RAPIN, C. H. Relationship Between Oral Health and Nutrition in Very Old People. Age Ageing, 28, p.463-8, 1999.

NAJAS, M. S.; ANDREAZZA, R.; SOUZA, A. L. M. Eating Patterns Among the Elderly of Different Socioeconomic Groups Resident in an Urban Area of Southeastern Brazil. Rev. Saúde Pública, v.28, n.3, 1994. 
NOVAES, M. R. C. G. et al. Suplementação de micronutrientes na senescência: implicações nos mecanismos imunológicos. Rev. Nutr., Campinas, v.18, n.3, p.367-76, maio/jun. 2005.

PHILLIPI, S. T. et al. Pirâmide alimentar adaptada: guia para escolha dos alimentos. Rev. Nutr., 12, p.65-80, 1999.

POEHLMAN, E. T. et al. Influence of Age and Endurance Training on Metabolic Rate and Hormones in Healthy Men. J. Appl. Physiol., 259, p.E66-E72, 1990. (Endocrinol Metab 22.)

SAMBROOK, P.; COOPER, C. Osteoporosis. Lancet. 2006 Jun 17; 367(9527): 2010-8. Review. Erratum in: Lancet, 2006; 368(9529): 28.

SCHIMIDT, M. I. et al. Doenças crônicas não transmissíveis no Brasil: carga e desafio atual. The Lancet, New York, v.377, n.9.781, p.1.949-61, 2011.

SOUSA, A. G. et al. Perfil sociodemográfico e nutricional de servidores em período de pré-aposentadoria. Rev. Pesq. Saúde, 12(3), p.16-21, set./dez. 2011.

SOUSA, V. M. C.; MARUCCI, M. F. N.; SGARBIERI, V. C. Protein Requirements for the Elderly Population: Review. J. Brazilian Soc. Food Nutr., São Paulo, v.34, n.1, p.199-209, abr. 2009.

STEEN, B. et al. Age Retirement in Women II. Dietary Habits and Body Composition. Compr. Gerontol., 2, p.78-82, 1988.

WESTERTERP, K. R. Limits to Sustainable Human Metabolic Rate. J. Exp. Biol., 204, p.3.183-7, 2001.

WONG, M. C.; McMILLAN, A. S. Tooth Loss, Denture Wearing and Oral Health-Related Quality of Life in Elderly Chinese People. Community dent Health, 22(3), p.156-61, set. 2005. 


\title{
8 \\ OUTRAS POSSIBILIDADES PARA A APOSENTADORIA'
}

\author{
Raiana Lídice Mór Fukushima \\ André Luis Vicente \\ Gilson Fuzaro Junior \\ Melissa Riani Costa Machado \\ José Luiz Riani Costa
}

Com o objetivo de destacar a amplitude de temas e enfoques que podem ser contemplados em um Programa de Preparação para Aposentadoria (PPA), o presente capítulo traz três novas abordagens relacionadas ao envelhecimento e à aposentadoria: animais de estimação, cinema e meio ambiente.

\section{A convivência com animais de estimação}

A convivência com animais de estimação vem se tornando cada vez mais frequente nas famílias brasileiras. Segundo dados da Associação Brasileira da Indústria de Produtos para Animais de Estimação (Abinpet), em 2012, o Brasil ocupava a quarta posição no quadro mundial, com 106,2 milhões de animais domésticos, atrás somente da China (288,2 milhões), Estados Unidos (224,3 milhões) e do Reino Unido (148,3 milhões). Ainda de

1. Agradecimento a Carla Cristina Machado Riani Costa e Hugo Leonardo Riani Costa pela colaboração na revisão do capítulo. 
acordo com a Abinpet (2012), estima-se que o Brasil apresente um crescimento de $5 \%$ ao ano.

Outros autores concluíram que a presença de animais de estimação, especificamente cães e gatos, contribui para a estimulação de carinho e afeto nos seres humanos (Anderline; Anderline, 2007). Os animais de estimação podem ser considerados verdadeiros facilitadores sociais, além de promover a integração entre crianças, adultos e idosos.

Para Bryant (2008), muitas pessoas procuram suporte social para enfrentar situações desfavoráveis, como desarranjos familiares, luto pela morte do cônjuge ou ente querido, hospitalizações e mudança de lar, encontrando no animal de estimação parte desse suporte.

Beck e Katcher (2003) pontuaram que os seres humanos se sentem mais seguros em compartilhar momentos da vida com animais de estimação, uma vez que estes frequentemente estão disponíveis para suprir as necessidades de afeto (McNicholas et al., 2005).

\section{Animais de estimação no envelhecimento}

Além das comorbidades associadas ao processo de envelhecimento, os idosos, muitas vezes, apresentam desarranjos psicossociais devido à aposentadoria ou à transição para a aposentadoria, e consequente perda da posição social. Segundo Alvarenga et al. (2008), as repercussões da aposentadoria englobam valores pessoais, sociais, culturais e econômicos e cada indivíduo enfrenta essa transição de maneira diferente. Para alguns, a aposentadoria é vista de forma positiva e permite às pessoas uma reorganização da vida. Para outros, a aposentadoria é substancialmente prejudicial, podendo afetar sua saúde psíquica. Rodrigues et al. (2005) apontaram que sentimentos e sintomas como a ansiedade, depressão, irritabilidade e insatisfação em geral são manifestações que podem ser decorrentes da aposentadoria, e que estas estão fortemente relacio- 
nadas com a piora da qualidade de vida relacionada à saúde (QVRS).

Múltiplas terapias não medicamentosas têm se mostrado alternativas eficazes no tratamento de quadros crônicos, principalmente na população idosa, colaborando com a redução de gastos em internações hospitalares, consultas médicas e medicamentos (Berenstein; Wajnman, 2008). A atividade física, a dança e o tai chi chuan, por exemplo, podem promover inúmeras vantagens ao processo de envelhecimento ativo e saudável (Merom et al., 2013). A prática regular de atividade física pode ocasionar vantagens para o bem-estar geral do idoso, além de promover o engajamento social (Keogh et al., 2009), tendo efeito positivo sobre os sintomas depressivos (Lindwall et al., 2006). Lail, McCormack e Rock (2011) realizaram uma investigação no Canadá com 428 participantes, na qual se identificou que indivíduos que possuíam cães eram mais sujeitos a praticar caminhadas recreativas pela vizinhança, quando comparados com indivíduos que não tinham cães, em todas as estações do ano, permitindo, assim, que esses indivíduos se mantivessem ativos por um período prolongado.

Alguns estudos buscaram identificar os benefícios sociais e psicológicos para a população idosa relacionados ao convívio com os animais domésticos. Heiden e Santos (2009), em sua investigação com 51 idosos participantes de grupos de terceira idade, com idade entre 60 e 84 anos, verificaram que os animais proporcionam alegria, companhia, segurança, passatempo e distração para os idosos, além de esses animais estabelecerem um vínculo afetivo com seu dono, sendo considerados, em alguns casos, parte da família. Costa et al. (2009) realizaram uma pesquisa com duzentas idosas, divididas em dois grupos (as que conviviam e as que não conviviam com animais), e observaram que a convivência com animal de estimação foi capaz de preencher a carência afetiva.

De acordo com Triebenbacher (2000), os animais são capazes de desempenhar diversos papéis na vida dos indivíduos, desde a figura de um amigo próximo até de um membro da família, e por 
esse motivo são considerados fundamentais nas etapas de transição da vida, como separação, aposentadoria e velhice.

Nessa perspectiva, pode-se afirmar que o convívio com animais domésticos pode ter efeitos benéficos para os seres humanos. No entanto, ter um animal doméstico exige determinadas responsabilidades e cuidados que, em alguns casos, os idosos não conseguem desempenhar.

Fabrício, Rodrigues e Costa (2004), em uma pesquisa sobre as causas e consequências das quedas na população idosa, identificaram que a presença de animais domésticos pode ocasionar a queda, principalmente se o equilíbrio e a marcha do idoso estiverem prejudicados. Barbosa e Nascimento (2001), em uma análise sobre a incidência de internações por motivo de quedas, observaram que a presença de animais domésticos pela casa é um dos fatores extrínsecos que podem aumentar a incidência desses acidentes. Diversas outras investigações também identificaram a companhia de animais domésticos como um fator de risco para quedas no âmbito residencial (Messias; Neves, 2009; Yamazaki; Ferreira, 2013).

Quando os animais não são adequadamente adestrados, há um risco maior de mordeduras e arranhaduras que podem ocasionar lesões propensas a infecção.

Além do risco de quedas, mordeduras e arranhaduras, é importante lembrar que animais de estimação, especialmente se não vacinados e vermifugados, podem transmitir doenças às pessoas, pelo contato direto ou indireto (Pereira; Ferreira, 2012). De acordo com Neto et al. (2011), são escassas as informações básicas sobre a posse responsável de animais de estimação e o risco de zoonoses, sendo necessária a maior divulgação dessas informações como maneira de reduzir os riscos à saúde e elevar a segurança da população em destaque.

Cabe também lembrar o peso econômico que a posse desses animais pode representar, com alimentação, cuidados gerais (banho e tosa), consultas e medicamentos. Outro aspecto que merece uma abordagem é o trabalho adicional que a manutenção da higiene da casa pode significar. Finalmente, é importante ter em mente que, 
como a expectativa de vida desses animais é bem menor que a dos humanos, pode ser um sofrimento o luto pela morte do animal de estimação.

Diante dos aspectos aqui levantados, recomenda-se que discussões sobre essa temática sejam incluídas no PPA, para que a posse de um animal de companhia em casa, sob orientação correta, possa promover efeitos benéficos aos indivíduos que estão passando pelo processo de aposentadoria e envelhecimento, além de ajudar a minimizar os riscos relacionados a essa posse.

\section{Intervenção assistida por animais}

Alguns estudos observaram que a população idosa pode obter benefícios por meio da intervenção assistida por animais (IAA) (Colombo et al., 2006; Banks; Banks, 2002; Stasi et al., 2004).

O termo IAA inclui duas categorias: a terapia assistida por animais (TAA), ou pet-terapia, e as atividades assistidas por animais (AAA).

A pet-terapia é uma intervenção realizada com animais que possui objetivos específicos, sendo parte de um processo de tratamento e deve ser acompanhada e supervisionada por um profissional da área de saúde que, conforme seu enfoque profissional, terá metas distintas e específicas para cada indivíduo. Segundo a organização Delta Society (atualmente conhecida como Pet Partners), essa ação tem por finalidade intervir no desempenho físico, social, emocional e cognitivo dos indivíduos.

Por outro lado, a AAA refere-se às atividades elaboradas com animais que oferecem oportunidades recreativas, bem como motivacionais e educacionais, com o objetivo de aperfeiçoar a qualidade de vida dos indivíduos (Queiroz, 2014). Nessa modalidade, não há um objetivo terapêutico específico.

A pet-terapia é entendida como uma terapia não farmacológica que, segundo Queiroz (2014), é capaz de trazer múltiplos benefícios a distintos grupos de indivíduos. Diversos autores já obser- 
varam resultados satisfatórios da pet-terapia. Para Moretti et al. (2011) e Berget, Ekeberg e Braastad (2008), a pet-terapia mostrou-se eficaz na diminuição de sintomas em pacientes com desordens psiquiátricas, assim como no auxílio a indivíduos com dependência química (Wesley; Minatrea; Watson, 2009), além da otimização da qualidade de vida em idosos residentes em instituições de longa permanência (Colombo et al., 2006). Stumm et al. (2012) observaram em um estudo com idosas com transtornos mentais que a pet-terapia aplicada em uma instituição de longa permanência teve como resultado a melhora do humor e interação entre as idosas e o maior vínculo entre a equipe, os médicos e pacientes, facilitando o cuidado.

Vale lembrar que todo animal de estimação deve estar em condições saudáveis, apto para ser utilizado nessas atividades e com todas as vacinas em dia, devidamente avaliado pelo veterinário (Verklan, 2015), com a finalidade de minimizar potenciais riscos.

Segundo estudos nacionais e internacionais, o animal mais utilizado em pet-terapia é o cão (Morrison, 2007), mas também podem ser utilizados animais como pássaros (Verklan, 2015), gatos (Hanson et al., 2008), cavalos (Bass; Duchowny; Llabre, 2009) e até mesmo animais robóticos (Ribi; Yokoyama; Turner, 2008; Kramer; Friedmann; Bernstein, 2009).

Toigo, Leal e Ávila (2008) desenvolveram uma pesquisa experimental com dez idosas entre 60 e 74 anos, moradoras do município de Caxias do Sul (RS), e observaram que sessões semanais de equoterapia, ou terapia com cavalos, resultaram na otimização do equilíbrio estático, reduzindo as possibilidades de desequilíbrios e, consequentemente, o risco de quedas. Silveira e Wibelinger (2011) concluíram em seu estudo que a equoterapia é uma alternativa inovadora e eficaz, capaz de melhorar a qualidade de vida e bem-estar do idoso.

Pode-se constatar que a pet-terapia é uma prática relativamente recente no Brasil, mas vem sendo considerada eficaz na vida diária de idosos, podendo auxiliar positivamente nos processos de cura e reabilitação de diversas doenças. Mais raro ainda é o desen- 
volvimento de atividades com animais com finalidades recreativas em idosos ou integrando um PPA.

\section{Cinema depois do trabalho}

O cinema tem sido utilizado como um recurso audiovisual em atividades educacionais, pois alia a força das imagens aos efeitos sonoros, complementando as informações do texto da narrativa. Assim, o cinema pode ser utilizado como ferramenta pedagógica, possibilita um elevado grau de comunicação e abre a possibilidade de discussão das questões humanas em diferentes perspectivas, abordando diversas esferas da vida.

As atividades culturais, assim como as de turismo e lazer, são importantes componentes de um PPA. Muitos trabalhadores têm dificuldade de acesso a essas atividades durante o período da vida fortemente marcado pelo trabalho, especialmente pela falta de tempo, aliada a dificuldades econômicas e responsabilidades com a família. Além disso, há uma concentração de equipamentos culturais na área central das cidades.

A utilização do cinema no âmbito do PPA tem o propósito de estimular a inclusão de projetos culturais e de lazer nos programas voltados à preparação para a aposentadoria e nas políticas públicas voltadas à população idosa. No caso do Núcleo Local Unesp-Unati, no câmpus de Rio Claro, o cinema tem sido utilizado como alternativa de educação não formal, tanto para idosos da comunidade como para os servidores que se preparam para a aposentadoria, além de ser reconhecido como uma atividade de lazer e entretenimento.

Em 2008, com o objetivo de superar a dificuldade de acesso da população idosa ao cinema, foi implantado na Unesp/Rio Claro o Projeto de Extensão "Cinema, Educação e Saúde", junto ao Departamento de Educação Física, do Instituto de Biociências. O projeto promoveu a exibição semanal de filmes envolvendo temas relacionados à saúde ou ao processo de envelhecimento, destinado aos 
participantes de outros projetos de Extensão Universitária do câmpus, especialmente o Programa de Atividade Física para a Terceira Idade (Profit), e aberto a toda a população idosa do município. Nos últimos anos, o convite estendeu-se aos servidores que se encontram próximos da aposentadoria. Mais recentemente, essa atividade deixou de se constituir como um projeto de extensão isolado e passou a integrar o Projeto de Extensão PPA-Unesp/Rio Claro, mantendo a mesma dinâmica.

No início de cada sessão de cinema do projeto é feita uma breve apresentação do filme, buscando destacar os aspectos relacionados à temática central e esclarecer questões técnicas ou relativas ao gênero do filme, com o cuidado de não inibir as diversas percepções possíveis. Em seguida, o filme é exibido em uma sala apropriada e ao final da sessão abre-se uma roda de conversa, visando à discussão de situações do filme relacionadas à realidade dos participantes, como uma possibilidade de estímulo e reflexão sobre a vida e o cotidiano. Os benefícios aos idosos incluem a sociabilidade e a oportunidade de reformular percepções que auxiliem a construção de novas formas de viver. Alguns dos filmes exibidos ao longo desses anos estão listados no Anexo deste livro.

Diferentes aspectos do envelhecimento e da aposentadoria são tratados de diversas formas em diferentes gêneros do cinema, de forma implícita ou explícita, em que as percepções dependem do olhar do indivíduo, influenciado pelo contexto.

Para mostrar a grande diversidade dessa arte, são exibidos filmes de diversos gêneros: dramas, comédias, documentários, curtas, filmes antigos e recentes, nacionais e estrangeiros (americanos, italianos, canadenses, franceses, espanhóis, argentinos, entre outros).

Ações de educação não formal voltadas à população idosa podem ganhar novos ares com a utilização da linguagem do cinema no processo ensino-aprendizagem, integrando a discussão de temas relacionados à determinação da saúde com outras políticas sociais, especialmente educação e cultura. Além disso, o fato de o idoso sair de casa cria a oportunidade de convívio social e aumenta as chances 
de envolver-se em programas de promoção da saúde, especialmente a prática regular de atividade física.

A presença de jovens e crianças em alguns dos filmes pode permitir um contato intergeracional que facilita trocas de experiências e saberes, evidenciando que um mesmo tema pode comportar diferentes pontos de vista.

\section{Envelhecimento, aposentadoria e meio ambiente}

Um dos temas menos abordados nas discussões que envolvem o envelhecimento e a aposentadoria é a questão ambiental. Chama a atenção o fato de essa temática não ter merecido qualquer referência na Lei da Política Nacional do Idoso (Brasil, 1994) ou no Estatuto do Idoso (Brasil, 2003), especialmente se considerada a ampla divulgação que vem sendo feita a respeito nas últimas décadas. O silêncio em relação aos problemas ambientais na legislação voltada à população idosa é ainda mais preocupante, pois esses problemas têm um impacto intensificado nesse grupo etário, como o caso da poluição urbana.

Nessa perspectiva, além de palestras, filmes e rodas de conversa envolvendo a temática ambiental, o PPA pode incluir algumas atividades ligadas ao meio ambiente, com destaque para as atividades físicas em áreas ecológicas (bosques, matas, hortos etc.), como:

a) "Caminhadas do Conhecimento", com monitores de várias áreas: Educação Física, Biologia, Ecologia, Geografia, Geologia etc.

b) Ginástica natural/ecológica, utilizando as condições naturais de relevo e vegetação de reservas ecológicas.

c) Atividades de ciclismo e montaria a cavalo em trilhas no espaço periurbano ou rural. 
Idealmente, tais atividades devem ter um caráter interdisciplinar e multissetorial, incluindo meio ambiente, educação, saúde, cultura, esporte, lazer e turismo.

Além disso, o PPA pode estimular a apresentação de propostas relacionadas ao meio ambiente nas políticas públicas voltadas à população idosa, tais como:

- Arborização de ruas, avenidas, praças e jardins utilizando árvores adequadas ao espaço urbano, conciliando os aspectos técnicos com as preferências da população. Poderia haver uma padronização por ruas, por quadras ou por bairros. Entre as variedades de plantas utilizadas, deveriam ser incluídas árvores características da vegetação nativa e árvores frutíferas, muitas delas fortemente associadas à época da infância dos atuais idosos.

- Apoio a hortas comunitárias e ao plantio de ervas medicinais, que representam tanto um benefício direto para os produtores, enriquecendo a alimentação e os cuidados de saúde, quanto podem significar uma fonte adicional de renda. Poderiam ser utilizados terrenos próprios do poder público, vazios urbanos e espaços ociosos das instituições que desenvolvem ações voltadas aos idosos, creches municipais, escolas etc.

- Implantação de bosques de vizinhança, integrando a recuperação ambiental com locais para a prática de atividades físicas e lazer. Seria interessante constituir espaços que lembrassem os antigos quintais e as fazendas onde muitos idosos passaram boa parte de sua infância e juventude.

- Apoio ao plantio de árvores nos quintais e jardins das residências, com o fornecimento de mudas e orientação técnica, além da instituição de estímulos, como a redução de tributos proporcional à área cultivada.

Outra possibilidade é desenvolver atividades que recuperem as informações acumuladas pelos idosos a respeito das transforma- 
ções promovidas no meio ambiente, tanto o natural como o construído pelo homem. Nessa atividade, é fundamental a participação de pessoas de diferentes idades, com ganhos adicionais em função do contato intergeracional.

\section{A participação de idosos na educação ambiental}

Os conhecimentos e experiências acumulados pela população idosa podem ser compartilhados com as novas gerações, proporcionando ao educando o contato, ainda que indireto, com o antigo meio, através de histórias e fotografias que resgatem a herança da família e sua ligação à terra. Quanto maior a diversidade de idades entre os participantes, mais rica a atividade, pois é importante que todos tenham consciência das transformações que a humanidade está provocando no meio ambiente, especialmente no processo de urbanização. Com base nessas reflexões foi elaborado um trabalho intitulado "Vovô e vovó como educadores ambientais" (Costa; Costa, 2003), apresentado em eventos de educação ambiental, que serviu de fundamento para as discussões aqui apresentadas.

Uma das técnicas utilizadas é a Memória Viva, que busca conhecer os fatos ocorridos no passado, com possibilidade de recriar, reconstruir ou retratar o meio ambiente e as características da vida na cidade e no campo para, com visão crítica, associar as mudanças promovidas no decorrer dos tempos (Cetesb, 2001).

Nessa atividade são colhidos depoimentos de pessoas idosas que vivem na comunidade, sendo interessante incluir os próprios avós dos participantes, além de comerciantes, funcionários da prefeitura e moradores da vizinhança que tenham raízes antigas no bairro e/ou cidade.

O relato deve ser livre, podendo seguir um roteiro que inclua dados sobre:

- A casa em que morava, como era feita, se existia quintal grande, horta, pomar. 
- A escola onde estudou, o trajeto da casa à escola, as brincadeiras e jogos etc.

- O que havia no local antes que o bairro fosse criado (fazenda, várzea etc.).

- Como eram os rios, riachos ou córregos que passavam pela cidade.

- Como eram os hábitos alimentares e a conservação dos alimentos.

- Como era feito o abastecimento de água (poço, diretamente do rio etc.).

- Como eram os meios de transporte e comunicação e as formas de energia.

- Quais eram as atividades econômicas predominantes e como se modificaram (Cetesb, 2001).

Em uma experiência desenvolvida nos Estados Unidos por Herman et al. (1992 apud Cetesb, 2001), os alunos entrevistavam seus avós e outros moradores antigos, documentando, com áudio e vídeo, atividades quase esquecidas, como a técnica de plantar seguindo as fases da lua, curtir couro, fiar e tecer. Os estudantes também percorriam as comunidades rurais para aprender sobre os hábitos e para ouvir histórias dos mais velhos. $\mathrm{O}$ folclore voltou a ocupar seu lugar; "emergiram charadas, jogos, ritos de passagem, festivais da terra, conhecimentos sobre o clima, medicina, arquitetura, lendas, preservação de alimentos, ferramentas e técnicas da agricultura" (Cetesb, 2001).

O mais interessante é que os idosos se beneficiam muito da atividade, na medida em que, além de reviverem momentos marcantes de suas vidas, sentem-se úteis e integrados na comunidade. Nessa atividade, todos os participantes saem ganhando, pois se conscientizam de que fazem parte de um grupo maior de pessoas, as quais têm características comuns (Cetesb, 2001).

Para a realização das atividades propostas, é importante envolver as entidades representativas dos idosos, além de contar com 
profissionais que tenham conhecimento técnico a oferecer para o aprimoramento do processo.

Outras atividades que também podem ser incluídas em um PPA:

- Estudar a vegetação e a paisagem urbana retratada em antigas fotografias e visitar os locais procurando analisar as mudanças.

- Voltar a um local que os idosos gostavam de frequentar quando jovens, conversando sobre o que havia ali e o que faziam.

- Descrever, com a ajuda dos migrantes, a história de seus locais de origem, destacando o uso da terra, a agricultura, a pesca etc.

- Através de um álbum de fotografias, estimular a discussão, indo além da identificação das pessoas e da relação de parentesco, procurando observar evidências da paisagem e de estilos de vida.

- Organizar uma exposição de fotos e objetos antigos da instituição ou empresa, estimulando que a história seja contada. (Cetesb, 2001)

Em Rio Claro (SP), a Lei da Política Municipal do Idoso (Rio Claro, 2004) incluiu essa questão nos seguintes termos:

Art. 28. O órgão municipal responsável pela área de Meio Ambiente deve:

a) Aproveitar o conhecimento da população idosa sobre a questão ambiental, como uso da água, tipo de alimento e história dos rios da cidade, enriquecendo as atividades de educação e cultura através de relatos para alunos do ensino fundamental e produção de documentários.

Em outro ponto da lei, o tema é retomado na perspectiva da integração do idoso com as demais gerações. 
Art. 31. Devem ser desenvolvidas ações que propiciem a integração do idoso com as demais gerações, bem como a reflexão sobre o processo de envelhecimento e as condições de vida da população idosa, devendo incluir:

a) realização de visitas de alunos dos diferentes níveis de ensino às instituições que prestam atendimento aos idosos, com desenvolvimento de atividades de integração e recreação;

b) estímulo à participação de idosos nas comemorações e datas cívicas;

c) realização de passeios para os idosos dos Grupos de Terceira Idade e Instituições de Longa Permanência para Idosos pela área urbana, preferencialmente com orientação e objetivos preestabelecidos;

d) estímulo ao contato da população idosa com as demais gerações, nos diferentes espaços de atuação destas (escolas, serviços de saúde, locais de trabalho etc.);

e) apoio a projetos para restauração de vagões de trens e de dependências da Fepasa (Estação Ferroviária, oficinas etc.), visando à implantação de programas que estimulem o intercâmbio de culturas e o resgate da memória. (Rio Claro, 2004)

Uma aplicação desses preceitos foi a exposição A história feita por nós, realizada por ocasião da XXVII Semana Municipal do Idoso, em 2009, que contou com fotos antigas da cidade, em tamanho ampliado, incluindo edificações que foram demolidas, atividades profissionais extintas, veículos antigos, carnaval de rua etc. Uma das idosas, ao sair da exposição, disse que foi emocionante rever locais que hoje estão tão modificados e destacou uma foto de uma antiga confeitaria que existia no centro da cidade. "Eu fiquei parada na frente daquela foto e me senti menina, com água na boca, indo comprar meu doce preferido. Senti até as pedras do calçamento da rua nos meus pés." 


\section{Referências bibliográficas}

ALVARENGA, L. N. et al. Repercussões da aposentadoria na qualidade de vida do idoso. Rev. Esc. Enferm. USP, v.43, n.4, p.796802, 2008.

ANDERLINE, G. P. O. S.; ANDERLINE, G. A. Benefícios do envolvimento do animal de companhia (cão e gato) na terapia, na socialização, e bem-estar das pessoas e o papel do médico veterinário. Rev. CFMV, v.1, n.41, p.70-5, 2007.

ASSOCIAÇÃOBRASILEIRA DA INDÚSTRIA DE PRODUTOS PARA ANIMAIS DE ESTIMAÇÃO (Abinpet). 2012. Disponível em: http://abinpet.org.br/imprensa/noticias/populacaode-pets-cresce-5-ao-ano-e-brasil-e-quarto-no-ranking-mundial/. Acesso em: mar. 2015.

BANKS, M. R.; BANKS, W. A. The Effects of Animal-Assisted Therapy on Loneliness in an Elderly Population in Long-Term Care Facilities. J. Gerontol., v.57, n.7, p.428-32, 2002.

BARBOSA, M. L. J.; NASCIMENTO, E. F. A. Incidência de internações de idosos por motivo de quedas, em um hospital geral de Taubaté. Rev. Biociênc., v.7, n.1, p.35-42, 2001.

BASS, M. M.; DUCHOWNY, C. A.; LLABRE, M. M. The Effect of Therapeutic Horseback Riding on Social Functioning in Children with Autism. J. Autism DevDisord, v.39, n.9, p.1.261-7, 2009 .

BECK, A. M.; KATCHER, A. H. Future Directions in Human-Animal Bond Research. American Behaviorial Scientist, v.47, n.1, p.79-93, 2003.

BERENSTEIN, C. K.; WAJNMAN, S. Efeitos da estrutura etária nos gastos com internação no Sistema Único de Saúde: uma análise de decomposição para duas áreas metropolitanas brasileiras. Cad. Saúde Pública, v.24, n.10, p.2.301-13, 2008.

BERGET, B.; EKEBERG, O.; BRAASTAD, B. O. Animal-Assisted Therapy with Farm Animals for Persons with Psychiatric Disorders: Effects on Self-Efficacy, Coping Ability and Quality of Life, a Randomized Controlled Trial. Clin. Pract. Epidemiol. Ment. Health, v.4, n.9, 2008. 
BRASIL. Lei n.10.741, de 1ㅇ de outubro de 2003, que cria o Estatuto do Idoso e dá outras providências, 2003.

. Lei n.8.842, de 4 de janeiro de 1994, que dispõe sobre a Política Nacional do Idoso, 1994.

BRYANT, B. K. Social Support in Relation to Human Animal Interaction. 2008. Paper Presented at the NICHD/Mars Meeting on Directions in Human-Animal Interaction Research: Child Development, Health and Therapeutic Interventions.

COLOMBO, G. et al. Pet Therapy and Institutionalized Elderly: a Study on 144 Cognitively Unimpaired Subjects. Arch. Gerontol. Geriatr., v.42, n.2, p.207-16, 2006.

COMPANHIA DE TECNOLOGIA DE SANEAMENTO AMBIENTAL DO ESTADO DE SÃO PAULO (Cetesb). Cartilha Educação e Participação. 2001.

COSTA, E. C. et al. Aspectos psicossociais da convivência de idosas com animais de estimação: uma interação social interativa. Psicol. Teor. Prat., v.11, n.3, p.2-15, 2009.

COSTA, M. R.; COSTA, J. L. R. Vovô e vovó como educadores ambientais. SEMINÁRIO DE EDUCAÇÃO AMBIENTAL, Rio Claro, 2003. Anais do...

FABRÍCiO, S. C. C.; RODRIGUES, R. A. P.; COSTA, M. L. Causas e consequências de quedas de idosos atendidos em hospital público. Rev. Saúde Pública, v.38, n.1, p.93-9, 2004.

HANSON, L. M. et al. Physiological Responses by College Students to a Dog and a Cat: Implications for Pet Therapy. N. Am. J. Psychol., v.10, n.3, p.519, 2008.

HEIDEN, J.; SANTOS, W. Benefícios psicológicos da convivência com animais de estimação para os idosos. Agora, v.16, n.2, p.48796, 2009.

KEOGH, J. W. L. et al. Physical Benefits of Dancing for Healthy Older Adults: a Review. J. Aging Phys. Act, v.17, n.4, p.479-500, 2009.

KRAMER, S. C.; FRIEDMANN, E.; BERNSTEIN, P. L. Comparison of the Effect of Human Interaction, Animal-Assisted Therapy and AIBO Assisted Therapy on Long-Term Care Residents with Dementia. Anthrozoös, v.22, n.1, p.43-57, 2009. 
LAIL, P.; McCORMACK, G. R.; ROCK, M. Does Dog-Ownership Influence Seasonal Patterns of Neighbourhood Based Walking Among Adults? A Longitudinal Study. BMC Public Health, 11(1), p.148-55, mar. 2011. )

LINDWALL, M. et al. Depression and Exercise in Elderly Men and Women: Findings from the Swedish National Study on Aging and Care. J. Aging Phys. Act, v.15, n.1, p.41-55, 2006.

McNICHOLAS, J. et al. Pet Ownership and Human Health: a Brief Review of Evidence and Issues. BMJ, v.331, n.7.527, p.1.252-4, 2005.

MEROM, D. et al. Can Social Dancing Prevent Fall in Older Adults? A Protocol of the Dance, Aging, Cognition, Economic (DAnCE) Fall Prevention Randomized Controlled Trial. BMC Public Health, v.13, n.1, p.477, 2013.

MESSIAS, M. G.; NEVES, R. F. A influência de fatores comportamentais e ambientais domésticos nas quedas em idosos. Rev. Bras. Geriatr. Gerontol., v.12, n.2, p.275-82, 2009.

MORETTI, F. et al. Pet Therapy in Elderly Patients with Mental Illness. Psychogeriatrics, v.11, n.2, p.125-9, 2011.

MORRISON, M. L. Health Benefits of Animal-Assisted Interventions. Complementary Health Practice Review, v.12, n.1, p.51-62, 2007.

NETO, L. C. et al. Programa de conscientização de idosos sobre posse responsável de animais de estimação em bairro periférico do município de Araçatuba, SP. Rev. Ciênc. Ext., v.7, n.2, p.102, 2011.

PEREIRA, C. R. A.; FERREIRA, A. P. Ocorrência e fatores de risco da criptosporidiose em felinos de companhia de idosos. Rev. Bras. Gerontol., v.15, n.4, p.681-91, 2012.

PET PARTNERS. Pet Therapy Program. Disponível em: http:// www.petpartners.org/PPTherapyAnimalProgram. Acesso em: mar. 2015.

QUEIROZ, R. C. F. B. Eficácia da intervenção assistida por animais na autopercepção de saúde, autoestima, sintomas depressivos e qualidade de vida relacionada à saúde em idosos residentes em instituição de longa permanência. Porto Alegre, 2014. p.119. Tese (Doutorado em Gerontologia Biomédica) - Pontifícia Universidade Católica do Rio Grande do Sul. 
RIBI, F. N.; YOKOYAMA, A.; TURNER, D. C. Comparison of Children's Behavior Toward Sony's Robotic Dog Aibo and a Real Dog: a Pilot Study (Report). Anthrozoös, v.21, n.3, p.245-56, 2008. RIO CLARO. Lei n.3.498, de 16 de dezembro de 2004, que instituiu a Política Municipal do Idoso de Rio Claro, 2004.

RODRIGUES, M. et al. A preparação para a aposentadoria: o papel do psicólogo frente a essa questão. Rev. Bras. Orientac. Prof., v.6, n.1, 2005.

SILVEIRA, M. M.; WIBELINGER, L. M. Equoterapia: qualidade de vida para o idoso sobre o cavalo. Kairós - Rev. da Facul. de Cien. Human. e Saúde, v.14, n.1, p.181-93, 2011.

STASI, M. F. et al. Pet Therapy: a Trial for Institutionalized Frail Elderly Patient. Arch. Gerontol. Geriat., v.38, supl.9, p.407-12, 2004. STUMM, K. E. et al. Terapia assistida por animais como facilitadora no cuidado a mulheres idosas institucionalizadas. REUFSM Rev. Enf da UFSM, v.2, n.1, p.205-12, 2012.

TOIGO, T.; LEAL JR., E. C. P.; ÁVILA, S. N. O uso da equoterapia como recurso terapêutico para melhora do equilíbrio estático em indivíduos da terceira idade. Rev. Bras. Geriatr. Gerontol., v.11, n.3, p.391-403, 2008.

TRIEBENBACHER, S. L. The Companion Animal within the Family System: the Manner in Which Animals Enhance Life within the Home. In: FINE, A. H. (Ed.). Handbook on Animal-Assisted Therapy: Theoretical Foundations and Guidelines for Practice. San Diego: Academic Press, 2000. p.481.

VERKLAN, T. M. Can my Pet Come with me, Please? Journal of Perinatal Eं Neonatal Nursing, v.29, n.1, p.91-2, 2015.

Wesley, M. C.; MinAtreA, N. B.; WATSON, J. C. Animal Assisted Therapy on the Treatment of Substance Dependence. Anthorozoös, v.22, n.2, p.137-48, 2009.

YAMAZAKI, A. L.; FERREIRA, E. G. Identificação dos fatores de risco relacionados a quedas em idosos inseridos na estratégia saúde da família. Rev. Saúde e Pesquisa, v.6, n.1, p.93-8, 2013. 


\title{
9 \\ BASES PARA UM PROGRAMA DE PREPARAÇÃO PARA A APOSENTADORIA
}

\author{
Amarilis Maria Muscari Riani Costa \\ José Luiz Riani Costa
}

Dependendo de uma série de fatores, o tempo pós-aposentadoria pode significar um dos melhores períodos da vida. Mas muitas coisas que acontecem nessa etapa não dependem apenas da pessoa, como o aparecimento de problemas de saúde na família ou o agravamento da situação financeira.

A legislação atribui responsabilidade pela implantação de Programa de Preparação para Aposentadoria (PPA) ao poder público e às empresas, mas não prevê penalidade para quem não cumprir esse preceito. Assim, ainda são raras as experiências nesse campo.

Os PPAs devem contar com a participação de uma equipe multiprofissional, capaz de ajudar os trabalhadores a superarem essa nova etapa, garantindo espaços para que as pessoas falem sobre suas expectativas, ansiedades e medos, devendo contar com apoio psicológico, quando necessário. Também é importante conhecer a experiência de outras pessoas que já estão aposentadas.

Uma das atividades mais frequentes nas experiências de PPA conhecidas é a realização de palestras abordando temas como: aspectos previdenciários, financeiros, legais, psicológicos e sociais da aposentadoria; envelhecimento ativo; alimentação saudável; dicas de lazer, cultura e turismo; relatos de experiência de outras instituições, além de outros temas que as pessoas podem sugerir, em função de suas necessidades específicas. Também compete ao PPA 
prover informações sobre diversas questões que podem interessar aos aposentados, como os recursos socioculturais e serviços da comunidade disponíveis a esse segmento da sociedade.

Mas um PPA não deve se limitar a palestras, sendo fundamental incluir rodas de conversa que criem um clima favorável à manifestação livre dos trabalhadores. Também são importantes as atividades físicas e as culturais, como as sessões de cinema acompanhadas por debate. Outras opções são vivências de relaxamento e meditação, oficinas de artes, jardinagem, culinária etc.

Como estão sendo discutidas alterações nas regras da aposentadoria, é preciso conhecer as normas vigentes e as mudanças que estão em curso, para decidir o melhor momento de formalizar o pedido de aposentadoria. O INSS e outros órgãos de previdência contam com programas de informação e esclarecimento sobre esses aspectos e devem ser procurados tanto pelos trabalhadores individualmente como pelos setores de recursos humanos/gestão de pessoas das instituições públicas e privadas.

Outro aspecto importante é transmitir ao trabalhador que a aposentadoria é um direito, resultante da luta de muitos que nos antecederam, e deve ser um tempo que permita a realização plena como pessoa que tem uma missão que vai muito além do mundo do trabalho.

Cabe destacar que os programas devem desenvolver suas ações com base nos seguintes princípios: participação opcional, respeito à decisão sobre o momento da aposentadoria, incentivo à autonomia nas suas decisões, participação na escolha das ações a serem desenvolvidas, observação do contexto cultural, incentivo à participação dos cônjuges em algumas atividades do programa, engajamento dos diversos níveis hierárquicos.

Embora a participação dos trabalhadores nas atividades do PPA deva ser opcional, advoga-se que todo PPA conte com um módulo básico oferecido a todos os trabalhadores que se aproximam da aposentadoria, com o objetivo de sensibilizar e motivar a participação nas diferentes atividades que compõem o programa. 
As reflexões levadas a cabo ao longo dos últimos anos, complementadas pelas informações colhidas na bibliografia utilizada, permitiram a formulação de diversas propostas para a implantação ou implementação de PPA, que estão agrupadas como se segue.

\section{Características gerais do PPA}

- As atividades do PPA devem ser realizadas durante a jornada de trabalho, sendo garantida a dispensa para participar.

- Os aposentados também devem ser convidados a participar das atividades do PPA.

\section{Propostas relacionadas à organização de um PPA}

- Formalizar a implantação do PPA, esclarecendo todos os segmentos envolvidos, especialmente chefes e supervisores, sobre os fundamentos do PPA.

- Estruturar um programa contínuo, com orientação e apoio permanentes, e não apenas com atividades pontuais e episódicas.

- Incluir palestras que abordem temas sugeridos pelos participantes do programa.

- Não limitar as atividades do PPA a palestras, sendo preciso privilegiar momentos de apoio e orientação individual, com profissionais capacitados, além de atividades físicas, culturais, vivências, oficinas etc.

- Incluir no PPA temas relacionados ao protagonismo do idoso, incluindo formação para o exercício do controle social, junto aos conselhos e conferências.

- Oferecer cursos de xadrez, línguas, instrumentos musicais diversos etc., incluindo os que se preparam para a aposentadoria e os aposentados. 
- Organizar palestras e outras atividades (atividades físicas/ esportivas, oficinas, festas, gincanas, excursões, exposição de fotos antigas, exposição de trabalhos que estão realizando, organização de atividades voluntárias) que possam facilitar a interação entre aposentados e trabalhadores em atividade, incluindo atividades intergeracionais.

- Divulgar a rede de apoio social existente no município, para as instituições, associações, sindicatos, entidades governamentais e não governamentais e a todos os trabalhadores, incluindo os aposentados e pensionistas.

- Incluir debates sobre as mudanças na legislação que rege a aposentadoria.

\section{Propostas que podem ser adotadas como complementação do PPA}

- Educação permanente dos profissionais da área de recursos humanos especificamente para orientação dos trabalhadores em relação à aposentadoria, contando com a participação de assistente social e psicólogo para qualificar esse atendimento.

- Estruturar um programa de saúde dirigido aos trabalhadores que se encontram próximos da aposentadoria e aos que já se aposentaram.

- Criar espaço físico para que os aposentados possam se encontrar, com computador com acesso à internet, livros, jornais, revistas e outros materiais de interesse.

- Intensificar a oferta de oportunidade de formação aos trabalhadores, em todos os níveis de ensino, incluindo os que estão mais próximos da aposentadoria.

- Paralelamente às ações que devem ser desenvolvidas pelas instituições, propõe-se que os sindicatos e associações de trabalhadores criem diretorias voltadas aos assuntos de in- 
teresse dos aposentados, incluindo orientação jurídica, como já acontece em alguns.

Com o objetivo de exemplificar diversos aspectos que podem ser contemplados em um PPA, são apresentados no Apêndice deste livro alguns links relacionados aos "10 Mandamentos da Aposentadoria Feliz", com áudios que contemplam temas abordados ao longo deste livro.

Os 10 Mandamentos para uma aposentadoria feliz apontam algumas ações que podem fazer toda diferença na qualidade de vida no pós-trabalho, e que podem ser assim resumidas:

I - Prepare-se para esta nova fase da vida, inclusive emocionalmente.

II - Mantenha-se sempre ativo: caminhe, jogue, brinque e, sobretudo, dance.

III - Participe de atividades culturais diversificadas, como música, cinema e teatro.

IV - Mantenha os laços com amigos e familiares, construindo redes de suporte social.

$\mathrm{V}$ - Seja um eterno aprendiz: língua estrangeira, instrumento musical, pintura, etc.

VI - Curta a natureza e conheça novos lugares, começando pelos mais próximos.

VII - Faça planos e tente realizá-los, participando das decisões que lhe dizem respeito.

VIII - Inclua legumes, verduras e frutas no seu cardápio, coma apenas o necessário.

IX - Cuide da sua saúde: realize exames regularmente e adote hábitos saudáveis.

X - Sorria sempre que possível; chore se necessário.

Estes conselhos podem ajudar a tornar o tempo da aposentadoria um dos períodos mais felizes de nossas vidas. Mas ao apre- 
140 JOSÉ L. RIANI COSTA • AMARILIS M. M. R. COSTA • GILSON FUZARO JUNIOR

sentar estas dicas, há sempre o risco de estabelecer tantas regras que poderiam tornar a vida artificial. Portanto, para não ficarmos escravos dessas normas, cabe incluir o 11ํMandamento: "Não leve esses dez mandamentos tão a sério". 


\section{CONSIDERAÇÕES FINAIS}

Tendo em vista as mudanças demográficas em curso e a tendência a postergar o momento da aposentadoria, as instituições poderiam adotar a diminuição progressiva da jornada ou da carga semanal de trabalho dos trabalhadores à medida que se aproximam da aposentadoria, visando a uma transição gradual para a vida no pós-trabalho, possibilitando maior disponibilidade de tempo para desenvolver atividades de seu interesse, apontada como um dos grandes benefícios da aposentadoria.

Espera-se que sejam realizados diferentes estudos que avaliem os indivíduos, antes, durante o processo de transição e após a aposentadoria, envolvendo as diversas situações existentes, tanto no setor público como no privado.

Finalmente, a expectativa é de que este livro possa colaborar para o debate do tema no interior das instituições públicas e nas empresas, buscando garantir as condições necessárias ao processo de envelhecimento e à aposentadoria digna dos trabalhadores.

Em função da experiência e da formação dos autores, não foi possível abordar nesta publicação alguns temas importantes que podem integrar um PPA, tais como: habitação, aspectos financeiros, cultura, lazer e turismo, religiosidade e sexualidade, entre outros. Talvez, com a incorporação da contribuição de outros profissionais, esses temas possam ser incluídos em uma futura edição ou, quem sabe, em um segundo livro. 


\section{APÊNDICE}

Neste apêndice é apresentado um texto baseado na proposta dos "10 mandamentos da aposentadoria feliz", que, de certa forma, sintetiza as discussões apresentadas ao longo do livro, com o objetivo de colaborar na implantação de PPA por parte de instituições públicas e privadas, bem como sugerir reflexões aos trabalhadores que se preparam para a aposentadoria e aos já aposentados.

A Unesp disponibiliza, por meio do Podcast Unesp, um conjunto de rádio releases sobre diversos assuntos, cujos conteúdos podem ser reproduzidos por emissoras de rádio e outros meios de comunicação de todo o país.

Por ocasião do Ciclo de Palestras sobre Preparação para Aposentadoria, organizado no câmpus de Rio Claro, em 2012, foi gravado um podcast que teve como título "Pesquisador da Unesp dá dicas para uma aposentadoria feliz", que pode ser acessado no link http://podcast.unesp.br/radiorelease-13072012-pesquisador -da-unesp-da-dicas-para-uma-aposentadoria-feliz.

A partir desse podcast foi produzida uma série especial com dez falas sobre os "10 mandamentos da aposentadoria feliz" que contou com a seguinte apresentação:

"O tempo pós-aposentadoria pode significar um dos melhores períodos da vida. José Luiz Riani Costa, pesquisador da Unesp em Rio Claro e membro do Núcleo Unesp-Unati (Universidade Aberta à Terceira Idade), desenvolveu dicas especiais para a con- 
quista da 'aposentadoria feliz' que podem ser resumidas em dez mandamentos. Especial elaborado por Melina Cintra”. A seguir são apresentados os títulos e respectivos links de 10 podcasts que poderão ajudar no desenvolvimento de atividades de Programas de Preparação para Aposentadoria. Na versão digital do livro, basta clicar sobre o link para ouvir ou fazer download do conteúdo gravado.

I - Prepare-se para esta nova fase da vida, inclusive emocionalmente: http://podcast.unesp.br/radiorelease-18072012-especial -aposentadoria-feliz-i- prepara-se-para-esta-nova-fase-da-vidainclusive-emocionalmente.

II - Mantenha-se sempre ativo: caminhe, jogue brinque e, sobretudo, dance: http://podcast.unesp.br/radiorelease-19072012 -especial-aposentadoria-feliz-ii-mantenha-se-sempre-ativocaminhe-jogue-brinque-e-sobretudo-dance.

III - Participe de atividades culturais diversificadas, como música, cinema e teatro: http://podcast.unesp.br/radiorelease -20072012-especial-aposentadoria-feliz-iii--participe-deatividades-culturais-diversificadas-como-musica-cinema-eteatro.

IV - Mantenha os laços com amigos e familiares, construindo redes de suporte social: http://podcast.unesp.br/radiorelease-23 072012-especial-aposentadoria-feliz-iv--mantenha-os-lacos-comamigos-e-familiaresconstruindo-redes-de-suporte-social.

V - Seja um eterno aprendiz: língua estrangeira, instrumento musical, pintura etc.: http:// podcast.unesp.br/radiorelease-24072 012-especial-aposentadoria-feliz-v-seja-um-eterno-aprendiz lingua-estrangeira-instrumento-musical-pintura-etc.

VI - Curta a natureza e conheça novos lugares, começando pelos mais próximos: http://podcast.unesp.br/radiorelease-2507 2012 -especial-aposentadoria-feliz-vi-curta-a-natureza-econheca-novos-lugares-comecando-pelos-mais-proximos.

VII - Faça planos e tente realizá-los, participando das decisões que lhe dizem respeito: http:// podcast.unesp.br/radiorelease-2607 
2012-especial-aposentadoria-feliz-vii--faca-planos-e-tenterealiza-los-participando-das-decisoes-que-lhe-dizem-respeito.

VIII - Inclua legumes, verduras e frutas no seu cardápio, coma apenas o necessário: http://podcast.unesp.br/radiorelease-2707 2012-especial-aposentadoria-feliz-viii--inclua-legumes-verdurase-frutas-no-seu-cardapio-coma-apenas-o-necessario.

IX - Cuide da sua saúde: realize exames regularmente e adote hábitos saudáveis: http://podcast.unesp.br/radiorelease-3007 2012-especial-aposentadoria-feliz-ix--cuide-da-sua-sauderealize-exames-regularmente-e-adote-habitos-saudaveis.

$\mathrm{X}$ - Sorria sempre que possível, chore se necessário: http:// podcast.unesp.br/radiorelease-31072012-especial -aposentadoria-feliz-x--sorria-sempre-que-possivel-chore-senecessario.

Também foi produzido um podcast sobre o Ciclo de Palestras sobre Preparação para Aposentadoria, cujo link é:

Unesp de Rio Claro promove palestras preparatórias para a aposentadoria: http://podcast.unesp.br/radiorelease-14072012-unesp - de-rio-claro-promove-palestras-preparatorias-para-aaposentadoria. 


\section{Anexo}

\section{Lista de filmes que podem ser utilizados em programas de preparação para a aposentadoria (PPA)}

- A balada de Narayama (Japão, 1983)

- A familia Savage (The Savages - Estados Unidos, 2007)

- Almoço em agosto (Pranzo di ferragosto - Itália, 2009)

- Amor (Amour - Alemanha, 2012)

- Antes de partir (The Bucket List - Estados Unidos, 2007)

- As confissões de Schmidt (About Schmidt - Estados Unidos, 2002)

- Cartas para Julieta (Letters to Juliet - Estados Unidos, 2010)

- Chuvas de verão (Brasil, 1977)

- Cocoon (Cocoon - Estados Unidos, 1985)

- Copacabana (Brasil, 2001)

- Corrente do bem (Pay it Forward - Estados Unidos, 2000)

- Dança comigo? (Shall We Dance? - Estados Unidos, 2004)

- De bem com a vida (How About You - Estados Unidos, 2009)

- De encontro com o amor (The Shadow Dancer - Irlanda, Inglaterra, França, 2005)

- Desafiando os limites (The World's Fastest Indian - Nova Zelândia, Estados Unidos, 2005)

- Diário de uma paixão (The Notebook - Estados Unidos, 2004) 
- Dois velhos mais rabugentos (Grumpier Old Men - Estados Unidos, 1995)

- Elza e Fred (Elza e Fred - Espanha, Argentina, 2012)

- Encontrando Forrester (Finding Forrester - Estados Unidos, 2000)

- Encontro marcado (Meet Joe Black - Estados Unidos, 1998)

- Estamos todos bem (Stanno tutti bene - Estados Unidos, 1989)

- Exótico Hotel Marigold (The Best Exotic Marigold HotelIrlanda, 2011)

- Feitiço do tempo (Groundhog Day - Estados Unidos, 1993)

- Intocáveis (Intouchables - França, 2012)

- Iris (Iris - Estados Unidos, 2001)

- Meu pai, uma lição de vida (Dad-Estados Unidos, 1989)

- Minhas tardes com Margueritte (La Tête en friche - França, 2012)

- Morangos silvestres (Smultronstället - Suécia, 1957)

- O filho da noiva (El hijo de la novia - Argentina, 2001)

- O indomável - assim é a minha vida (Nobody's Fool-Estados Unidos, 1994)

- Para sempre Alice (Still Alice - Estados Unidos, França, 2015)

- Parente é serpente (Parenti serpenti - Itália, 1992)

- Piaf (La Môme - França, 2007)

- Regresso para Bountiful (The Trip to Bountiful - Estados Unidos, 1985)

- Tio Nino (Uncle Nino - Estados Unidos, 2009)

- Tomates verdes fritos (Fried Green Tomatoes - Estados Unidos, 1991)

- Um amor para toda a vida (Closing the Ring - Estados Unidos, 2007)

- Uma história real (The Straight Story - Estados Unidos, França,1999)

- Vestígios de uma paixão (This Can't Be Love - Estados Unidos, 1994) 


\section{SOBRE OS ORGANIZADORES}

JOSÉ LUIZ RIANI COSTA - Graduado em Medicina, especialista em Medicina do Trabalho. Mestre em Clínica Médica e Doutor em Saúde Coletiva pela Unicamp. Especialista em Políticas e Gestão Governamental pela Enap. Doutorado em Saúde Coletiva. Professor da Unesp, Departamento de Educação Física/câmpus Rio Claro. Coordenador do Projeto de Extensão Programa de Preparação para a Aposentadoria (PPA) -Unesp/câmpus de Rio Claro e do Laboratório de Atividade Física e Envelhecimento (Lafe).

AMARILIS MARIA MUSCARI RIANI COSTA - Graduada em Serviço Social pela Pontifícia Universidade Católica de Campinas (PUC-Campinas). Especialista em Políticas Sociais pela Universidade de Brasília (UnB). Mestre em Gerontologia pela Pontifícia Universidade Católica de São Paulo (PUC-SP). Assistente social da Seção Técnica de Saúde da Unesp (aposentada) e membro do Núcleo Local Unesp-Unati/câmpus de Rio Claro.

GILSON FUZARO JUNIOR - Graduado em Educação Física pela Universidade Federal de São Carlos (UFSCar) e em Nutrição pelo Centro Universitário Central Paulista. Mestre em Ciências da Motricidade - Unesp/câmpus de Rio Claro. Doutorando em Clínica Médica na Faculdade de Medicina de Ribeirão Preto (FMRP) - Universidade de São Paulo (USP/Ribeirão Preto). 


\section{SOBRE OS DEMAIS AUTORES}

ANDRÉ LUIS VICENTE - Graduando em Pedagogia - Unesp/ câmpus de Rio Claro.

CARLA ANDREZZA ANDREATTO - Graduada em Psicologia. Mestre em Ciências da Motricidade - Unesp/câmpus de Rio Claro.

ELISANGELA GISELE DO CARMO - Graduada em Gerontologia - UFSCar. Especialista em Gestão de Organização Pública de Saúde pela Universidade Federal do Estado do Rio de Janeiro (Unirio). Mestre em Ciências da Motricidade. Doutoranda em Desenvolvimento Humano e Tecnologias - Unesp/câmpus de Rio Claro.

JESSICA RODRIGUES PEREIRA - Graduada em Educação Física. Mestre e doutoranda em Ciências da Motricidade - Unesp/ câmpus de Rio Claro.

JOSÉ FELIPE RIANI COSTA - Graduado em Odontologia pela FOP/Unicamp. Especialista em Autogestão em Saúde pela ENSP/ Fiocruz. Especialista em Regulação de Saúde Suplementar, da Agência Nacional de Saúde Suplementar (ANS). Mestrando em Saúde Pública pela ENSP/Fiocruz. 
LAIS SCARPARI - Graduada em Educação Física. Mestranda em Ciências da Motricidade - Unesp/câmpus de Rio Claro.

MARISA SILVANA ZAZZETTA - Graduada em Serviço Social. Especialização em Gerontologia Social. Mestrado e doutorado em Serviço Social. Professora adjunta da Universidade Federal de São Carlos (UFSCar), junto ao Departamento de Gerontologia.

MELISSA RIANI COSTA MACHADO - Graduada em Ecologia pela Unesp/câmpus de Rio Claro. Mestre em Tecnologia Ambiental e Recursos Hídricos. Doutoranda em Desenvolvimento, Sociedade e Cooperação Internacional pela Universidade de Brasília (UnB). Pesquisadora-tecnologista em Informações e Avaliações Educacionais do Instituto Nacional de Estudos e Pesquisas Educacionais Anísio Teixeira (Inep).

OSCAR GUTIÉRREZ HUAMANÍ - Graduado e licenciado em Educação Física na Universidade Nacional de San Cristóbal de Huamanga. Mestre em Educação Física pela Universidad Nacional Mayor de San Marcos, Peru. Doutor em Ciências da Motricidade - Unesp/câmpus de Rio Claro. Professor da Universidad Nacional San Cristobal de Huamanga, Peru.

PAULA SECOMANDI DONADELLI - Graduada em Educação Física. Mestranda em Ciências da Motricidade - Unesp/ câmpus de Rio Claro.

PAULO FERNANDO MORAES - Graduado em Educação Física. Especialista em Ciências do Treinamento, Nutrição e Condicionamento Físico e Atividade Física para Grupos Especiais. Mestre em Ciências da Motricidade - Unesp/câmpus de Rio Claro.

POLLYANNA NATALIA MICALI - Graduada em Educação Física. Mestre e Doutoranda em Ciências da Motricidade - Unesp/ câmpus de Rio Claro. 
RAIANA LÍDICE MÓR FUKUSHIMA - Graduada em Gerontologia - UFSCar. Mestranda em Ciências da Motricidade Unesp/câmpus de Rio Claro.

REISA CRISTIANE DE PAULA VENANCIO - Graduada em Educação Física pela Unesp/câmpus de Rio Claro e em Gerontologia pela UFSCar. Especialista em Atividade Física Adaptada e Saúde e em Gestão de Organização Pública da Saúde. Mestranda em Ciências da Motricidade - Unesp/câmpus de Rio Claro.

RUTH GELEHRTER COSTA LOPES - Graduada em Psicologia pela PUC-SP. Mestrado em Psicologia Social pela PUC-SP. Doutorado em Saúde Pública pela Universidade de São Paulo. Atualmente, é professora associada da PUC-SP.

SUZANA CARIELO DA FONSECA - Graduada em Fonoaudiologia. Mestre em Linguística Aplicada e Estudos da Linguagem. Doutora em Linguística Aplicada e Estudos da Linguagem pela Pontifícia Universidade Católica de São Paulo (PUC-SP). Especialização em Projetos Sociais pelo Senac-SP. Atualmente, é assistente-doutora da PUC-SP.

ÚRSULA VIRGÍNIA PEREIRA - Graduada em Educação Física. 
SOBRE O LIVRO

Formato: $14 \times 21 \mathrm{~cm}$

Mancha: $23,7 \times 42,10$ paicas

Tipologia: Horley Old Style 10,5/14 2016

\section{EQUIPE DE REALIZAÇÃO}

Coordenação Geral

Pedro Barros (Tikinet Edição Ltda.) 